\title{
WestVirginiaUniversity
}

THE RESEARCH REPOSITORY @ WVU

Graduate Theses, Dissertations, and Problem Reports

2004

\section{Factors influencing older adult collaboration on health problems}

\author{
Kelly L. Snyder \\ West Virginia University
}

Follow this and additional works at: https://researchrepository.wvu.edu/etd

\section{Recommended Citation}

Snyder, Kelly L., "Factors influencing older adult collaboration on health problems" (2004). Graduate Theses, Dissertations, and Problem Reports. 784.

https://researchrepository.wvu.edu/etd/784

This Thesis is protected by copyright and/or related rights. It has been brought to you by the The Research Repository @ WVU with permission from the rights-holder(s). You are free to use this Thesis in any way that is permitted by the copyright and related rights legislation that applies to your use. For other uses you must obtain permission from the rights-holder(s) directly, unless additional rights are indicated by a Creative Commons license in the record and/ or on the work itself. This Thesis has been accepted for inclusion in WVU Graduate Theses, Dissertations, and Problem Reports collection by an authorized administrator of The Research Repository @ WVU. For more information, please contact researchrepository@mail.wvu.edu. 
Factors Influencing Older Adult Collaboration on Health Problems

\author{
Kelly L. Snyder \\ Thesis submitted to the \\ Eberly College of Arts and Sciences \\ in partial fulfillment of the requirements \\ for the degree of \\ Master of Arts \\ in \\ Psychology
}

JoNell Strough, Ph.D., Chair

Kevin Larkin, Ph.D.

Julie Patrick, Ph.D.

Department of Psychology

Morgantown, West Virginia
2004

Keywords: older adults, collaboration, heart problems, arthritis 


\section{ABSTRACT \\ Factors Influencing Older Adult Collaboration on Health Problems}

Kelly L. Snyder

The current study examined the factors (i.e., gender, marital status, domain of the problem and severity of the problem) that influence older adults' strategy ratings on health-related problems. One hundred twenty-eight community-dwelling adults aged 60 and older $(M=71.4$ years, $S D=$ 7.21) rated strategies to solve four hypothetical health problems in two domains: heart, arthritis (one mild problem and one severe problem in each domain). Overall, results suggest that gender and marital status, as well as the domain, and severity of health problems impact older adults' rating of strategies to solve health-related problems. The effects of gender, marital status and severity differed within each of the domains of health problems. Gender and marital status interacted with severity in the heart domain. Gender significantly impacted strategy ratings in the severe condition whereas marital status significantly impacted males' strategy ratings in the mild condition. Gender and marital status did not interact with severity level in the arthritis domain; however, severity level did affect strategy ratings in the arthritis domain. Gender and marital status significantly affected overall ratings when collapsed across severity level in the arthritis domain. Findings illustrate the importance of considering all of the factors (i.e., gender, marital status, domain of health problem, and severity of health problem) that influence the strategies that older adults use to solve health-related problems. Implications for the health care field are discussed. 


\section{TABLE OF CONTENTS}

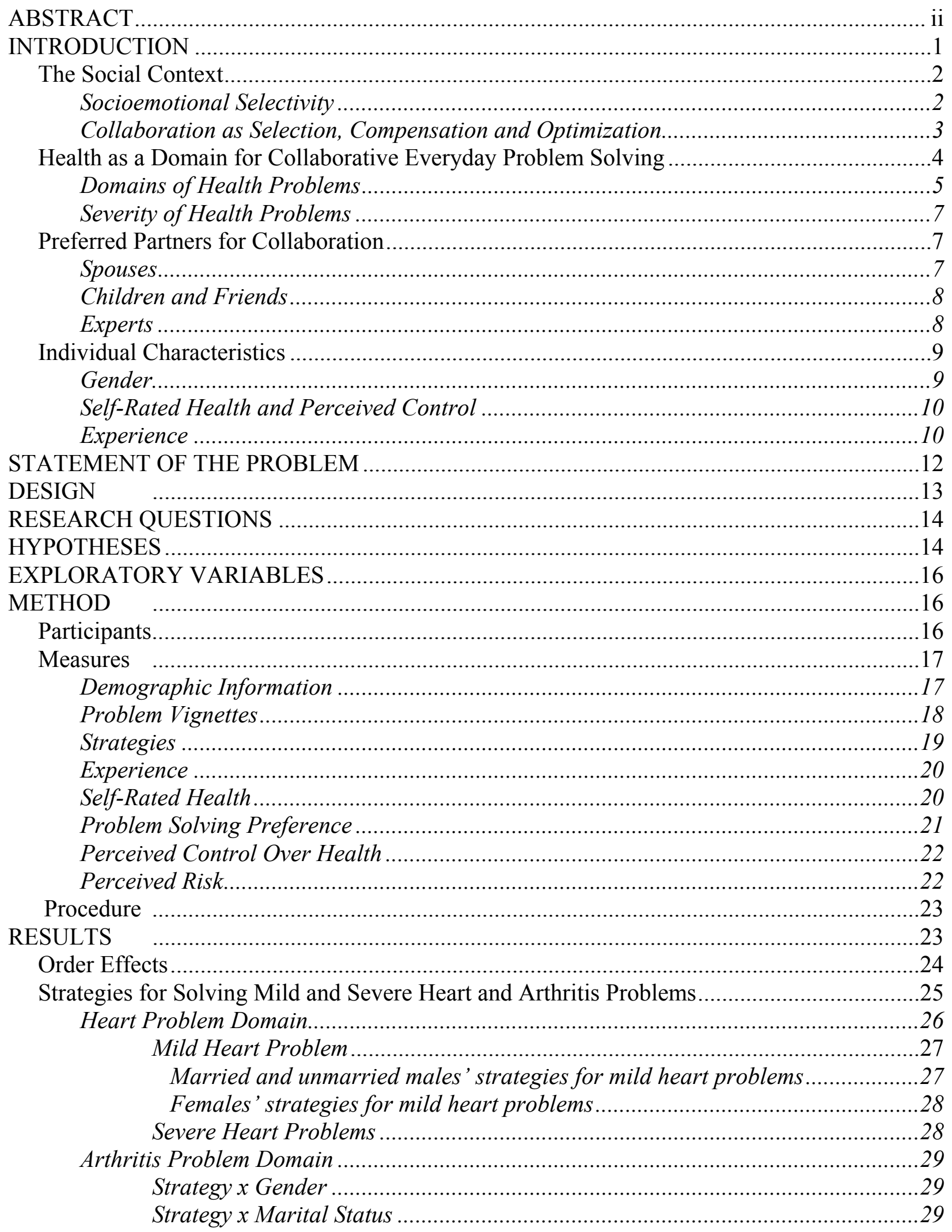




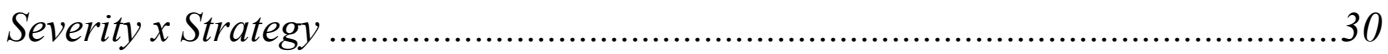

Married Adults Problem-Solving Strategies ............................................................................

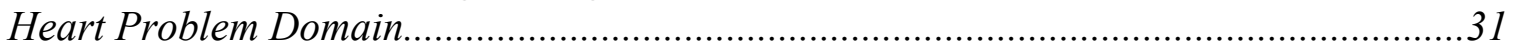

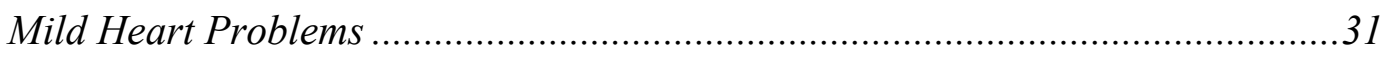

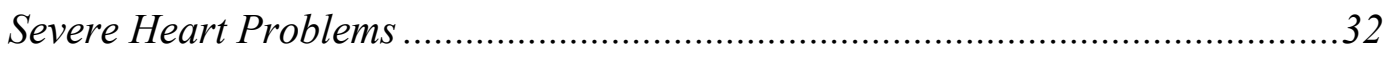

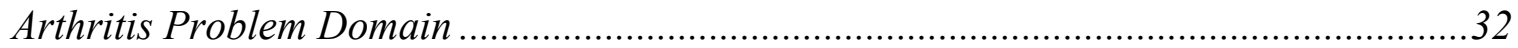

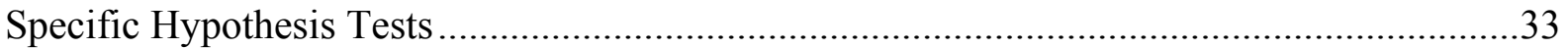

The Role of Experience on Problem Solving Strategies...........................................................34

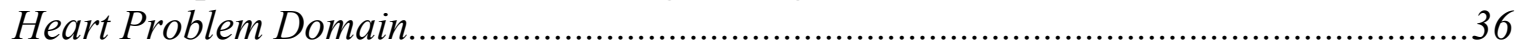

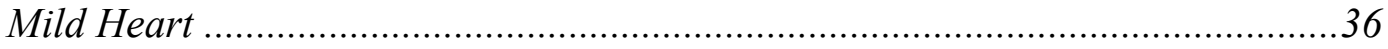

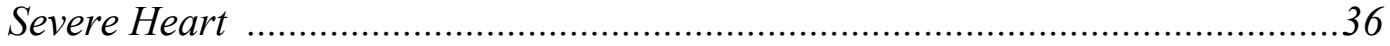

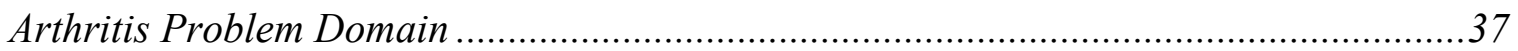

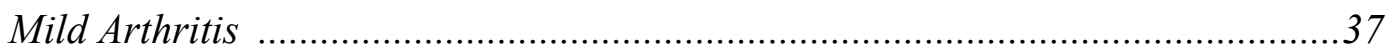

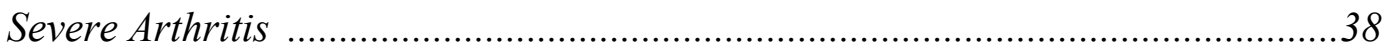

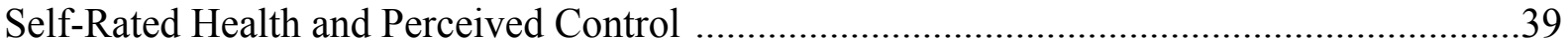

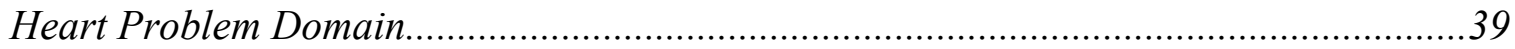

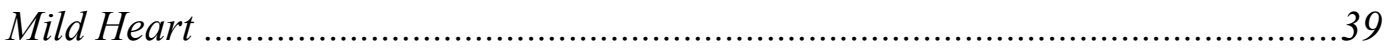

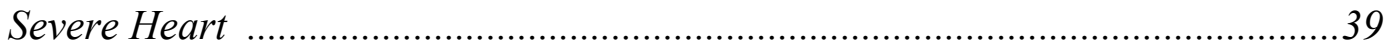

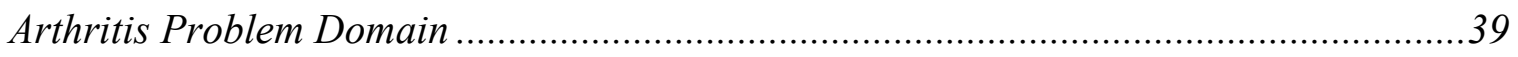

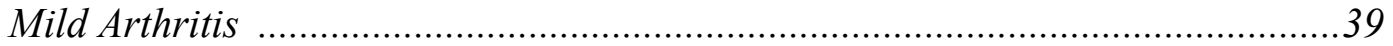

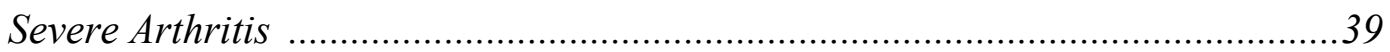

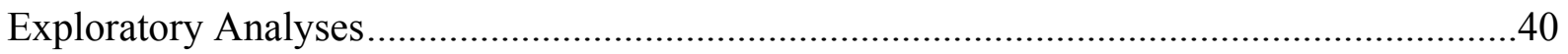

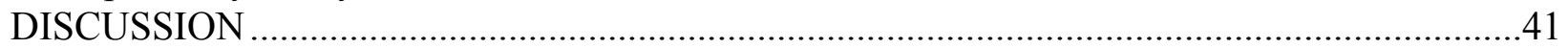

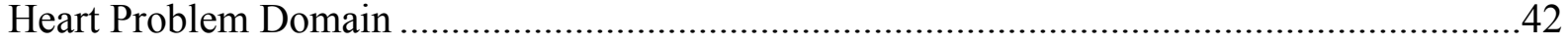

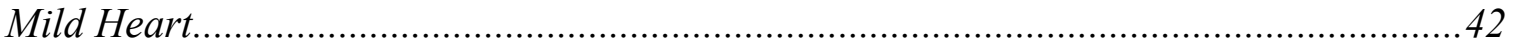

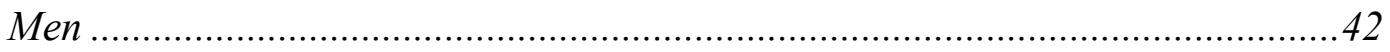

Married versus unmarried men ..................................................................42

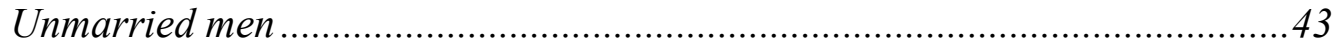

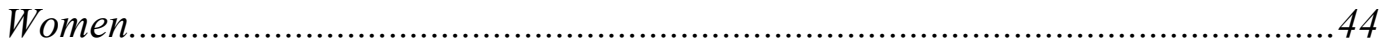

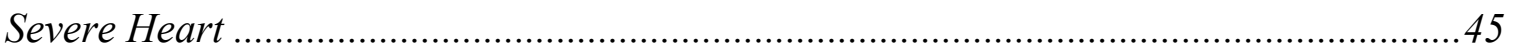

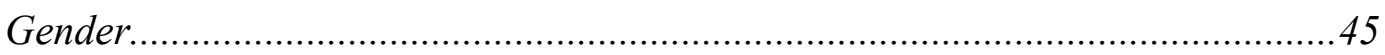

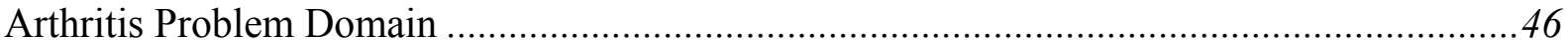

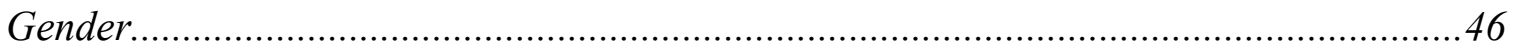

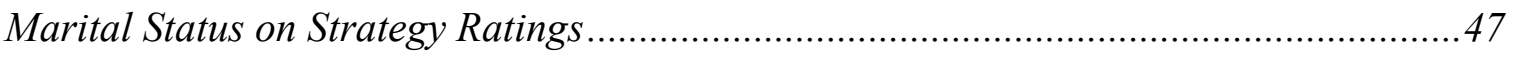

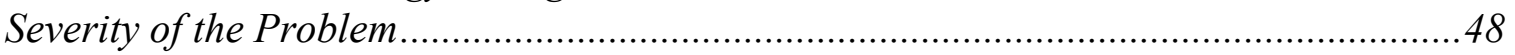

The Role of Experience on Problem Solving Strategies............................................................4

Experience: Continuous Assessment versus Categorical Assessment ………………......50

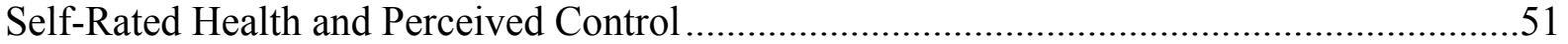

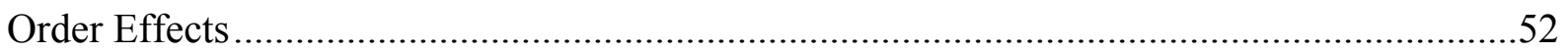

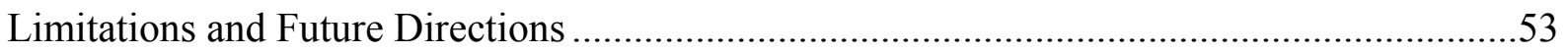

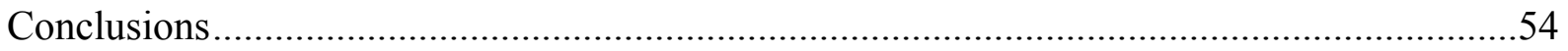

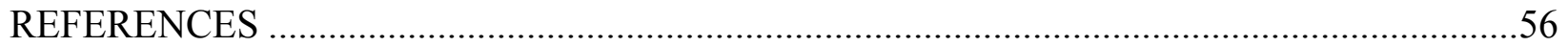

Table 1: Problem-Solving Strategies for Heart Problems: Means and (Standard Errors)..........62

Table 2: Problem-Solving Strategies for Arthritis Problems: Means and (Standard Errors) ......65

Table 3: Problem-Solving Strategies of Married Adults on Heart Problems: Means and (Standard Errors). 
Table 4: Problem-Solving Strategies for Married Adults on Arthritis Problems: Means and

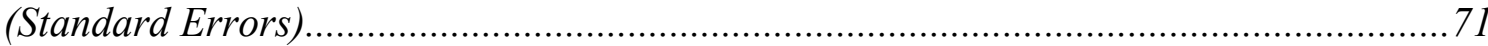

Table 5: Number of Persons Reporting Personal Experience with Heart and Arthritis Conditions by Severity, Gender, and Marital Status........................................................................ 74

Table 6: Intercorrelations Among Self-Rated Health, Perceived Control, Experience (continuous measure) and Ratings of Strategies for Mild Heart Problems ..................................... 75

Table 7: Intercorrelations Among Self-Rated Health, Perceived Control, Experience (continuous measure) and Ratings of Strategies for Severe Heart Problems .......................................76

Table 8: Intercorrelations Among Self-Rated Health, Perceived Control, Experience (continuous measure) and Ratings of Strategies for Mild Arthritis Problems .................................. 77

Table 9: Intercorrelations Among Self-Rated Health, Perceived Control, Experience (continuous measure) and Ratings of Strategies for Severe Arthritis Problems .................................78

Table 10: Frequencies of Background Variables by Gender and Marital Status ........................79

Table 11: Knowledge of Heart and Arthritis Problems by Gender and Marital Status: Means

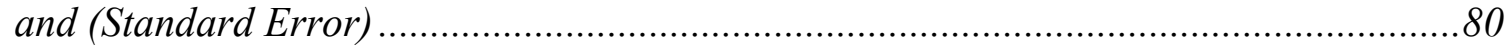

Table 12: Number of Friends and Relatives with whom there is Contact by Gender and Marital Status: Means and (Standard Error)

Table 13: Self-Rated Health and Perceived Control by Gender and Marital Status: Means and (Standard Error)....

Table 14: Mean Number (standard deviation) of Physical Illnesses by Severity, Gender, and Marital Status

Figure 1: Mean Strategy Ratings for Married and Unmarried Males on Mild Heart Problems ..84 Figure 2: Mean Strategy ratings for Males and Females on Severe Heart Problems.................85 Figure 3: Mean Strategy Ratings for Males and Females on Arthritis Problems .......................86 Figure 4: Mean Strategy Ratings for Married and Unmarried Adults on Arthritis Problems ......87

Figure 5: Mean Strategy Ratings for Mild and Severe Arthritis Problems .................................88

Figure 6: Mean Strategy Ratings for Females on Mild Heart Problems..................................89

Figure 7: Mean Strategy Ratings for Mild Heart Problems by Marital Status and Gender .........90

Figure 8: Mean Strategy Ratings for Severe Heart Problems by Marital Status and Gende ........91

Figure 9: Mean Strategy Ratings for Mild Arthritis Problems by Marital Status and Gender .....92 Figure 10: Mean Strategy Ratings for Severe Arthritis Problems by Marital Status and Gender 93 Appendix A: Everyday Health Questionnaire .94

Appendix B: Summary Table for Gender x Marital Status x Domain x Severity x Strategy Repeated Measures MANOVA 


\section{Factors Influencing Older Adult Collaboration on Health Problems}

An emerging area of research focuses on collaboration in older adulthood or the ways in which older adults incorporate others in their problem solving and decision-making (Strough \& Margrett, 2002). The area of older adult collaboration is fairly new. Existing research has investigated collaboration on memory tasks (Gould, Kurzman, \& Dixon, 1994; Gould, Trevithick, \& Dixon, 1991), errand planning, social problem solving, and everyday problem solving tasks (Margrett \& Marsiske, 2002). The everyday problem domains in which older adults prefer to work with others and alone also have been investigated (Strough, Cheng \& Swenson, 2002). Health is a very important everyday domain for older adults. Approximately $80 \%$ of older adults live with at least one chronic illness and 50\% have at least two (National Center for Chronic Disease Prevention and Health Promotion, 1999). Older adults tend to consume a disproportionate amount of medical services relative to their overall number in the population (Park, 1999). There is a lack of literature on health-related collaborative problem solving in older adults although research has indicated the need for such studies (Strough, et al.). Of interest to the current study is how older adults draw from experts, specifically doctors, and nonexperts, such as family and friends, to deal with health-related problems.

This study attempted to answer the following questions related to collaboration of older adults with both experts and non-experts on health-related issues. What are the factors (e.g. aspects of the problem) that are important for understanding older adult's collaboration on health-related problems? Do demographic variables such as marital status, parental status and gender and individual characteristics such experience, perceived health, and perceived control over health impact the strategies that older adults' choose when solving health related problems? 


\section{The Social Context}

Recent research examines how the social context influences everyday problem solving and decision-making in older adults. Various terms have been applied to this type of research: collaborative cognition (Dixon, 1992; Strough, Patrick, Swenson, Cheng \& Barnes, 2003), interactive minds (Baltes \& Staudinger, 1996), and socially shared cognition (Resnick, Levine \& Teasdale, 1991). Collaboration refers to the processes by which two or more individuals work together to make decisions or solve problems (Dixon, 1992; Strough, Patrick, et al., 2003). Collaboration research is guided by the premise that cognition in general is a social phenomenon. When facing a problem or challenge, others are often involved in the problem or are readily available to assist in the process of solving the problem. For example, Goodnow and colleagues (2002) examined caregiving as collaboration. They showed that there can be several possible contributors who have certain tasks and amounts of participation. A community nurse may take the role of physical caregiver while a spouse or family member takes the role of emotional caregiver. The amount of collaboration with each member of the social network may vary. Perhaps an older adult will collaborate with many people when solving problems; however, they may collaborate more with one person, such as spouse.

\section{Socioemotional Selectivity Theory}

According to socioemotional selectivity theory, with age there is a reduction in the number of persons in the social network (Carstensen, 1991). However, this theory posits that the decrease in the number of people in the social network is due to persons selecting others to maximize social and emotional gains. Interactions with acquaintances and friends decrease from early adulthood on; however, interactions with spouses and siblings increase across adulthood and old age (Carstensen). Emotional closeness in relationships with relatives and close friends 
increases throughout adulthood and old age (Carstensen, 1992). In summary, socioemotional selectivity theory states that older adults tend to keep persons in their social network that will be of some benefit to them. Interactions in which they derive little benefit often decrease. So, perhaps the people that older adults keep in their social networks serve certain needs. Within the smaller, emotionally closer social network, perhaps there are specific persons who function as a resource for collaboration on everyday problems including health problems.

\section{Collaboration as Selection, Compensation and Optimization}

Studies examining the collaboration of older adults often have focused on the idea of compensation (Gould et al, 1991; see Meegan \& Berg, 2002 for a review). Throughout the lifespan there are gains and losses in both cognitive and physical ability (Baltes \& Baltes, 1990). With age, there tends to be more losses than gains (Backman \& Dixon, 1992; Baltes \& Baltes). Losses can be compensated for. According to the model of Selective Optimization with Compensation (Baltes \& Baltes), the physical and cognitive losses that older adults experience are compensated for in a variety of ways. For example, use of a wheelchair may compensate for a loss of mobility due to severe arthritis. The act of writing lists (e.g., grocery lists) may serve to compensate for cognitive declines in memory.

Collaboration with others to solve problems may function as selection, optimization and/or compensation. An older adult may select which problems to seek assistance from others in solving. Optimization refers to the processes or mechanisms by which progress is achieved and maintained (Marsiske, Lang, Baltes \& Baltes, 1995). Collaboration with others on health related problems might be a way to reach the optimal or best decision regarding the problem. For example, an older adult suffering from arthritic symptoms may consult a friend or relative in order to make the best decision regarding how to treat arthritis. An older adult may also 
collaborate with others on solving a problem or making a decision in order to compensate for declines in cognitive functioning or problem-solving skills.

\section{Health as a Domain for Collaborative Everyday Problem Solving}

Although there has been an increase in the amount of research concerning collaborative problem solving in older adulthood, the literature is lacking empirical investigations of collaborative problem solving on health-related issues. Health is a very important domain for older adults. When asked to describe an everyday problem, older adults more than any other age group (middle-aged, college students or preadolescents) tend to mention problems in the domain of health (Sansone \& Berg, 1993). In a study examining individuals' goals for solving everyday problems, Strough, Berg and Sansone (1996) found that older adults report physical goals that often involved health-related issues more often than did any other age period across the lifespan. Strough, Patrick, and colleagues (2003) found that older adults reported health problems when asked to describe problems that they collaborated with others to solve, consulted others for advice on how to solve, or solved alone. The current study differs from that of Strough, Patrick, and colleagues. Strough, Patrick, and colleagues examined older adult collaboration in many domains; however, the study did not examine collaboration with specific people or in specific domains of health. The current study examined older adults' collaboration in the specific domains of heart and arthritis. The current study also examined the specific relationships from which the older adults' can seek assistance (i.e., doctor, spouse, relative, someone else). One way to examine older adults' collaboration on health-related problems is to examine their strategy use for solving everyday health problems. Strategies for solving everyday problems can be divided into strategies that include others in the problem-solving process and strategies for solving the problem alone or ignoring the problem. Various labels have been applied to 
strategies that incorporate others in the problem solving process such as problem-focused action (Blanchard-Fields, et al., 1995) and passive-dependent behavior (Cornelius \& Caspi, 1987). Individual versus interpersonal strategies have been studied in research examining preferences for collaboration.

\section{Domains of Health Problem}

Although research has shown that health is an important domain for older adults (Strough et al., 1996; 2003), specific domains, or types of health have not been examined in the literature on older adult collaboration. The specific domain of health problem may also be important for understanding the strategies that older adults use to solve health-related problems. Arthritis and heart problems are two important domains of health problems for older adults. Nearly $50 \%$ of people 65 and older suffer from arthritis (Center for Disease Control and Prevention, 2002) and arthritis is the number one cause of disability in the United States (Arthritis Foundation, 1995). Heart disease is one of the leading causes of death among people 65 years and older (National Center for Chronic Disease Prevention and Health Promotion, 1999). A majority of the nearly 5 million United States patients with heart failure are 65 years and older (Center for Disease Control and Prevention, 2002). When asked to report health, older adults listed pains in the limbs and heart problems in the top five symptoms and complaints (Thorslund \& Norstrom, 1993).

Arthritis and heart problems are everyday problems in the sense that older adults need to attend to them on a day-to-day basis, whether it is relief of continuous joint pain or changes in daily diet and exercise. Although arthritis and heart problems both fall within the domain of everyday health-related problems, there may be differences in the two that affect the type of problem-solving strategies (i.e., alone versus with others) used. Differences in functional ability 
and mortality rates related to the health problem may impact the type of strategies used.

Arthritis is the leading cause of functional disability in the United States and it is estimated that the disease limits the daily activities of 7 million people in the United States alone (Center for Disease Control and Prevention, 2002). Older adults who suffer from arthritis may need assistance with many physical activities, such as transportation and meal preparation. Older adults who seek physical assistance from others have people available to them on a regular basis to help assist in other areas, such as problem solving on health-related issues. Although arthritis is a major concern in terms of functional disability, it is not a life-threatening disease. However, heart related problems are often life threatening. In the United States, someone dies each minute from a heart-related event (Center for Disease Control and Prevention). Perhaps older adults will be more likely to seek assistance from others when the health-problem is life threatening.

Research has distinguished problems as ill-structured or well-structured problems (Sinnott, 1989). Well-structured problems have clearly defined solutions, whereas ill-structured problems may have several solutions. Heart disease as conceptualized in the current study is a well-defined problem; there are very distinct solutions on how to avoid and treat heart problems, such as daily exercise and a continually healthy diet. Arthritis, on the other hand, is a chronic disease. Arthritis is ill-structured in the sense that there may be several ways to alleviate the suffering and these ways are not as clear-cut or defined. In a study that examined self-care of older adults, McDonald-Miszczak, Wister and Gutman (2001) found that objective factors (e.g., doctor diagnosis and number of doctor visits) and illness-specific beliefs were predictors of selfcare behavior of arthritis patients, whereas general beliefs (e.g., general well-being and selfefficacy) were predictors of self-care behavior for heart problem patients. This research suggests that differences in the nature of the heath problem (i.e., mortality, functional ability, chronic 
versus acute, well-structured versus ill-structured) influence the strategies that older adults use to solve such problems. Therefore, differences in the type of health problem may influence the strategies that older adults choose to solve the problems.

\section{Severity of the Health Problem}

Strough, and colleagues (2003) found that severity of the problem influenced the strategies that grandparents used when solving grandchild care problems. Grandparents were more likely to seek assistance from other people when dealing with problems of neglect than when dealing with babysitting problems. Severity of the health problem may impact the strategies that older adults use to solve health-related problems.

\section{Preferred Partners for Collaboration}

As indicated by Goodnow and colleagues (2002), there are multiple people in the social context, including both professional and family members, from whom older adults can draw information and assistance when solving problems and making decisions about health. Who in the social context do older adults use as resources when solving health-related everyday problems?

\section{Spouses}

Much of the existing literature examines collaboration with spouses. Strough, Patrick, and colleagues (2003) found that older married adults reported a preference to collaborate with their spouses as compared to other family members or friends when solving everyday problems. Margrett (1999) found that older adults collaborating with their spouse on everyday problems benefited more than those collaborating with unfamiliar partners. Dixon (1996) found that older married couples perform better on a story recall task than older individuals. Marital status also influences expectations about collaboration (Gould et al., 1991; Margrett \& Marsiske, 2002). 
Gould and colleagues (2002) examined recall in older adult dyads and found that although older adults expected to perform better working with their spouse than with an unfamiliar partner, familiar partners did not necessarily recall more information than unfamiliar partners. Spouses seem to be a very important partner for collaboration on solving everyday problems whether considering actual performance or expectations about performance.

\section{Children and friends}

Although spouses are a readily available source of collaboration for those who are married, research indicates that others, such as children and friends, also serve as collaborative partners. Adult children may be a source of collaboration, especially for unmarried older adults. For example, Strough and colleagues (2003) found that unmarried older adults reported a preference to work with their adult children as compared to other family members or friends. Friends may also serve as an important source for collaboration. Child and adolescent research shows that collaboration with friends as compared to others can be beneficial especially on difficult tasks (Azmitia \& Montgomery, 1993; c. f. Swenson, 2000). Perhaps older adults may choose to collaborate with a friend when they are experiencing a severe health problem as compared to a mild health problem, especially when family is not available.

\section{Experts}

Experts, such as doctors, may serve as potential partners for collaboration. The fact that older adults tend to consume a disproportionate amount of medical services relative to their overall number in the population (Park, 1999) suggests that older adults seek medical help through professionals or experts. However, Turk-Charles, Meyerowitz and Gatz (1997) found that older adult cancer patients reported more information seeking from non-medical sources than did younger adults. This research indicates the need for studies that directly examines the 
factors (e.g. individual characteristics, and severity of problem) that influence older adults' collaboration with doctors on health problems.

\section{Individual Characteristics}

\section{Gender}

Gender is an important variable to consider when examining collaboration. Margrett and Marsiske (2002) examined gender differences in collaboration in everyday problem solving and found that gender affects perceptions of collaboration. Akiyama, Elliot and Antonucci (1996) examined relationships of older adults in terms of gender and found that overall older adults tended to have more women in their social networks and that men reported more support from their wives than women reported support from husbands. Together, this research suggests that men and women view the process of collaboration and their social support systems differently, which may impact their choice to collaborate with others on health-related problems or solve health-related problems alone.

Strough and colleagues (2002) found gender differences in preferences for collaborative and individual everyday problem solving that were consistent with gender-stereotyped roles. Men were more likely to prefer to solve problems such as assembling products, household repair and maintenance problems alone and women were more likely to prefer to solve meal preparation problems alone. Men tended to prefer to collaborate on meal preparation. Women tended to prefer to collaborate on assembling products and household-repair and maintenance problems. There were, however, no significant gender differences in problem-solving preferences for the domain of health although women reported preferring to solve medication problems alone (Strough, et al.). Strough and colleagues examined preferences for collaboration with others in terms of generalized others or anyone. Perhaps when specific categories of people 
(i.e., doctor, spouse, relative) are examined, gender differences will emerge for solving everyday problems in the health domain. In addition, preferences for collaboration in the domain of health may be due to some underlying aspect of health problems that has not been examined, such as severity of the problem or experience with the problem.

\section{Self-Rated Health and Perceived Control}

An individual's perceived health and perceived control may impact ratings for strategies to solve health-related problems. Strough, and colleagues (2002) examined older adult's preferences for collaboration when solving everyday problems and found that in general older adults preferred to solve problems alone; however, many demographic and individual characteristic variables such as perceived health, perceived control, gender and marital status and the type, or domain, of problem influenced preferences for including others in the problemsolving process. For example, when preferences for solving everyday problems in general were examined, older adults who rated their health as less positive and perceived less control over the future preferred to include others. When preferences for solving health-related everyday problems alone and with others were examined, older adults who rated their health as more positive preferred to work alone whereas those who rated their health as less positive preferred to solve problems with others. Thus, perceived health and perceived control may influence preferences for strategies that incorporate others in solving everyday health-related problems and strategies for solving everyday heath-related problems alone.

\section{Experience}

Prior experience with health problems is another variable of interest when examining the problem-solving strategies (i.e., alone versus with others) that older adults use to solve healthrelated problems. One important consideration when examining experience is different types of 
experience. Experience can be gained either personally (i.e., by directly experiencing the problem oneself) or vicariously (i.e., indirectly by someone else who has directly experienced such a problem). "Lay" experts are persons who have experienced a similar problem. For example, a person whose close friend has undergone treatment for a particular disease may be more experienced than someone who has never known anyone with the disease. Pierce (1996) found that when making medical decisions, patients tend to remember their friends and family's experiences with similar problems. Perhaps when dealing with a health problem older adults seek out friends and family members who have experienced a similar type of problem.

Experience has been operationalized as consisting of personal experience only (Berg, Meegan, and Klaczynski, 1999; Cornelius \& Caspi, 1997) or personal and vicarious experience combined (Strough, Patrick, \& Swenson, 2002). There is a difference between personally experiencing a health problem and experiencing a health problem through someone else (i.e., vicariously); therefore, the current study focuses on the influence of personal experience only. Research on the effect of experience on problem solving is inconsistent. Cornelius and Caspi (1987) found no correlation between experience and problem solving strategy. Denney and Pearce (1989) reported that experience was positively correlated with the number of problem solutions generated. Berg, Meegan, and Klaczynski (1999) found that experience did not affect number of problem solving strategies generated. Strough, Patrick and Swenson (2003) found that experience influenced the type of strategies for solving everyday problems but not the number of strategies. Experienced older adults as compared to those who were inexperienced were more likely to choose the strategy "seek assistance" when dealing with a problem of suspected grandchild neglect. There was no significant difference between those with experience and those without experience on the behavioral self-regulation strategy which was 
defined as self-initiated action by the problem solver to make his or her own behavior conform to the demands of the problem. Also, experience did not have an effect on "ignore type" cognitive regulation strategies. These findings suggest that experience does not influence taking action to solve the problem versus ignoring the problem; however, experience influences whether to solve problem alone or involve others in the problem-solving process.

Inconsistencies in the literature may be due to the way experience is assessed. Experience, either personal or vicarious, can be measured as a categorical (i.e., yes or no) or a continuous (i.e., how often) variable. For example, one can indicate that yes, they have experience with the problem or one can indicate the amount of experience they have. Cornelius and Caspi (1989) and Berg, et al. (1999) assessed experience as a continuous variable. Strough, and colleagues (2003) assessed experience as a categorical variable and in Denney and Pearce (1989) experience was not directly assessed but inferred. When experience is assessed as a continuous variable, no effects on problem solving strategies are found; however, when experience is assessed as a categorical variable effects are found. Perhaps whether someone has experienced a health-related problem will affect problem solving strategies; however, the magnitude of experience may not impact the strategies. The present study examines experience as both a categorical and continuous variable. Perhaps, as was the case in Strough, and colleagues, when experience is assessed as a categorical variable, older adults who report experience with health problems will be more likely to seek assistance from others than those who report no experience.

\section{STATEMENT OF THE PROBLEM}

Research has examined older adults' collaboration on memory tasks (Gould, Trevithick, \& Dixon, 1991; Gould, Kurzman, \& Dixon, 1994), errand planning, social problem solving, 
everyday problem solving, (Margrett \& Marsiske, 2002), and the everyday problem domains in which older adults are likely to prefer to include others (Strough, et al., 2003). Various literature indicates that health is an important domain for older adults (Sansone \& Berg, 1993; Strough, et al, 1996; Strough, Patrick, et al., 2003). The literature is lacking studies that examine the factors that influence older adult collaboration on health issues, particularly in specific domains of health. Demographic variables such as marital status, parental status, and gender, and individual characteristics such as experience, perceived health, and perceived control over health may impact the strategies that older adults choose to solve health-related problems. Factors (e.g. aspects of the problem) such as domain of the problem and severity of the problem may also be important for understanding older adult's collaboration on health-related problems.

\section{DESIGN}

The main independent variables were marital status (married, unmarried), gender (male, female), domain of problem (i.e., heart, arthritis), severity of problem (i.e., mild, severe) and experience (some, none). Other independent variables included: perceived health, perceived control, and problem solving preferences (general and health specific).

The dependent variables were problem-solving strategy ratings. The problem solving strategies were: do nothing, discuss with a doctor, discuss with spouse (if married), discuss with relative, discuss with someone else, ignore the problem, do something to take your mind off of the problem, deal with the problem alone, take an aspirin or over-the-counter pain reliever, pray, look up information about what the symptoms mean, go to the hospital, do something else. Interpersonal strategies (i.e., discuss with a doctor, discuss with spouse, discuss with relative, discuss with someone else) and self-strategies (i.e., do nothing, deal with it alone) were analyzed in the present study. 


\section{RESEARCH QUESTIONS}

1) What are the factors that are important for understanding older adult's collaboration on health-related problems?

2) Do demographic variables such as marital status, and gender, and individual characteristics such as experience, perceived health, perceived control over health and problem-solving preferences impact collaboration of older adults?

3) Do characteristics of the problem such as domain and severity influence collaboration?

\section{HYPOTHESES}

Marital and Parental Status

1.) Strough, Patrick, et al. (2003) found that married older adults prefer to use their spouses as compared to others as a collaborative resource. Therefore, it was hypothesized that married older adults would rate the strategy "discuss with spouse" higher than other interpersonal strategies (i.e., discuss with doctor, discuss with relative, discuss with someone else) on health-related problems.

2.) Strough, Patrick, et al. (2003) found that unmarried older adults prefer to use their adult children as compared to others as a collaborative resource. Therefore, it was hypothesized that unmarried older adults would rate the strategy "discuss with relative" higher than other interpersonal strategies on health-related problems.

3.) Unmarried older adults and those without children may lack the social support system that typically comes from a spouse or child. Therefore, it was hypothesized that unmarried older adults would rate "consult a doctor" higher than married older adults.

\section{Gender}


4.) Akiyama and colleagues (1996) found that older adult men reported more support from their wives than women reported support from their husbands. Therefore, it was hypothesized that married men would rate " consult a spouse" higher than married women.

\section{Experience}

5.) Strough and colleagues (2003), found that experience may influence collaboration when assessed as a categorical variable. For example, experienced grandparents are more likely to seek assistance from other people when faced with a grand-parenting problem (Strough, et al.). Therefore, it was hypothesized that older adults who have experienced health problems would rate interpersonal strategies (i.e., doctor, spouse, relative, other) higher than those without experience when solving health related issues.

Severity

6.) Strough and colleagues (2003) found that grandparents were more likely to seek assistance from other people when dealing with problems of neglect than when dealing with babysitting problems. Therefore it was hypothesized that adults would rate the interpersonal strategies (i.e., doctor, spouse, relative, other) higher when the problem is severe as compared to mild.

Perceived Health

7.) Strough and colleagues (2002) found that older adults who rated their health as more positive preferred to work alone whereas those who rated their health as less positive preferred to solve problems with others. Therefore, it was hypothesized that higher perceived health scores would be negatively correlated with ratings of interpersonal strategies and positively correlated with ratings of self- strategies. 


\section{Perceived Control}

8.) Strough, et al. (2002) found that older adults who perceived less control over the future preferred to include others in everyday problem solving. Therefore it was hypothesized that higher perceived control over health scores would be negatively correlated with ratings on interpersonal strategies and positively correlated with ratings on self-strategies.

\section{EXPLORATORY VARIABLES}

Gender. There are inconsistencies within the literature on gender differences in problem solving. Research has not examined gender differences in solving everyday health problems using strategies that examine specific relationships (i.e., doctor, spouse, relative, another person), therefore overall analyses of gender differences in strategy ratings were exploratory.

Domain. Although research (McDonald-Miszczak, et al. , 2001) has indicated differences in self-care behavior associated with the type of health problem (arthritis, heart and hypertension), this has not been examined in regards to collaborative problem solving, and thus the analyses of domain of health were exploratory.

\section{METHOD}

\section{Participants}

A power analysis for a three-way interaction showed that 128 people were needed to detect medium effect sizes with $80 \%$ power. The two additional variables in the current study are within subjects repeated factors, which increases power. The sample consisted of 128 community-dwelling adults aged 60 and older $(M=71.4$ years, $S D=7.21)$ recruited through television and newspaper advertisements, and personal referrals from Morgantown, West Virginia and surrounding areas. Recruitment took place at senior centers, independent living 
facilities, and various volunteer group meetings. Thirty-two married male older adults, 32 unmarried male older adults, 32 married female older adults and 32 unmarried female older adults were recruited. Sixty-one participants were married, 3 were single but living as married, 51 were widowed, 2 were divorced, and 10 were never married. The participants who were single but living as married were considered married for the purposes of this study. Sixty percent of the sample completed high school only, $15 \%$ completed some college, $8 \%$ completed 4 -year college degree, and $17 \%$ completed a postgraduate degree. Ninety-two percent of the sample was Caucasian, which was representative of the local population. Average income of the sample was between $\$ 30,001$ and $\$ 40,000$. The older adults participated in the study for a small gift upon completion of the questionnaires. The participants were also entered into a drawing with the chance to win $\$ 50.00$.

\section{Measures}

All participants completed the Everyday Health Issues of Older Adults Questionnaire. The Everyday Health Issues of Older Adults Questionnaire was created using problem-solving vignettes and the existing instruments described below (see Appendix A).

\section{Demographic Information}

A demographic questionnaire contained general questions regarding sex, age, race, education, residency, income, children, siblings, religious affiliation, marital status (i.e., married, living as married, widowed, divorced, never married), living status (i.e., alone, with others), work history and current employment.

As background health information, participants were asked to provide information regarding the gender of their physician, frequency of doctor visits, access to health care, and general health conditions. To assess the number of physical illnesses, the checklist contained in 
the National Long Term Care Survey (National Center for Health Statistics, 1982) was used. Respondents reported on whether they had been diagnosed with any of 33 physical health problems. Participants were then asked to list the month and year in which they were diagnosed and current or past health problems if they were not on the list provided. Number of prescription or over the counter drugs, and reasons for taking them were also reported. Participants were asked to rate on a 5-point likert-type scale $(1=$ does not interfere, $5=$ prevents completely $)$ the degree that health problems interfered with things they used to do and things they want to do. For participants who indicated a current heart-related or arthritic problem, they were asked to rate severity of the problem on a 5-point likert-type scale $(1=$ very mild, $5=$ very severe $)$. As background information, participants' knowledge of heart problem and arthritis symptoms was assessed. Participants were asked to state either "true" or "false" whether a symptom was related to heart and arthritis problems. There were 10 symptom items for each type of health problem (i.e., heart and arthritis). Information on symptoms of heart problems was taken from the American Heart Association(2002). Information on symptoms of arthritis problems was taken from the Arthritis Foundation (1995). Knowledge of heart problem symptoms and knowledge of arthritic symptoms were calculated separately. The participant received 1 point for each correct answer and zero points for each incorrect answer. A higher score indicated better knowledge of symptoms related to the health problem.

\section{Problem Vignettes}

Preferences for strategies used to solve everyday health-related problems were assessed through the use of vignettes. Vignettes have been shown to be a useful way to examine strategies used to solve everyday problems (Berg, 1989; Blanchard-Fields, Jahnke \& Camp, 1995; Patrick \& Strough, 2004; Watson \& Blanchard-Fields, 1998). Participants were asked to answer 
questions concerning four vignettes (2 domains x 2 levels of severity). Two vignettes involved typical symptoms associated with arthritis, such as joint pain (Arthritis Foundation, 1995). Two vignettes involved typical symptoms associated with heart disease, such as chest pain and difficulty breathing (American Heart Association, 2002). Severity was varied within the vignettes. One vignette described a severe arthritis problem (i.e., "Imagine that your hands and knees ache all the time. Simple things such as getting dressed, eating, and getting up out of chairs are always very difficult".); one described a less severe arthritis problem (i.e., "Imagine that as you are getting dressed, your fingers begin to hurt and start to swell. Ten minutes later they are still hurting”.). Heart problems are conceptualized as an acute illness in the vignettes. One vignette described a severe heart problem (i.e., "Imagine that you awake suddenly in the middle of the night with throbbing pains in your chest and arm. You feel enormous pressure in the center of your chest and you are sweating. It is very difficult to breathe and 10 minutes later the pain is still there".); one described a less severe heart problem (i.e., "Imagine that one evening as you are eating dinner, you notice a slight pain in your chest and it seems a little difficult to breathe. You break out into a cold sweat and start to feel nauseous. After 10 minutes the pain and nausea are still there".).

\section{Strategies}

Problem-solving strategies for each problem were listed and participants were asked to rate from (1) "Not at All Likely" to (5) "Very Likely" the likelihood they would engage in each strategy. The problem solving strategies included in the questionnaire were "do nothing", “discuss with a doctor", "discuss with spouse" (if married), "discuss with relative", "discuss with someone else", "ignore the problem", "do something to take your mind off of the problem", "deal with the problem alone", "take an aspirin or over-the-counter pain reliever", "pray", "look 
up information about what the symptoms mean", "go to the hospital", "do something else". The strategies of "discuss with doctor", "discuss with spouse", "discuss with relative", discuss with someone else", "ignore the problem", and "deal with the problem alone" were of main interest due to the collaborative and individual nature of the strategies. The strategies of "do nothing", "do something to take your mind off of your problems", "take an aspirin or over-the-counter pain reliever", "pray", "look up information about what the symptoms mean", "go to the hospital", "do something else" were generated in order to be exhaustive and allow for a larger range of strategies to be considered. Therefore, participants could consider the strategies of interest from within a larger range of strategies.

\section{Experience}

To assess personal experience with health problems in each condition (i.e., heart severe, heart mild, arthritis severe, arthritis mild), the participant was asked to indicate whether they had ever experienced the same type of problem (yes/no), and how long ago (7-point likert-type scale; $0=$ within the past three weeks, $7=6$ months ago or more), and how often (7-point likert-type scale; $1=$ every few years, $7=$ everyday) the problem was experienced. To assess vicarious experience, the participant was asked if he or she knew anyone who had ever experienced the problem. If the participant chose "discuss with a relative" or "discuss with someone else" they were asked to report their relationship to that person (e.g., relative, sibling, friend). They were also asked if that person had ever experienced the problem, how long ago (using the same 7point scale), and how often (using the same 7-point likert-type scale).

\section{Self-Rated Health}

The 4-item self-rated health scale from the Multilevel Assessment Instrument (Lawton, Moss, Fulcomer \& Kleban, 1982) was used to assess perceived health. Lawton and colleagues 
(1982) report a Cronbach's alpha of .76. Participants were asked to rate their overall health at the present time from (1) excellent to (4) poor. Participants were asked "Is your health now (1) better, (2) about the same, or (3) not as good as it was 3 years ago?" Participants were asked if their health problems stand in the way (1) not at all, (2) a little or (3) a great deal of doing the things they want to do. Participants were asked, "Compared with most other people your age, would you say your health is: (1) better, (2) the same or (3) not as good. Participants were asked, "Compared with most people your own age, would you say your health is: (1) better, (2) the same or (3) not as good. Raw Scores were reversed so that and higher scores indicated better perceived health. Total perceived health score was computed by summing the scores for each item. Cronbach's alpha for the current sample was .74. The scale had a possible range from 4 to 16 and an actual range of 7 to 16 , with a mean of 13.11 and standard deviation of 1.83 .

\section{Problem-Solving Preferences}

A modified version of the problem-solving preference scale used by Strough, and colleagues (2002) assessed preferences for solving problems alone and with others in the domain of health. This data was collected for future use; therefore, it is not examined in the current study. Three items corresponded to each of the following strategies: doctor, spouse, relative someone else, and alone. Participants were asked: how often the participant worked with another person (i.e., doctor, spouse, relative, someone else) or alone $(1=$ never, $5=$ very often $)$, how much the participant prefers to work with another person (i.e., doctor, spouse, relative, someone else) or alone $(1=$ do not prefer, $5=$ very much prefer $)$, and how much the participants like to work with another person (i.e., doctor, spouse, relative, someone else) or alone $(1=$ do not like, 5 = very much like) to solve health-related problems. 


\section{Perceived Control over Health}

Wallston, Wallston, and De Vellis's Multidimensional Health Locus of Control (MHLC) scales were used to assess perceived control over health. The MHLC is divided into three subscales: internal health locus of control, powerful others health locus of control, and chance health locus of control. The authors reported a Cronbach's alpha of .86 for the internal locus of control subscale, a .83 for the powerful others health locus of control subscale, and a .84 for the chance health locus of control subscale. Participants were asked to rate on a 6-point likert-type scale how much they agree from (1) strongly agree to (7) strongly disagree with 18 statements concerning one's control over health. For example, participants were asked to rate the degree to which they agreed or disagreed with the following statement: "If I become sick, I have the power to make myself well again". Scores were reversed so that higher scores indicated higher perceived control. An overall perceived control over health score was computed by summing the scores of the subscales. Cronbach's alpha for the sample was .55. The scale had a possible range of 18 to 108 and an actual range from 52 to 86 , with a mean of 68.47 and standard deviation of 7.55 .

\section{Perceived Risk}

The perceived risk portion of Lachman and Weaver's (1998) perceived control over health scale was modified to correspond to the health domains in the present study. This data was collected for future use; therefore, it is not examined in the current study. To assess perceived risk, participants were asked to rate perceived risk of having a heart attack and getting arthritis as (1) higher, (2) lower or (3) about the same as compared to other same-gender individuals of the same age. 


\section{Procedure}

The study was thoroughly described to the participants and informed consent was obtained. All data was collected in accordance with the Health Insurance Portability and Accountability Act (HIPAA) and a HIPAA authorization form was signed. Participants were asked to complete the Everyday Health Issues of Older Adults Questionnaire in its entirety. Questionnaires were completed individually at home or in the Lifespan Development Laboratory at West Virginia University. Three participants completed the survey and returned it via mail. Directions on how to complete the questionnaire were thoroughly described and any questions were answered. The questionnaire took approximately an hour to complete. The problem vignettes were counterbalanced to control order effects. The order of the vignettes in version 1 was arthritis severe, heart mild, heart severe, and arthritis mild. The order of the vignettes in version 2 was heart severe, arthritis mild, arthritis severe, heart mild. The order of the vignettes in version 3 was heart mild, heart severe, arthritis mild, arthritis severe. The order of the vignettes in version 4 was arthritis mild, arthritis severe, heart mild and heart severe. Eight married men, 8 married women, 8 unmarried men and 8 unmarried women completed each version. After completion of the questionnaire, the participant chose a small gift as a thank you.

\section{RESULTS}

Before conducting analyses, missing data for strategy ratings in each of the four conditions was replaced using the overall mean. For the "discuss with doctor" strategy, the percent of data that was missing data replaced ranged from $4 \%$ in the arthritis severe condition to $6 \%$ in the heart mild condition. For the "discuss with relative" strategy, the percent of missing data replaced ranged from $3 \%$ in the heart mild condition to $6 \%$ in the arthritis mild condition. For the "discuss with someone else" strategy, the percent of missing data replaced ranged from 
$5 \%$ in the arthritis severe condition to $6 \%$ in the heart mild condition. For the strategy "ignore the problem", the percent of missing data replaced ranged from $6 \%$ in the arthritis severe condition to $8 \%$ in the heart mild condition. For the strategy "deal with the problem alone", the percent of missing data replaced ranged from $5 \%$ in the arthritis severe condition to $8 \%$ in the heart mild condition.

Boxplots were used to screen for outliers separately for each group (i.e., unmarried males, married males, unmarried females, married females) on each strategy within each domain and severity level. Results indicated that no significant outliers were present. Skewness and Kurtosis were used to examine normality of the data. Although skewness and Kurtosis values indicated a deviation from normality (i.e., did not equal zero), the sample size was large enough that deviation from normality would not make a substantive difference in analyses (Tabachnick \& Fidell, 2001).

\section{Order Effects}

To examine order affects, a 4 (version) X 5 (strategy) repeated measures MANOVA was conducted. The strategies included in this analysis were "discuss with doctor", "discuss with relative", "discuss with someone else", "ignore the problem" and "solve the problem alone". The strategy "discuss with spouse" was not included in the analysis due to the inclusion of both married and unmarried older adults. Results indicated a significant version x strategy interaction, $F(4,121)=127.177, p<.01, e t a^{2}=.808$. To follow-up the significant two-way interaction, univariate ANOVAs were conducted for each strategy. Results indicated that version significantly impacted the ratings on the "discuss with relative" strategy, $F(3,127)=$ 5.451, $p<.01, e t a^{2}=.117$. Bonferroni tests indicated that adults rated "discuss with relative" significantly higher in version 4 (arthritis mild, arthritis severe, heart mild and heart severe; $M=$ 
$3.985, S D=.236$ ) than in both version 2 (heart severe, arthritis mild, arthritis severe, heart mild; $M=2.969, S D=.236$ ) and version 3 (heart mild, heart severe, arthritis mild, arthritis severe; $M=$ $2.719, S D=.236$ ). Results indicated that version significantly impacted the "discuss with someone else" strategy, $F(3,127)=3.834, p<.05$, eta $^{2}=.085$. Bonferroni tests indicated that adults rated "discuss with someone else" significantly higher in version 4 (arthritis mild, arthritis severe, heart mild and heart severe; $M=3.374, S D=.225$ ) than in version 3 (heart mild, heart severe, arthritis mild, arthritis severe; $M=2.375, S D=.225$ ). Results indicated that version significantly impacted the "ignore the problem" strategy, $F(3,127)=6.293, p<.01$, eta ${ }^{2}=.132$. Bonferroni tests indicated that adults rated "ignore the problem" significantly higher in version 2 (heart severe, arthritis mild, arthritis severe, heart mild; $M=2.583, S D=.203$ ) than in both version 1 (arthritis severe, heart mild, heart severe, and arthritis mild; $M=1.594, S D=.203$ ) and version 4 (arthritis mild, arthritis severe, heart mild and heart severe; $M=1.434, S D=.203$ ). Version significantly affected the strategies of "discuss with relative", "discuss with someone else", and "ignore the problem". Version did not significantly affect the strategies of "discuss with doctor" or "deal with the problem alone". Order of conditions (i.e., version) was not included as a between subjects variable because the vignettes were counterbalanced; therefore, order effects should not impact interpretations of results.

Strategies for Solving Mild and Severe Heart and Arthritis Problems To examine the relative differences among strategy ratings of older adults, a 2 (gender) $\mathrm{x}$ 2 (marital status) x 2 (domain) x 2 (severity) x 5 (strategy) repeated measures MANOVA was conducted. The strategies included in this analysis were "discuss with doctor", "discuss with relative", "discuss with someone else", "ignore the problem" and "solve the problem alone". The strategy "discuss with spouse" was not included in the analysis due to the inclusion of both 
married and unmarried older adults. Unmarried adults did not rate the strategy "discuss with spouse." Gender (male, female) and marital status (married, unmarried) were the between subject variables. Domain (heart, arthritis), severity (mild, severe), and strategy (discuss with doctor, discuss with relative, discuss with someone else, ignore and alone) were the within subject variables.

The multivariate analysis revealed a significant five-way interaction for domain $\mathrm{x}$ severity x strategy x gender x marital status, $F(4,121)=2.882, p<.05$, eta ${ }^{2}=.087$ (statistics for higher order interactions will be included in the text; see Appendix B for all lower order interactions). Given that different symptoms and different modes of treatment are associated with each of the health problems (i.e., heart and arthritis), the 5-way interaction was first broken down by domain or type of problem. Both marital status and gender have been shown to impact collaboration (Margrett \& Marsiske, 2002); therefore, the interaction was further broken down by marital status and gender. The effects of severity of the problem have not been well documented in relation to collaboration; therefore, the effects was considered last. Specific hypotheses were addressed in a separate section under results.

\section{Heart Problem Domain}

A 2 (gender) x 2 (marital status) x 2 (severity) x 5 (strategy) repeated measures MANOVA was conducted for the heart domain. The analysis revealed a significant four-way interaction for severity $\mathrm{x}$ strategy $\mathrm{x}$ gender $\mathrm{x}$ marital status, $F(4,121)=3.170, p<.05$, eta ${ }^{2}=$ .095. To follow-up the significant four-way interaction, repeated measures MANOVAs were conducted separately for the two severity levels (i.e., mild and severe) within the heart problem domain. 


\section{Mild Heart Problems}

A 2 (gender) x 2 (marital status) x 5 (strategy) repeated measures MANOVA revealed a significant three-way interaction for strategy $\mathrm{x}$ gender $\mathrm{x}$ marital status, $F(4,121)=4.716, p$ $<.01, e t a^{2}=.135$. To follow-up the significant three-way interaction, repeated measures MANOVAs were conducted to compare marital status separately for males and females within the mild heart problem domain.

Married and unmarried males' strategies for mild heart problems. For males, a 2 (marital status) x 5 (strategy) repeated measures MANOVA revealed a significant main effect for strategy, $F(4,59)=130.890, p<.01, e t a^{2}=.899$, and a significant two-way interaction of strategy x marital status, $F(4,59)=5.979, p<.01$, eta $^{2}=.288$. Univariate ANOVAs for each strategy were conducted to follow-up the significant two-way interaction. Analyses indicated that unmarried males rated "discuss with someone else" higher than did married males, $F(1,63)$ $=11.219, p<.01, e t a^{2}=.153$. Married males rated "deal with the problem alone" significantly higher than did unmarried males, $F(1,63)=9.475, p<.01$, $e^{2} a^{2}=.133$. (see Table 1 and Figure 1). There were no significant differences between married and unmarried males' ratings of "discuss with doctor", "discuss with relative", and "ignore the problem" when dealing with a mild heart problem. Therefore, for males, the hypothesis that unmarried adults would rate “discuss with doctor" higher than married adults was not supported.

To address the hypothesis that unmarried older adults would rate "discuss with relative" higher than the other interpersonal strategies (i.e., discuss with doctor, discuss with someone else), simple contrasts were conducted for unmarried males. Simple contrasts compared each strategy to the "discuss with relative" strategy. Results indicated a significant difference between “discuss with a doctor" and "discuss with relative". $F(1,31)=47.06, p<.01, e^{2}=.603$. 
Unmarried males rated "discuss with doctor" $(M=4.52)$ significantly higher than "discuss with relative" $(M=2.50)$. Therefore, the hypothesis was not supported for males in the heart mild condition (see Table 1 and Figure 1).

Female's strategies for mild heart problems. For females, a 2 (marital status) x 5 (strategy) repeated measures MANOVA revealed a significant main effect for strategy, $F(4,59)$ $=35.304, p<.01, e t a^{2}=.705$. There were no significant differences between married and unmarried females on strategy ratings when dealing with a mild heart problem (see Table 1). Therefore, for females, the hypothesis that unmarried adults would rate "discuss with doctor" higher than married adults was not supported.

Deviation contrasts were used to follow-up the significant main effect of strategy for females on mild heart problems. Deviation contrasts compared the means of each strategy to the overall mean. Results indicated that females rated "discuss with doctor" significantly higher than the grand mean, $F(1,62)=130.558, p<.01$, $e t a^{2}=.678$, and "discuss with relative" significantly higher than the grand mean, $F(1,62)=11.882, p<.01$, eta ${ }^{2}=.161$. Females rated "ignore the problem" significantly lower than the grand mean, $F(1,62)=55.287, p<.01$, eta $^{2}=.471$ (see Figure 6). There were no significant differences between the grand mean and the mean strategy ratings for "discuss with someone else" and "deal with the problem alone."

\section{Severe Heart Problems}

A 2 (gender) x 2 (marital status) x 5 (strategy) repeated measures MANOVA revealed a significant main effect for strategy, $F(4,121)=294.432, p<.01$, eta $^{2}=.907$, and a significant two-way interaction of strategy $\mathrm{x}$ gender, $F(4,121)=5.268, p<.01$, eta $^{2}=.148$. Univariate ANOVAs using gender (male, female) as the between subject variable were conducted to followup the significant two-way interaction. Analyses revealed that males rated "discuss with doctor" 
significantly higher than did females, $F(1,127)=11.898, p<.01$, eta ${ }^{2}=.086$. Females rated "discuss with relative" significantly higher than did males, $F(1,127)=7.509, p<.01$, eta ${ }^{2}=$ .056. There were no significant gender differences on the ratings of "discuss with someone else", "ignore the problem", and "deal with the problem alone" when the problem was a severe heart problem (see Table 1 and Figure 2).

\section{Arthritis Problem Domain}

\section{A 2 (gender) x 2 (marital status) x 2 (severity) x 5 (strategy) repeated measures}

MANOVA was conducted for the domain of arthritis. The analysis revealed significant main effects for severity, $F(1,124)=12.425, p<.01$, eta ${ }^{2}=.091$, and strategy, $F(1,124)=81.837, p$ $<.01$ eta $^{2}=.730$, and significant two-way interactions for strategy x gender, $F(1,124)=8.727$, $p<.01, e^{2} a^{2}=.224$, strategy x marital status, $F(1,124)=7.248, p<.01$, eta ${ }^{2}=.193$, and severity $\mathrm{x}$ strategy, $F(1,124)=11.801, p<.01$, $e^{2} a^{2}=.281$. Each significant interaction was followed up.

\section{Strategy $x$ Gender}

Univariate ANOVAs were conducted to follow-up the significant effect of strategy $\mathrm{x}$ gender. Results indicated that females rated "discuss with relative" $F(1,126)=5.640, p<.05$, $e t a^{2}=.043$, and "discuss with someone else", $F(1,127)=23.760, p<.01, e t a^{2}=.159$ significantly higher than did males (see Figure 3). There were no gender differences on the ratings of the strategies of "discuss with doctor", "ignore the problem" and "deal with the problem alone" when dealing with an arthritis problem.

\section{Strategy x Marital Status}

Univariate ANOVAs were conducted to follow-up the significant effect of strategy $\mathrm{x}$ marital status. For arthritis problems, results indicated that married older adults rated "ignore the 
problem" significantly higher than unmarried adults, $F(1,63)=4.643, p<.05$, eta ${ }^{2}=.036$ (see Figure 4). There were no significant differences between married and unmarried adults on the other strategies (i.e., "discuss with doctor" "discuss with relative", "discuss with someone else", and "deal with the problem alone") when dealing with an arthritis problem.

To address the hypothesis that unmarried older adults would rate "discuss with relative" higher than the other interpersonal strategies (i.e., discuss with doctor, discuss with someone else), simple contrasts were conducted for unmarried adults. Results indicate a significant difference between "discuss with a doctor" and "discuss with relative", $F(1,63)=23.554$, $p<.01, e^{2} a^{2}=.272$. Unmarried males rated "discuss with doctor" $(M=3.90)$ significantly higher than "discuss with relative" $(M=3.15)$. The strategy ratings for "discuss with relative" did not differ significantly from the strategy ratings for "discuss with someone else"; therefore, the hypothesis was not supported in the arthritis domain (see Table 2).

\section{Severity x Strategy}

To follow-up the severity x strategy interaction, paired sample $t$-tests were conducted to examine the effect severity had on each strategy. Considering the number of consecutive t-tests conducted, confidence level was set at $99 \%$ to be more conservative. For arthritis problems, results indicated older adults rated "discuss with a doctor", $t(127)=-7.419, p<.01$, "discuss with relative", $t(127)=-2.157, p<.01$, and "discuss with someone else", $t(127)=-2.074, p<.01$ higher when the arthritis problem was severe as compared to mild (see Table 2 and Figure 5). There were no significant differences between severe and mild problems on the ratings for 'ignore the problem" and "deal with the problem alone",

The hypothesis that adults would rate the interpersonal strategies (i.e., doctor, spouse, relative, other) higher when the problem is severe as compared to mild was supported in the 
arthritis domain. Results indicated that older adults rated "discuss with a doctor", $t(127)=$ $7.419, p<.01$, and "discuss with someone else", $t(127)=-2.074, p<.01$ higher when the arthritis problem was severe as compared to mild. There were no significant differences between severe and mild problems on the ratings for "ignore the problem" and "deal with the problem alone".

\section{Married Older Adult Problem Solving Strategies}

To examine the relative differences among strategy ratings of married older adults, a 2 (gender) x 2 (domain) x 2 (severity) x 6 (strategy) repeated measures MANOVA was conducted. Gender (male, female) was the between subject variable. Domain (heart, arthritis), severity (mild, severe), and strategies (discuss with doctor, discuss with spouse, discuss with relative, discuss with someone else, ignore and alone) were the within subject variables. The analysis revealed a significant four-way interaction for domain $\mathrm{x}$ severity $\mathrm{x}$ strategy $\mathrm{x}$ gender, $F(5,58)=$ 2.545, $p<.05, e t a^{2}=.180$. To follow-up this interaction, repeated measures MANOVAs were conducted separately for effects in the two domains of health problems (i.e., heart and arthritis).

\section{Heart Problem Domain}

A 2 (gender) x 2 (severity) x 6 (strategy) repeated measures MANOVA was conducted for the heart problem domain. The analysis revealed a significant three-way interaction for severity x strategy x gender, $F(5,58)=3.251, p<.05$, $e t a^{2}=.219$. To follow-up the significant three-way interaction, repeated measures MANOVAs were conducted separately for each of the two severity levels (i.e., mild and severe).

\section{Mild Heart Problems}

A 2 (gender) x 6 (strategy) repeated measures MANOVA revealed a significant main effect for strategy, $F(5,58)=156.866, p<.01$, eta ${ }^{2}=.931 . \quad$ A significant two-way interaction for strategy x gender, $F(5,58)=5.397, p<.01$, eta ${ }^{2}=.318$, was also found. Univariate 
ANOVAs were conducted for each strategy to follow-up the significant two-way interaction (i.e., strategy $\mathrm{x}$ gender). The results of the univariate ANOVAs indicate that married females rated "discuss with someone else" significantly higher than married males, $F(1,63)=10.895, p$ $<.01, e t a^{2}=.149$ when dealing with mild heart problems. Married females also rated "ignore the problem" significantly higher than married males, $F(1,63)=7.007, p=.01$, eta ${ }^{2}=.102$ when dealing with mild heart problems (see Table 3). There were no significant gender differences for ratings of "discuss with doctor", "discuss with spouse", "discuss with relative" and "solve the problem alone" when the problem was a mild heart problem (see Table 3).

\section{Severe Heart Problems}

A 2 (gender) x 6 (strategy) repeated measures MANOVA revealed a significant main effect for strategy, $F(5,58)=183.621, p<.01, e t a^{2}=.941$. Deviation contrasts were used to follow-up the significant main effect of strategy. Results indicated that married adults rated "discuss with doctor" significantly higher than the grand mean, $F(1,58)=448.029, p<.01$, eta $^{2}=.878$, "discuss with spouse" significantly higher than the grand mean, $F(1,58)=469.217, p<.01$, eta ${ }^{2}$ $=.883$. Married adults rated "deal with the problem alone" significantly lower than the grand mean, $F(1,58)=204.568, p<.01$, $e t a^{2}=.767$, and "ignore the problem" significantly lower than the grand mean $F(1,58)=25.428, p<.01$, eta $^{2}=.291$. For severe heart problems there was no significant two-way interaction between strategy and gender (see Table 3).

\section{Arthritis Problem Domain}

A 2 (gender) x 2 (severity) x 6 (strategy) repeated measures MANOVA was conducted for the domain of arthritis. The analysis revealed significant main effects for severity, $F(5,58)$ $=8.387, p<.01$, eta $^{2}=.119$, and strategy, $F(5,58)=188.319, p<.01$, eta $^{2}=.842$, and significant 
two-way interactions for strategy $\mathrm{x}$ gender, $F(5,58)=5.840, p<.05$, eta ${ }^{2}=.335$, and severity $\mathrm{x}$ strategy, $F(5,58)=4.058, p<.01, e t a^{2}=.259$.

ANOVAs were conducted to follow-up the significant two-way interactions. For the strategy $\mathrm{x}$ gender interaction, univariate ANOVAs indicated that males rated "discuss with doctor" significantly higher than did females, $F(1,63)=5.152, p<.05$, eta ${ }^{2}=.077$, and females rated "discuss with someone else" significantly higher than males, $F(1,63)=17.962, p<.05$, $e t a^{2}=.225$. There were no significant gender differences for ratings of "discuss with spouse", "discuss with relative", "ignore the problem" and "solve the problem alone" when the problem was a mild arthritis problem (see Table 4).

To follow-up the severity x strategy interaction, paired sample $t$-tests were conducted to examine the effect severity had on each strategy. Confidence level was set at $99 \%$ to be more conservative. Results indicated older adults rated "discuss with a doctor", $t(63)=-4.973, p<.01$, and "discuss with spouse", $t(63)=-4.706, p<.01$, higher when the arthritis problem was severe as compared to mild. There were no significant differences between severe and mild problems on the ratings for "discuss with relative" and "ignore the problem".

\section{Specific Hypotheses Tests}

It was hypothesized that married older adults would rate the strategy "discuss with spouse" higher than other interpersonal strategies on health-related problems. To examine the hypothesis, a repeated measures MANOVA with strategies as the repeated measures was conducted. Results indicated that the hypothesis was supported partially only in the severe heart condition, $F(5,59)=185.60, p<.01, e t a^{2}=.940($ see Table 1$)$. Simple contrasts indicated that married adults rated "discuss with spouse" significantly higher than "discuss with relative", $F(1$, $63)=70.757, p<.01, e t a^{2}=.529$. Married adults rated "discuss with spouse" significantly higher 
than "discuss with someone else", $F(1,63)=161.561, p<.01$, eta ${ }^{2}=.719$. There were no significant differences in the "discuss with spouse" and "discuss with doctor" ratings.

It was also hypothesized that gender would impact the ratings of the "discuss with spouse" strategy; married men would rate "discuss with spouse" higher than married women. This hypothesis was not supported in any condition. There were no significant gender differences for ratings of "discuss with spouse".

The hypothesis that adults would rate the interpersonal strategies (i.e., doctor, spouse, relative, other) higher when the problem is severe as compared to mild was supported in the arthritis domain (see Figures 3 and 4). Results indicated older adults rated "discuss with a doctor", $t(63)=-4.973, p<.01$, and "discuss with spouse", $t(63)=-4.706, p<.01$, higher when the arthritis problem was severe as compared to mild. There were no significant differences between severe and mild problems on the ratings for "discuss with relative" and "ignore the problem".

\section{The Role of Experience on Problem Solving Strategies}

Participants rated the categorical measure of experience for each condition (i.e., heart mild, heart severe, arthritis mild, arthritis severe). See Table 5 for the frequencies of those participants with personal and vicarious experience with health problems. For arthritis mild problem, approximately $8 \%$ of the experience data was missing. For the arthritis severe problem, approximately $14 \%$ of the experience data was missing. For the heart mild problem, approximately $11 \%$ of the experience data is missing. For the heart severe problem, approximately $4 \%$ of the data was missing. Analyses using the categorical data are based upon those participants who provided a valid response. 
Participants rated the continuous measure of experience for each condition (i.e., heart mild, heart severe, arthritis mild, arthritis severe). Sample sizes for the continuous measure of experience were limited due to the amount of missing data for each condition The relatively high frequencies of missing data for the continuous measure of experience reflects that only participants who had at least some experience responded to this question. For the arthritis mild problem, approximately $73 \%$ of the experience data was missing. For the arthritis severe problem, approximately $61 \%$ of the experience data was missing. For the heart mild problem, approximately $91 \%$ of the experience data was missing. For the heart severe problem, approximately $88 \%$ of the experience data was missing. Analyses using the continuous data are based upon those participants who provided a valid response.

To examine the effect of personal experience on strategy ratings, a 2 (experience) x 5 (strategy) MANOVA was conducted for each of the four domain/severity conditions (i.e., heart mild, heart severe, arthritis mild, and arthritis severe). MANOVAs were conducted separately for each condition because experience was assessed at the level of domain and severity. The categorical measure of personal experience (yes, no) was the between subject variableand strategies (discuss with doctor, discuss with spouse, discuss with relative, discuss with someone else, ignore and alone) were the within subject variables.

The following analyses were conducted to address the hypothesis that older adults who have experienced health problems would rate interpersonal strategies (i.e., doctor, spouse, relative, other) higher than those without experience when solving health related issues. 


\section{Heart Problem Domain}

\section{Mild Heart}

A 2 (experience) x 5 (strategy) MANOVA was conducted to examine the effect of the categorical measure of experience on strategy ratings for the mild heart condition. Results indicated that experience did impact the strategy ratings, $F(1,111)=3.463, p<.01$, eta $^{2}=.135$. Follow-up univariate ANOVAs for each strategy showed that experience had a significant effect on the strategies of "discuss with doctor", $F(1,116)=4.451, p<.05$, eta ${ }^{2}=.037$, and "deal with the problem alone", $F(1,116)=4.451, p<.05$, eta $^{2}=.037$. Older adults without experience $(M$ $=4.534, S D=.808)$ with mild heart problems rated the strategy "discuss with a doctor" higher than did those with experience $(M=4.036, S D=.970)$. Older adults with experience $(M=$ $2.857, S D=1.406$ ) with mild heart problems rated the strategy "deal with the problem alone" higher than did those without experience $(M=1.630, S D=.999)$. Experience with mild heart problems did not affect ratings on the strategies of "discuss with relative", "discuss with someone else", and "ignore the problem". Pearson correlation coefficients were computed using the continuous measure of experience. When assessed continuously, experience with mild heart problems was not related to ratings' on any strategy.

\section{Severe Heart}

A 2 (experience) x 5 (strategy) MANOVA was conducted to examine the effect of the categorical measure of experience on strategy ratings for the severe heart condition. Results indicated that experience did impact the strategy ratings, $F(1,123)=7.759, p<.01$, eta ${ }^{2}=.247$. Follow-up Univariate ANOVAs for each strategy showed that experience had a significant effect on the strategies of "discuss with doctor", $F(1,123)=26.594, p<.01$, eta ${ }^{2}=.179$, "discuss with a relative", $F(1,123)=8.200, p<.01, e t a^{2}=.063$, and "discuss with someone else", $F(1,123)$ 
$=4.002, p<.05, e^{2} a^{2}=.032$. Older adults without experience $(M=4.878, S D=.347)$ with severe heart problems rated the strategy "discuss with a doctor" higher than did those with experience $(M=4.252, S D=.940)$. Older adults without experience $(M=3.314, S D=1.675)$ with severe heart problems rated the strategy "deal with the problem alone" higher than did those with experience $(M=2.137, S D=1.155)$. Older adults without experience $(M=2.837, S D=$ 1.491) with severe heart problems rated the strategy "discuss with someone else" higher than did those with experience $(M=2.097, S D=1.173)$.

Pearson correlation coefficients were computed using the continuous measure of experience. The continuous measure of experience with severe heart problems was significantly positively related to the strategies of "discuss with relative", $r(13)=.747, p<.01$, and "discuss with someone else", $r(13)=.848, p<.01 \quad$ (see Table 7 for all severe heart correlations).

\section{Arthritis Problem Domain}

\section{Mild Arthritis}

A 2 (experience) x 5 (strategy) MANOVA was conducted to examine the effect of experience on strategy ratings for the mild arthritis condition. Results indicated that experience did not impact the strategy ratings in the mild arthritis condition, $F(1,114)=1.146, p=.340$, $e t a^{2}=.048$. Pearson correlation coefficients were computed using the continuous measure of experience. When assessed continuously, experience with mild arthritis problems was not related to ratings' on any strategy. However, lower levels of experience when experience was assessed as a continuous variable in the mild arthritis condition, $r(35)=-.459, p<.01$, was associated with higher self-rated health scores. (see Table 9 for all mild arthritis correlations). 


\section{Severe Arthritis}

A 2 (experience) x 5 (strategy) MANOVA was conducted to examine the effect of experience on strategy ratings for the severe arthritis condition. Results indicated that experience did impact the strategy ratings, $F(1,108)=7.722, p<.01$, eta ${ }^{2}=.263$. Follow-up univariate ANOVAs for each strategy showed that experience had a significant effect on the strategies of "discuss with relative", $F(1,113)=9.687, p<.05$, eta $^{2}=.046$, "discuss with someone else", $F(1,113)=37.927, p<.01$, eta $^{2}=.183$, and "ignore the problem", $F(1,113)=$ $19.055, p<.01$, eta $^{2}=.145$. Older adults with experience $(M=3.505, S D=1.072)$ with severe arthritis problems rated the strategy "discuss with a relative" higher than did those without experience $(M=2.917, S D=1.521)$. Older adults with experience $(M=3.659, S D=.918)$ with severe arthritis problems rated the strategy "discuss with someone else" higher than did those without experience $(M=2.497, S D=1.424)$. Older adults without experience $(M=2.381, S D=$ 1.413) with severe arthritis problems rated the strategy "ignore the problem" higher than did those with experience $(M=1.416, S D=.755)$. Pearson correlation coefficients were computed using the continuous measure of experience. When assessed continuously, experience with severe arthritis problems was not related to ratings' on any strategy.

The hypothesis that older adults who have experienced health problems would rate interpersonal strategies (i.e., doctor, spouse, relative, other) higher than those without experience when solving health related issues was partially supported when assessed as a categorical variable in the severe arthritis condition. Adults with experience rated "discuss with a relative" and "discuss with someone else" higher than those without experience in the severe arthritis condition. The hypothesis was not supported in any other condition. When assessed as a 
continuous variable, experience was significantly positively related to the strategies of "discuss with relative" and "discuss with someone else" in the severe heart condition.

\section{Self-Rated Health and Perceived Control}

Pearson correlations were used to address the hypotheses related to self-rated health and perceived control. Pearson correlation coefficient matrixes with 99\% confidence levels were computed separately for each condition (i.e., heart mild, heart severe, arthritis mild, arthritis severe).

\section{Heart Problem Domain}

\section{Heart Mild}

Higher perceived control scores were associated with lower ratings on the strategy of "discuss with relative", $r(113)=-.287, p<.01$. Higher self-rated health scores were associated with higher ratings on the strategy of "discuss with relative", $r(126)=.255, p<.01$ (see Table 6 for all mild heart correlations).

Heart Severe

Self-rated health and perceived control were not significantly correlated with any strategy in the severe heart condition (see Table 7).

\section{Arthritis Problem Domain}

\section{Arthritis Mild}

Self-rated health and perceived control were not significantly correlated with any strategy in the severe heart condition (see Table 8).

\section{Arthritis Severe}

Higher perceived control scores were associated with lower ratings on of "discuss with relative", $r(113)=-.316, p<.01$. Higher self-rated health scores were associated with lower 
ratings on the strategy of "deal with the problem alone", $r(126)=-.393, p<.01$ (see Table 9 for all severe arthritis correlations).

In summary, it was hypothesized that higher perceived health scores would be negatively correlated with ratings of interpersonal strategies and positively correlated with ratings of selfstrategies. Results indicate that the hypothesis for self-rated health was not supported in any condition (see Tables 7 thru 9). It was hypothesized that higher perceived control scores would be negatively correlated with ratings of interpersonal strategies and positively correlated with ratings of self-strategies. Results indicate that the hypothesis for perceived control was partially supported in the mild heart and severe arthritis conditions (see Tables 7 and 9).

\section{Exploratory Analyses}

Exploratory analyses were conducted to help rule out reasons for group differences in problem solving strategy ratings based on extraneous variables, such as number of persons in the social network or number of physical illnesses. Exploratory analyses were conducted for education and income (see Table 10), general knowledge of heart and arthritis problems (see Table 11), number of persons in the social network (see Table 12), self-rated health and perceived control (see Table 13), and number of reported physical illnesses (see Table 14). Pearson chi-square tests were used to examine group differences in education. Pearson chisquare test statistics showed that a greater number of unmarried males reported obtaining a graduate degree as compared to married males, Pearson $X^{2}(1, \mathrm{~N}=62)=13.29, p<.01$. A greater number of unmarried females as compared to married females reported obtaining a graduate degree, Pearson $X^{2}(1, \mathrm{~N}=63)=4.20, p<.05$. A greater number of unmarried females as compared to unmarried males reported receiving some college education, Pearson $X^{2}(1, \mathrm{~N}=62)$ $=5.44, p<.05$. A greater number of married males as compared to unmarried males reported 
receiving some college education, Pearson $X^{2}(1, \mathrm{~N}=62)=5.44, p<.05$. A greater number of unmarried males as compared to unmarried females reported receiving a four-year degree, Pearson $X^{2}(1, \mathrm{~N}=62)=5.44, p<.05$. Income was recoded to form a continuous variable using the median of each range of income. A 2 (gender) x 2 (marital status) univariate ANOVA was conducted to examine group differences on income. Results indicated that unmarried adults ( $M$ $=\$ 23,375, S D=\$ 1526.76)$ reported a greater yearly income as compared to married adults $(M=$ $\$ 28254.61, S D=\$ 1566.31), F(1,120)=4.98, p<.05$, eta $^{2}=.04$. Results indicated that females answered more questions about symptoms related to heart problems correctly than males (see Table 12), and married adults report having more friends and relatives in their social network (see Table 13). There were no significant group differences in number of physical illnesses reported.

\section{DISCUSSION}

Overall, results suggest that gender, marital status, and the domain, and severity of health problems impact the strategies that older adults use to solve health-related problems. Although research has examined the importance of gender and marital status (Margrett \& Marsiske, 2001) and severity of problem (Strough, et al., 2003) in relation to older adults' collaboration in general domains, this study examined the interactions of the various factors specifically in the domain of health with different types of health problems. Findings illustrate the importance of considering individual characteristics (i.e., gender, marital status), and aspects of the problem (i.e., domain of health problem, and severity of health problem) that influence the strategies that older adults use to solve health-related problems. The information is particularly useful considering that health is an important domain for older adults (Strough, et al., 2002) and the specific type of health problems examined in this study (heart and arthritis) are extremely 
prevalent in the older adult population (National Center for Chronic Disease Prevention and Health Promotion, 1999).

\author{
Heart Problem Domain
}

Mild Heart

Men

Married versus unmarried men. Gender influenced adults' strategy ratings for mild heart problems, and marital status further qualified men's strategy ratings for mild heart problems. It was hypothesized that unmarried adults would rate "discuss with doctor" higher than married adults presumably due to unmarried adults having a smaller social network. The hypothesis was not supported for men dealing with mild heart problems; unmarried males rated "discuss with someone else" significantly higher than married males. Examination of the means indicated that unmarried men rated "discuss with someone else" higher than "discuss with relative" and married men rated "discuss with relative" higher than "discuss with someone else" (see Figure 1). Exploratory analyses of the background information showed that married adults as compared to unmarried adults, both men and women, reported a significantly greater number of relatives with whom they maintained regular contact (see Table 12); therefore, married individuals have more relatives in their social network with whom to collaborate. In addition, background information also showed that married adults as compared to unmarried adults, both men and women, reported a significantly greater number of friends with which they maintained regular contact (see Table 12). Thus, married individuals appear to have larger kin and non-kin social networks than unmarried individuals. Participants were asked to report the number of friends and relatives with whom they have regular contact (i.e., speak or write at least once a month). Although married adults report greater numbers of both relatives and friends they perhaps have 
more contact with relatives whereas unmarried adults may have more contact with persons outside of the family. In the future it may be useful to examine the amount of contact with persons in the social network instead of just the numbers of persons in the social network.

Although married men reported a greater number of people in their social network, married men rated "deal with the problem alone" significantly higher than unmarried men. Married men may not be utilizing persons in their networks as a source of collaboration when dealing with mild heart problems. The idea that married men prefer to solve mild heart problems alone builds upon previous research. Strough, and colleagues, (2002) found that, in general, older adults preferred to solve problems alone, and Berg, and colleagues (1998) found that individuals often report that they solve everyday problems alone. The current study shows that the preference for solving problems alone in the domain of health is qualified by marital status and gender. Future research is needed to examine whether marital status and gender impact whether adults' prefer to solve problems alone in other specific domains besides health.

Unmarried men. Unmarried men rated "discuss with doctor" significantly higher than "discuss with relative". Therefore, the hypothesis that unmarried adults would rate "discuss with relative" higher than other interpersonal strategies was not supported when dealing with mild heart problems (see Figure 1). However, the finding that unmarried men rated "discuss with doctor" higher than "discuss with relative" when dealing with mild heart problems is important because it indicates that although unmarried men may not be as open to self-disclosure with just anyone, they may be willing to discuss heart-related issues with medical professionals. 


\section{Women}

Marital status did not impact older women's strategy ratings on mild heart problems. Women rated "discuss with doctor" and "discuss with relative" higher than the grand mean and "ignore the problem" lower than the grand mean. In general, women rated the interpersonal strategies higher than the self-strategies (see Figure 6). This finding is consistent with the traditional gender role that women emphasize personal relationships to a greater extent than do men (Moen, 1996); therefore, women may be more likely to discuss a health-related issue with another person. However, examination of the means indicated that men's ratings of mild heart problems shows the similar general pattern of interpersonal strategies rated higher than self strategies.

When only married adults were considered, gender influenced the ratings of strategies for mild heart problems. Married women rated "discuss with someone else" and "ignore the problem" significantly higher than married men (see Table 3). Again, the finding that married women rated "discuss with someone else" higher than did married men is consistent with the traditional gender role that women emphasize personal relationships to a greater extent than do men (Moen, 1996). The fact that married women did not rate the family strategies (i.e., "discuss with spouse" and "discuss with relative") higher than did men but rated the strategy "discuss with someone else" higher than did men is consistent with Akiyama, et al. (1996). Akiyama and colleagues examined the relationships of older adults and found that men reported receiving support from their wives whereas women reported receiving support from friends. Therefore married women may be more likely than men to discuss problems with another person besides family members. 


\section{Severe Heart}

Gender

In contrast to findings for mild heart problems, for severe heart problems marital status was not associated with differential ratings of strategies; however, gender influenced the ratings of "discuss with doctor" and "discuss with relative" (see Figure 2). Men rated "discuss with doctor" significantly higher than did women and women rated "discuss with relative" significantly higher than did men. The finding that men rated "discuss with relative" higher than did men is consistent with research that indicates that women report more support from family and friends than do men (Akiyama, et al, 1996). The finding is consistent with previous research that shows women report less desire to become involved in the decision-making process when they have a particular disease (Beaver, Luker, Owens, Leinster, Degner, \& Sloan, 1996). Therefore, perhaps the finding that men rated "discuss with doctor" significantly higher than did women in the severe condition illustrates the tendency for women to be less involved in the health decision-making process, which includes discussing issues with a doctor. Although men rated "discuss with doctor" higher than did women when dealing with severe heart problems, examination of the means indicated that women did not necessarily rate "discuss with doctor" low, just lower than did men (see Figure 7).

Although men rated "discuss with doctor" higher than women, examination of the means indicated than both men and women rated the "discuss with doctor" strategy higher when the heart problem was severe as compared to mild. This indicates that older adults are likely to seek medical professional assistance when the problem is severe; however, they may be less likely to seek medical assistance when the problem is mild. Future research needs to examine ways in 
which to encourage older adults to seek medical assistance prior to the problem becoming severe in order to perhaps prevent health problems.

When married adults' problem-solving strategies for severe heart problems were examined, gender did not impact strategy ratings; however, results indicated that married adults chose the strategy "discuss with spouse" higher than any other strategy (i.e., discuss with doctor, discuss with relative, discuss with someone else, ignore the problem, deal with the problem alone). Spouses are a readily available source for collaboration. The finding is consistent with the finding that older married adults reported a preference to collaborate with their spouses as compared to other family members or friends when solving everyday problems (Strough, et al., 2002).

\section{Arthritis Problem Domain}

For arthritis problems, gender, marital status and severity of the problem influenced strategy ratings; however, there were no significant interactions between gender, marital status and severity of the problem as was found when examining heart problems (see Figures 8 and 9).

\section{Gender}

When the influence of gender on problem-solving strategy was examined for both married and unmarried adults, results indicated that women rated "discuss with relative" and "discuss with someone else" significantly higher than did men (see Figure 3). The finding that women rated the interpersonal strategies of "discuss with relative" and "discuss with someone else" higher than did men is similar to the results in the heart problem domain. Women tended to rate the interpersonal strategies that included others higher than did men when solving healthrelated problems regardless of the type of health problems or the severity of the problem. Men and women did not rate "discuss with doctor", "ignore the problem", or "deal with the problem 
alone" differently when both married and unmarried adults were considered. However, similar to the results for severe heart problems and in contrast to results for mild heart problems, when married adults only were considered, men rated "discuss with doctor" significantly higher than did females. Again, men may be more likely than women to discuss a health issue with a doctor because females may be less likely than men to become involved in the health decision-making process (Beaver, et al., 1996). Although men rated "discuss with doctor" higher than did women when dealing with arthritis problems, examination of the means indicated that women did not necessarily rate "discuss with doctor" low, just lower than did men (see Figures 8 and 9).

\section{Marital Status on Strategy Ratings}

When the influence of marital status on problem-solving strategy was examined, results indicated that married older adults rated "ignore the problem" significantly higher than unmarried older adults when dealing with both mild and severe arthritis problems (see Figure 4). Although married adults rated "ignore the problem" higher than unmarried adults, examination of the means indicated that both married and unmarried adults rated the interpersonal strategies higher than the alone strategies. Therefore, it is likely that older adults do involve others when dealing with arthritis problems.

Unmarried adults rated "discuss with doctor" significantly higher than "discuss with relative". Therefore, the hypothesis that unmarried adults would rate "discuss with relative" higher than other interpersonal strategies was not supported in the arthritis domain. However, the finding that unmarried adults rated "discuss with doctor" higher than "discuss with relative" when dealing with mild arthritis problems is important because it indicates that unmarried older adults may be likely to discuss their arthritis problems with a medical professional even when the problem is mild. 


\section{Severity of Problem}

When the influence of severity on problem-solving strategies was examined for both married and unmarried older adults, results indicated that older adults rated the interpersonal strategies of "discuss with doctor", "discuss with relative" and "discuss with someone else" higher when the arthritis problem was severe as compared to mild (see Figure 5). When married adults only were considered, results indicated that older adults rated "discuss with a doctor", and "discuss with spouse" higher when dealing with a severe arthritis problem than when dealing with a mild arthritis problem (see Table 4). Overall, perhaps older adults are more likely to seek assistance from others when the arthritis problem is severe as compared to mild.

The finding that older adults are more likely to seek assistance from others when the arthritis problem is severe as compared to a mild arthritis problem is consistent with research that shows that older adults may be more likely to seek assistance from others when dealing with severe problems than when dealing with mild problems. Strough, and colleagues (2003) found that grandparents are more likely to seek assistance from others when dealing with a problem of grandchild neglect then when dealing with a babysitting problem. The current study shows that the effect of severity on older adult collaboration is similar when dealing with health problems or social problems.

\section{The Role of Experience on Problem Solving Strategies}

It was hypothesized that older adults who have experienced health problems would rate interpersonal strategies (i.e., doctor, spouse, relative, other) higher than those without experience. Results indicated that a categorical measure of experience significantly influenced strategy ratings in the mild heart, severe heart and severe arthritis conditions. Experience did not influence ratings for mild arthritis problems. In the mild heart condition, adults without 
experience with mild heart problems rated the strategy "discuss with a doctor" higher than did those with experience. Older adults with experience with mild heart problems rated the selfstrategy of "deal with the problem alone" higher than did those without experience. In the severe heart condition, older adults without experience rated the interpersonal strategies (i.e., "discuss with doctor", "discuss with relative", and "discuss with someone else") higher than older adults with experience with severe heart problems. Older adults with experience rated the self-strategy of "deal with the problem alone" significantly higher than older adults without experience. In the severe arthritis condition, older adults with experience rated "discuss with a relative", and "discuss with someone else" significantly higher than older adults without experience. Older adults without experience rated "ignore the problem" higher than older adults with experience.

These findings are inconsistent with that of Strough, Patrick and Swenson (2002). Strough and colleagues found that experienced older adults as compared to those who were inexperienced were more likely to choose the strategy "seek assistance" when dealing with a severe problem (i.e., suspected grandchild neglect). In the current study, older adults with experience dealing with the severe problems were more likely to deal with the problem without involving another person. The inconsistency with Strough and colleagues may be due to the difference in the type of problems addressed. The idea of suspected child neglect involves harm to someone other than the older adult (i.e., the grandchild) therefore, when an older adult has experienced the negative effects of grandchild neglect, he or she may be likely to involve another person so that the child does not get harmed in any way. Dealing with a severe health problem does not necessarily involve harm to another person. Also, persons encountering the problem for the first time (i.e., no experience) may turn to others; however, those with experience may know 
the appropriate action to take when experiencing the problem; therefore, they are more likely to deal with the problem without involving others.

\section{Experience: Continuous Assessment versus Categorical Assessment}

The results of the effects of experience on problem-solving strategies in the current study differ depending on whether experience is assessed categorically or continuously. When experience was assessed as a continuous variable, it was significantly positively related to the strategy of "discuss with relative" in the severe heart condition. That is, the more experience that a person has with a severe heart problem, the more likely they were to involve another person in the problem solving process. The finding is consistent with Strough, Patrick and Swenson (2002). However, this finding is opposite of the results when experience is assessed as a categorical variable. When assessed as a categorical variable, older adults without experience are more likely to involve others.

Cornelius and Caspi (1989) and Berg, Meegan and Klaczynski (1999) assessed personal experience as a continuous variable and did not find an effect on problem-solving strategies. Strough, Patrick and Swenson (2002) assessed personal and vicarious experience as a categorical variable and experience was shown to have an effect on strategies. The present study examined personal experience as both a categorical and continuous variable; participants reported experience as a categorical variable (i.e., yes, no) and a continuous variable (i.e., how often). Interestingly, when experience was assessed as a continuous variable, results were consistent with Strough, Patrick and Swenson. This finding indicates that inconsistencies in the literature regarding the impact of experience on problem-solving strategies may not be due to the way in which experience is assessed. Perhaps the best way to assess experience is a continuous measure that ranges from never experienced to experience often. 
Perhaps inconsistencies in the literature are due to the way in which the construct of experience is viewed (i.e., personal versus personal and vicarious). Strough and colleagues (2002) examined personal and vicarious experience combined, whereas, Cornelius and Caspi, Berg, and colleagues, and the current study examined personal experience only. In summary, the current study illustrates the need to further examine the impact of experience on the health problem-solving strategies of older adults.

\section{Self-Rated Health and Perceived Control}

It was hypothesized that higher perceived health scores would be negatively correlated with ratings of interpersonal strategies and positively correlated with ratings of self- strategies. Results indicated that the hypothesis for self-rated health was not supported in any condition. In the mild heart condition, self-rated health was significantly positively correlated with the strategy of "discuss with relative". That is, positive perceived health was associated with an increased likelihood of discussing the problem with a relative. In the severe arthritis condition, self-rated health was significantly negatively correlated with the strategy of "deal with the problem alone". That is, positive perceived health was associated with a decreased likelihood of dealing with the problem alone. These findings are inconsistent with Strough and colleagues (2002). Strough and colleagues examined various problem domains and found that older adults who rated their health as more positive preferred to work alone whereas those who rated their health as less positive preferred to solve problems with others. Strough and colleagues did not examine the effect of self-rated in the specific domain of health. Health is a very important domain for older adults. Perhaps when dealing with a heart-related problem older adults feel that they should discuss the issue with others even if they perceive themselves to be healthy. 
It was hypothesized that higher perceived control over health would be negatively correlated with ratings on interpersonal strategies and positively correlated with ratings on selfstrategies. Results indicated that the hypothesis for perceived control was partially supported in the mild heart condition and the severe arthritis condition. In the mild heart and severe heart conditions, greater perceived control was associated with a decreased rating of discussing the problem with a relative. This suggests that persons who feel in control of their health may not feel the need to include others when dealing with health-related problems and may not be as likely to seek assistance from friends and family.

\section{Order Effects}

Order of the vignettes impacted ratings for the strategies of "discuss with a relative", "discuss with someone else" and "ignore the problem". Adults rated "discuss with relative" significantly higher in version 4 (arthritis mild, arthritis severe, heart mild and heart severe) than in both version 2 (heart severe, arthritis mild, arthritis severe, heart mild) and version 3 (heart mild, heart severe, arthritis mild, arthritis severe. Adults rated "discuss with someone else" significantly higher in version 4 (arthritis mild, arthritis severe, heart mild and heart severe) than in version 3 (heart mild, heart severe, arthritis mild, arthritis severe). Adults rated "ignore the problem" significantly higher in version 2 (heart severe, arthritis mild, arthritis severe, heart mild) than in both version 1 (arthritis severe, heart mild, heart severe, and arthritis mild) and version 4 (arthritis mild, arthritis severe, heart mild and heart severe). This indicates that earlier vignettes influenced the strategy ratings of vignettes presented later. Overall, these results suggest that adults rated discussing the situation with others higher when the severe heart vignette was later in the sequence and rated to ignore the problem higher when the severe heart vignette was earlier. Perhaps experiencing mild or non-life-threatening events serves to activate 
social support. However, when a severe life-threatening event (i.e., severe heart problem) is experienced first, the mild and non-life-threatening may not seem as urgent; therefore, persons choose to ignore the problem instead of discussing it with others. Version did not significantly affect the strategies of "discuss with doctor" or "deal with the problem alone". The vignettes in the current study were counterbalanced; therefore, order effects should not impact the interpretations of the results.

\section{Limitations and Future Directions}

One limitation of the current study is the self-report nature of predicted behavior in response to a hypothetical vignette. Participants were asked to report on how they would react if they were faced with a similar situation. Although hypothetical vignettes have been shown to be a useful way to examine problem-solving strategies (Berg, 1989; Blanchard-Fields, et al., 1995; Watson \& Blanchard-Fields, 1998), one cannot be certain how they will react unless faced with actual problem. It is possible that older adults may react differently if they were actually faced with a similar situation. In an actual situation, one could examine the methods that the older adult chose to deal with the specific problem. For example, one could use retrospective self-report to determine whether a heart patient included a spouse or friends when dealing with their own heart-related problem. Another strategy would be to conduct a longitudinal study that examines the strategies that heart patients use each time they deal with a heart-related problem.

Another limitation of the current study is the use of forced rating, close-ended strategies. Perhaps older adults would generate different problem-solving strategies than the ones provided. In the future, open-ended strategy generation should be used and perhaps compared to the current results. Also, the current study was limited to only heart and arthritis problems. 
Although heart and arthritis problems are the two most prevalent health problems in older adulthood, other common health problems, such as cancer, need to be examined. For example, one may expect the findings from a study that examines the strategies used to solve cancerrelated problems more similar to the findings for the heart domain in the current study because cancer is a potentially life-threatening disease.

The sample was also limited in that it was almost entirely Caucasian. Perhaps older adults of different races and ethnic backgrounds would respond differently to the vignettes. In the future, a more racially/ethnically diverse population should be examined; however, one must be considerate of cultural differences that could influence the responses to the current measures. For example, in other cultures it may not be socially appropriate to discuss health issues with friends; therefore, the strategy of "discuss with someone else" may not be relevant. Recent literature, such as Stewart and Napoles-Springer (2003), emphasizes the need for researchers to examine the functional equivalence of measures when assessing health disparities in a population that is different from that with which the measure was devised. Methods such as cognitive interviewing (Willis, 1994; Sarkisian, Hayes, Berry \& Mangione, 2002) and multitrait scaling (Sarkisian, et al.) could be used to examine the equivalence of measures across racial/ethnic groups.

\section{Conclusions}

Findings from the current study contribute to the knowledge about the strategies that older adults use when solving health-related problems. Findings show that there are differences in the ways in which older adults solve health-related problems that depend on many factors, such as domain of the problem, severity of the problem, and gender, and marital status of the older adult. Professionals in the health care field can draw from these results when designing 
Factors Influencing 55

programs to encourage older adults to seek professional medical assistance. The results indicate that different strategies may be needed to encourage older adults to seek medical help for different types of health problems. 


\section{REFERENCES}

Akiyama, H., Elliot, K., \& Antonucci, T. C. (1996). Same-sex and cross-sex relationships. Journal of Gerontology: Psychological Sciences, 51B(6), 374-382.

American Heart Association. (2002). Heart and Stroke Statistical Update.

Azmitia, M., \& Montgomery, R. (1993). Friendship, transactive dialogues, and the development of scientific reasoning. Social Development, 2, 202-221.

Backman, L., \& Dixon, R. A. (1992). Psychological compensation: a theoretical framework. Psychological Bulletin, 112(2), 259-283.

Baltes, P. B., \& Baltes, M. M. (1990). Psychological perspectives on successful aging: The model of selective optimization with compensation. In P. B. Baltes \& M.M. Baltes (Eds.), Successful aging: Perspectives from the behavioral sciences (pp. 1-34). New York: Cambridge University Press.

Baltes, P. B., \& Staudinger, U. M. (Eds.) (1996). Interactive minds: Life-span perspectives on the social foundations of cognition. New York: Cambridge University Press.

Beaver, K., Luker, K., Owens, R., Leinster, S., Degner, F., \& Sloan, J. (1996). Treatment decision making in women newly diagnosed with breast cancer. Cancer Nursing, 19(1), 8-19.

Berg, C. A. (1989). Knowledge of strategies for dealing with everyday problems from childhood through adolescence. Developmental Psychology, 25(4), 607-618.

Berg, C. A., Meegan, S.P., \& Klaczynski, P. (1999). Age and experiential differences in strategy generation and information requests for solving everyday problems. International Journal of Behavioral Development, 23, 615-639. 
Blanchard-Fields, F., Jahnke, H. C., \& Camp. C. (1995). Age differences in problemsolving style: The role of emotional salience. Psychology and Aging, 10, 173180.

Carstensen, L. L. (1991). Socioemotional selectivity theory: Social activity in life-span context. Annual Review of Gerontology and Geriatrics, 11, 195-217.

Carstensen, L. L. (1992). Social and emotional patterns in adulthood: Support for socioemotional selectivity. Psychology and Aging, 7, 331-338.

Center of Disease Control. (2002). Arthritis by the numbers. National Center for Health Statistics.

Cheng, S. (2002). A comparison of collaborative and individualistic problem solving in younger and older adults on an everyday task. Unpublished doctoral dissertation. West Virginia University, Morgantown, West Virginia.

Cornelius, S. W., \& Caspi, A. (1987). Everyday problem solving in adulthood and old age. Psychology and Aging, 2(2), 144-153.

Denney, N. W., \& Pearce, K. A. (1989). A developmental study of practical problem solving in adults. Psychology and Aging, 4, 438-442.

Dixon, R. A. (1992). Contextual approaches to adult intellectual development. In R. J. Sternberg \& C. A. Berg (Eds.), Intellectual development (pp 350-380). New York: Cambridge.

Dixon, R. A. (1996). Collaborative memory and aging. In D. J. Herrmann, C. McEnvoy, C. Hertzog, P. Hertel, \& M. K. Johnson (Eds.) Basic and applied memory research theory in context (pp. 359-383). Mahwah, NJ: Lawrence Erlbaum Associates. 
Goodnow, J. J., Lawrence, J. A., Ryan, J., Karantzas, G., \& King, K. (2002). Extending studies of collaborative cognition by way of caregiving situations. International Journal of Behavioral Development, 26(1), 16-25.

Gould, O. N., Kurzman, D., \& Dixen, R. A. (1994). Communication during prose recall conversations by young and old dyads. Discourse Processes, 17, 149-165.

Gould, O. N., Trevithick, L., \& Dixon, R. A. (1991). Adult age differences in elaborations produced during prose recall. Psychology and Aging, 6, 93-99.

Lawton, M. P., Moss, M. S., Fulcomer, M., \& Kleban, M. H. (1982). A research and service oriented multilevel assessment instrument. Journal of Gerontology, 37, 91-99.

Margrett, J. A., \& Marsiske, M. (2001). Gender differences in older adults’ everyday cognitive collaboration. International Journal of Behavioral Development, $26(1), 45-59$

Marsiske, M., Lang, F.R., Baltes, P. B., \& Baltes, M. M. (1995). Selective optimization with compensation: Life-span perspectives on successful human development. In L. Backman \& R. A. Dixon (Eds.). Compensating for psychological deficits and declines: maintaining losses and promoting gains (pp. 35-79), New Jersey: Lawrence Erlbaum Associates, Inc.

Meegan, S. P., \& Berg, C. A. (2002). Contexts, functions, forms, and processes of collaborative everyday problem solving in older adulthood. International Journal of Behavioral Development, 26(1), 6-15. 
Moen, P. (1996). Gender, age, and the life course. In R. H. Binstock and L. K. George (Eds.), Handbook of Aging and the Social Sciences, $4^{\text {th }}$ edition (pp. 171-187), New York: Academic Press.

National Center for Chronic Disease Prevention and Health Promotion, (1999). Chronic Disease Notes and Reports, 12(3).

National Center for Health Statistics. (1982). Long-Term Care Survey. Interview Schedule. 1982. NCHS Form LTC-3. Rockville, MD: Author.

Park, D. C. (1999). Aging and the controlled and automatic processing of medical information and medical intentions. In D. C. Park, R. W. Morrell, \& K. Shifren (Eds.), Processing of Medical Information in Aging Patients (pp. 3-23). New Jersey: Lawrence Erlbaum Associates, Inc.

Patrick, J. H., \& Strough, J. (2004). Everyday problem solving: experience, strategies, and behavioral intentions. Journal of Adult Development, 11(1), 9-19.

Pierce, P. F. (1996). When the patients chooses: Describing unaided decisions in health care. Human Factors, 38, 278-287.

Resnick, L. B., Levine, J. M., \& Teasdale, S.D. (Eds.) (1991). Perspectives on socially shared cognition. Washington, D.C.: American Psychological Association.

Sarkisian, C. A., Hays, R. D., Berry, S., \& Mangione, C. M. (2002). Development, reliability, and validity of the expectations regarding aging (ERA-38) survey. Gerontologist, 42(4), 534-542.

Sansone, C., \& Berg, C. A. (1993). Adapting to the environment across the life span: Different processes or different inputs? International Journal of Behavior Development, 16(2), 215-241. 
Sinnott, J. D. (1989). A model for solution of ill-structured problems: Implications for everyday and abstract problem solving. In J. D. Sinnott (Ed.), Everyday problem solving (pp. 7299). New York: Praeger.

Stewart, A. L., \& Napoles-Springer, A. M. (2003). Advancing health disparities research: Can we afford to ignore measurement issues? Medical Care, 41(11), 1207-1220.

Strough, J., Berg, C. A., \& Sansone, C. (1996). Goals for solving everyday problems across the life span: Age and gender differences in salience of interpersonal concerns. Developmental Psychology,_32 (6), 1106-1115.

Strough, J., \& Margrett, J. (2002). Overview of special section on collaborative cognition in later adulthood. International Journal of Behavioral Development, 26(1), 1-5.

Strough, J., Patrick, J. H., Swenson, L., Cheng, S., \& Barnes, K. A. (2003). Collaborative everyday problem solving: Interpersonal relationships and problem dimensions. The International Journal of Aging and Human Development, 56(1), 43-66.

Strough, J., Cheng, S., \& Swenson, L. (2002). Preferences for Collaborative and Individual everyday problem solving in later adulthood. International Journal of Behavioral Development, 26(1), 26-35.

Strough, J., Patrick, H. H., \& Swenson, L. M. (2003). In B. Hayslip \& J. H. Patrick (Eds.), Working with custodial grandparents. New York: Springer.

Swenson, L. M. (2000). Influences of friendship,friendship quality, and gender on collaborative processes and performance. Unpublished master's thesis. West Virginia University, Morgantown, West Virginia

Tabachnick, B. G., \& Fidell, L. S. (2001). Using multivariate statistics ( $4^{\text {th }}$ edition). Needham Heights, MA: Allyn \& Bacon. 
Thorslund, M. \& Norstrom, T. (1993). The relationship between different survey measures of health in an elderly population. The Journal of Applied Gerontology, 12(1), 61-70.

Turk-Charles, S., Meyerowitz, B. E., \& Gatz, M. (1997). Ages differences in information- seeking among cancer patients. International Journal of Human Development 2 45(2), 85-98.

Watson, T. L., \& Blanchard-Fields, F. (1998). Thinking with your head and your heart: Age differences in everyday problem-solving strategy preferences. Aging, Neuropsychology and Cognition, 5(3), 225-240.

Willis, G. B. (1994). Cognitive interviewing and questionnaire design: A training manual. Centers for Disease Control and Prevention. 
Table 1

Problem-Solving Strategies for Heart Problems: Means and (Standard Errors)

Mild

Males

Females

Total

\begin{tabular}{|c|c|c|c|c|c|c|c|c|c|}
\hline & Married & Unmarried & Total & Married & Unmarried & Total & Married & Unmarried & Total \\
\hline \multirow[t]{2}{*}{ Discuss with Doctor } & 4.66 & $4.52_{c}$ & 4.58 & 4.49 & 4.38 & $4.43 *$ & 4.57 & 4.45 & 4.51 \\
\hline & $(.14)$ & $(.14)$ & $(.10)$ & $(.14)$ & $(.14)$ & $(.10)$ & $(.10)$ & $(.10)$ & $(.07)$ \\
\hline \multirow[t]{2}{*}{ Discuss with Relative } & 2.91 & $2.50_{\mathrm{c}}$ & 2.71 & 3.29 & 3.75 & $3.52 *$ & 3.10 & 3.13 & 3.11 \\
\hline & $(.27)$ & $(.27)$ & $(.19)$ & $(.27)$ & $(.27)$ & $(.19)$ & $(.19)$ & $(.19)$ & $(.13)$ \\
\hline \multirow{2}{*}{$\begin{array}{l}\text { Discuss with Someone } \\
\text { Else }\end{array}$} & $1.81^{\mathrm{a}}$ & $2.99^{\mathrm{a}}$ & 2.40 & 2.90 & 3.24 & 3.07 & 2.35 & 3.12 & 2.73 \\
\hline & $(.23)$ & $(.23)$ & $(.16)$ & $(.23)$ & $(.23)$ & $(.16)$ & $(.16)$ & $(.16)$ & $(.12)$ \\
\hline \multirow[t]{2}{*}{ Ignore the Problem } & 1.24 & 2.40 & 1.82 & 1.84 & 2.14 & $1.99 *$ & 1.54 & 2.27 & 1.91 \\
\hline & $(.66)$ & $(.66)$ & $(.47)$ & $(.66)$ & $(.66)$ & $(.47)$ & $(.47)$ & $(.47)$ & $(.33)$ \\
\hline \multirow[t]{2}{*}{ Deal with Problem Alone } & $2.41^{b}$ & $1.37^{\mathrm{b}}$ & 1.89 & 1.87 & 2.28 & 2.08 & 2.14 & 1.83 & 1.98 \\
\hline & $(.23)$ & $(.23)$ & $(.16)$ & $(.23)$ & $(.23)$ & $(.16)$ & $(.16)$ & $(.16)$ & $(.11)$ \\
\hline \multirow[t]{2}{*}{ Total } & 2.61 & 2.76 & 2.69 & 2.88 & 3.16 & 3.02 & 2.74 & 2.96 & 2.85 \\
\hline & $(.15)$ & $(.11)$ & $(.08)$ & $(.15)$ & $(.15)$ & $(.11)$ & $(.11)$ & $(.11)$ & $(.08)$ \\
\hline
\end{tabular}


Table 1 cont.

Severe

Males

Females

Total

\begin{tabular}{|c|c|c|c|c|c|c|c|c|c|}
\hline & Married & Unmarried & Total & Married & Unmarried & Total & Married & Unmarried & Total \\
\hline \multirow[t]{2}{*}{ Discuss with Doctor } & 5.00 & 4.87 & $4.94^{\mathrm{d}}$ & 4.60 & 4.60 & $4.60^{\mathrm{d}}$ & 4.80 & 4.73 & 4.77 \\
\hline & $(.10)$ & $(.10)$ & $(.07)$ & $(.10)$ & $(.10)$ & $(.07)$ & $(.07)$ & $(.07)$ & $(.05)$ \\
\hline \multirow[t]{2}{*}{ Discuss with Relative } & 3.09 & 2.44 & $2.77^{\mathrm{e}}$ & 3.39 & 3.70 & $3.54^{\mathrm{e}}$ & 3.24 & 3.07 & 3.16 \\
\hline & $(.28)$ & $(.28)$ & $(.20)$ & $(.28)$ & $(.28)$ & $(.20)$ & $(.20)$ & $(.20)$ & $(.14)$ \\
\hline \multirow{2}{*}{$\begin{array}{l}\text { Discuss with Someone } \\
\text { Else }\end{array}$} & 2.46 & 2.74 & 2.60 & 2.80 & 3.01 & 2.91 & 2.63 & 2.88 & 2.75 \\
\hline & $(.26)$ & $(.26)$ & $(.18)$ & $(.26)$ & $(.26)$ & $(.18)$ & $(.18)$ & $(.18)$ & $(.13)$ \\
\hline \multirow[t]{2}{*}{ Ignore the Problem } & 1.76 & 1.14 & 1.45 & 1.38 & 1.40 & 1.39 & 1.57 & 1.27 & 1.42 \\
\hline & $(.35)$ & $(.35)$ & $(.24)$ & $(.35)$ & $(.35)$ & $(.24)$ & $(.24)$ & $(.24)$ & $(.17)$ \\
\hline \multirow[t]{2}{*}{ Deal with Problem Alone } & 1.45 & 1.96 & 1.71 & 1.35 & 1.94 & 1.65 & 1.41 & 1.95 & 1.68 \\
\hline & $(.22)$ & $(.22)$ & $(.15)$ & $(.22)$ & $(.22)$ & $(.15)$ & $(.15)$ & $(.15)$ & $(.11)$ \\
\hline \multirow[t]{2}{*}{ Total } & 2.76 & 2.63 & 2.69 & 2.71 & 2.93 & 1.65 & 2.73 & 2.78 & 2.76 \\
\hline & $(.11)$ & $(.11)$ & $(.08)$ & $(.11)$ & $(.11)$ & $(.12)$ & $(.08)$ & $(.08)$ & $(.06)$ \\
\hline
\end{tabular}

table continues 
Table 1 cont.

Total

Males Females Total

\begin{tabular}{lccccccccccc}
\hline & Married & Unmarried & Total & Married & Unmarried & Total & Married & Unmarried & Total \\
\hline Discuss with Doctor & 4.83 & 4.69 & 4.76 & 4.54 & 4.49 & 4.52 & 4.69 & 4.59 & 4.64 \\
& $(.09)$ & $(.09)$ & $(.06)$ & $(.09)$ & $(.09)$ & $(.06)$ & $(.06)$ & $(.06)$ & $(.05)$ \\
& 3.00 & 2.47 & 2.74 & 3.34 & 3.73 & 3.53 & 3.17 & 3.10 & 3.13 \\
Discuss with Relative & $(.25)$ & $(.25)$ & $(.18)$ & $(.25)$ & $(.25)$ & $(.18)$ & $(.18)$ & $(.18)$ & $(.13)$ \\
& 2.14 & 2.87 & 2.50 & 2.85 & 3.12 & 2.99 & 2.49 & 3.00 & 2.74 \\
Discuss with Someone & $(.22)$ & $(.22)$ & $(.16)$ & $(.22)$ & $(.22)$ & $(.16)$ & $(.16)$ & $(.16)$ & $(.11)$ \\
Else & 1.50 & 1.77 & 1.64 & 1.61 & 1.77 & 1.69 & 1.56 & 1.77 & 1.66 \\
Ignore the Problem & $(.38)$ & $(.38)$ & $(.27)$ & $(.38)$ & $(.38)$ & $(.27)$ & $(.27)$ & $(.27)$ & $(.19)$ \\
& 1.93 & 1.67 & 1.80 & 1.61 & 2.11 & 1.86 & 1.77 & 1.89 & 1.83 \\
& $(.18)$ & $(.18)$ & $(.13)$ & $(.18)$ & $(.18)$ & $(.13)$ & $(.13)$ & $(.13)$ & $(.09)$
\end{tabular}

Note. Matching letters within a row represent significant group differences, $p<.05$. Matching letters within a column represent significant group differences, $p<.05$. Asterisks $(*)$ represent significant difference from the grand mean, $\mathrm{p}<.05$. 
Table 2

Problem-Solving Strategies for Arthritis Problems: Means and (Standard Errors)

\section{Mild}

Males

Females

Total

\begin{tabular}{|c|c|c|c|c|c|c|c|c|c|}
\hline & Married & Unmarried & Total & Married & Unmarried & Total & Married & Unmarried & Total \\
\hline \multirow[t]{2}{*}{ Discuss with Doctor } & 4.24 & 3.19 & 3.71 & 3.62 & 3.67 & 3.65 & 3.93 & 3.44 & $3.68_{a}$ \\
\hline & $(.22)$ & $(.22)$ & $(.16)$ & $(.22)$ & $(.22)$ & $(.16)$ & $(.16)$ & $(.16)$ & $(.11)$ \\
\hline \multirow[t]{2}{*}{ Discuss with Relative } & 3.00 & 2.60 & 2.80 & 3.03 & 3.31 & 3.17 & 3.01 & 2.95 & $2.98_{b}$ \\
\hline & $(.23)$ & $(.23)$ & $(.16)$ & $(.23)$ & $(.23)$ & $(.16)$ & $(.16)$ & $(.16)$ & $(.11)$ \\
\hline \multirow{2}{*}{$\begin{array}{l}\text { Discuss with Someone } \\
\text { Else }\end{array}$} & 2.03 & 2.46 & 2.25 & 2.65 & 3.66 & 3.15 & 2.34 & 3.10 & $2.70_{\mathrm{c}}$ \\
\hline & $(.21)$ & $(.21)$ & $(.15)$ & $(.21)$ & $(.21)$ & $(.15)$ & $(.15)$ & $(.15)$ & $(.11)$ \\
\hline \multirow[t]{2}{*}{ Ignore the Problem } & 2.33 & 2.06 & 2.19 & 2.33 & 1.86 & 2.09 & 2.33 & 1.96 & 2.14 \\
\hline & $(.20)$ & $(.20)$ & $(.14)$ & $(.20)$ & $(.20)$ & $(.14)$ & $(.14)$ & $(.14)$ & $(.10)$ \\
\hline \multirow[t]{2}{*}{ Deal with Problem Alone } & 2.44 & 2.35 & 2.40 & 2.48 & 2.07 & 2.28 & 2.46 & 2.21 & 2.34 \\
\hline & $(.25)$ & $(.25)$ & $(.18)$ & $(.25)$ & $(.25)$ & $(.18)$ & $(.18)$ & $(.18)$ & $(.12)$ \\
\hline \multirow[t]{2}{*}{ Total } & 2.81 & 2.53 & 2.67 & 2.82 & 2.92 & 2.87 & 2.81 & 2.73 & 2.77 \\
\hline & $(.09)$ & $(.09)$ & $(.06)$ & $(.09)$ & $(.09)$ & $(.06)$ & $(.06)$ & $(.06)$ & $(.04)$ \\
\hline
\end{tabular}


Table 2 cont.

Severe

$\begin{array}{lll}\text { Males } & \text { Females } & \text { Total }\end{array}$

\begin{tabular}{|c|c|c|c|c|c|c|c|c|c|}
\hline & Married & Unmarried & Total & Married & Unmarried & Total & Married & Unmarried & Total \\
\hline \multirow[t]{2}{*}{ Discuss with Doctor } & 4.78 & 4.17 & 4.48 & 4.36 & 4.54 & 4.45 & 4.57 & 4.36 & $4.46_{a}$ \\
\hline & $(.13)$ & $(.13)$ & $(.10)$ & $(.13)$ & $(.10)$ & $(.09)$ & $(.09)$ & $(.09)$ & $(.06)$ \\
\hline \multirow[t]{2}{*}{ Discuss with Relative } & 2.91 & 2.98 & 2.94 & 3.32 & 3.73 & 3.53 & 3.11 & 3.36 & $3.23_{b}$ \\
\hline & $(.24)$ & $(.24)$ & $(.17)$ & $(.24)$ & $(.24)$ & $(.17)$ & $(.17)$ & $(.17)$ & $(.12)$ \\
\hline \multirow{2}{*}{$\begin{array}{l}\text { Discuss with Someone } \\
\text { Else }\end{array}$} & 2.19 & 2.72 & 2.45 & 3.28 & 3.65 & 3.47 & 2.73 & 3.19 & $2.96_{c}$ \\
\hline & $(.21)$ & $(.21)$ & $(.15)$ & $(.21)$ & $(.21)$ & $(.15)$ & $(.15)$ & $(.15)$ & $(.10)$ \\
\hline \multirow[t]{2}{*}{ Ignore the Problem } & 2.50 & 1.72 & 2.11 & 1.74 & 1.64 & 1.69 & 2.12 & 1.68 & 1.90 \\
\hline & $(.21)$ & $(.21)$ & $(.15)$ & $(.21)$ & $(.21)$ & $(.15)$ & $(.15)$ & $(.15)$ & $(.10)$ \\
\hline \multirow[t]{2}{*}{ Deal with Problem Alone } & 1.91 & 2.10 & 2.00 & 2.20 & 2.29 & 2.24 & 2.10 & 2.20 & 2.12 \\
\hline & $(.24)$ & $(.24)$ & $(.17)$ & $(.27)$ & $(.27)$ & $(.17)$ & $(.17)$ & $(.17)$ & $(.12)$ \\
\hline \multirow[t]{2}{*}{ Total } & 2.86 & 2.74 & 2.80 & 2.98 & 3.17 & 3.08 & 2.92 & 2.95 & 2.94 \\
\hline & $(.08)$ & $(.08)$ & $(.06)$ & $(.08)$ & $(.08)$ & $(.06)$ & $(.06)$ & $(.06)$ & $(.04)$ \\
\hline
\end{tabular}


Table 2 cont.

Total

Males $\quad$ Females Total

\begin{tabular}{|c|c|c|c|c|c|c|c|c|c|}
\hline & Married & Unmarried & Total & Married & Unmarried & Total & Married & Unmarried & Total \\
\hline \multirow[t]{2}{*}{ Discuss with Doctor } & 4.51 & 3.68 & 4.10 & 3.99 & 4.12 & 4.05 & 4.25 & $3.90_{\mathrm{g}}$ & 4.07 \\
\hline & $(.15)$ & $(.15)$ & $(.11)$ & $(.15)$ & $(.15)$ & $(.11)$ & $(.11)$ & $(.11)$ & $(.07)$ \\
\hline \multirow[t]{2}{*}{ Discuss with Relative } & 2.95 & 2.79 & $2.87^{\mathrm{d}}$ & 3.18 & 3.52 & $3.35^{\mathrm{d}}$ & 3.06 & $3.15_{\mathrm{g}}$ & 3.11 \\
\hline & $(.20)$ & $(.20)$ & $(.14)$ & $(.20)$ & $(.20)$ & $(.14)$ & $(.14)$ & $(.14)$ & $(.10)$ \\
\hline \multirow{2}{*}{$\begin{array}{l}\text { Discuss with Someone } \\
\text { Else }\end{array}$} & 2.11 & 2.59 & $2.35^{\mathrm{e}}$ & 2.96 & 3.66 & $3.31^{\mathrm{e}}$ & 2.53 & 3.12 & 2.83 \\
\hline & $(.12)$ & $(.12)$ & $(.12)$ & $(.17)$ & $(.17)$ & $(.12)$ & $(.12)$ & $(.12)$ & $(.08)$ \\
\hline \multirow[t]{2}{*}{ Ignore the Problem } & 2.41 & 1.89 & 2.15 & 2.04 & 1.75 & 1.89 & $2.23^{\mathrm{f}}$ & $1.82^{\mathrm{f}}$ & 2.02 \\
\hline & $(.14)$ & $(.14)$ & $(.01)$ & $(.14)$ & $(.14)$ & $(.01)$ & $(.01)$ & $(.01)$ & $(.07)$ \\
\hline \multirow[t]{2}{*}{ Deal with Problem Alone } & 1.17 & 2.23 & 2.20 & 2.34 & 2.18 & 2.26 & 2.26 & 2.20 & 2.23 \\
\hline & $(.21)$ & $(.21)$ & $(.15)$ & $(.21)$ & $(.21)$ & $(.15)$ & $(.15)$ & $(.15)$ & $(.11)$ \\
\hline \multirow[t]{2}{*}{ Grand Total } & 2.83 & 2.63 & 2.73 & 2.90 & 3.05 & 2.97 & 2.87 & 2.84 & 2.85 \\
\hline & $(.07)$ & $(.07)$ & $(.05)$ & $(.07)$ & $(.07)$ & $(.05)$ & $(.05)$ & $(.05)$ & $(.04)$ \\
\hline
\end{tabular}

Note. Matching letters within a row represent significant group differences, $p<.05$. Matching letters within a column represent significant group differences, $p<.05$ (note: table continues across 3 pages). 
Table 3

Problem-Solving Strategies of Married Adults on Heart Problems: Means and (Standard Errors)

Mild

\begin{tabular}{lccc} 
Strategy & Males & Females & Total \\
\hline Discuss with Doctor & 4.66 & 4.49 & 4.57 \\
Discuss with Spouse & $(.16)$ & $(.16)$ & $(.11)$ \\
& 4.83 & 4.63 & 4.73 \\
Discuss with Relative & $(.11)$ & $(.11)$ & $(.08)$ \\
& 2.90 & 3.28 & 3.10 \\
Discuss with Someone Else & $(.27)$ & $(.27)$ & $(.20)$ \\
& $1.81^{\mathrm{a}}$ & $2.89^{\mathrm{a}}$ & 2.35 \\
Ignore the Problem & $(.23)$ & $(.23)$ & $(.16)$ \\
& $1.24^{\mathrm{b}}$ & $1.84^{\mathrm{b}}$ & 1.54 \\
Deal with Problem Alone & $(.16)$ & $(.16)$ & $(.11)$ \\
& 2.41 & 1.87 & 2.14 \\
\hline Total & $(.25)$ & $(.25)$ & $(.18)$ \\
& 2.98 & 3.17 & 3.07 \\
& $(.07)$ & $(.07)$ & $(.05)$
\end{tabular}


Table 3 cont.

Severe

\begin{tabular}{|c|c|c|c|}
\hline Strategy & Males & Females & Total \\
\hline \multirow[t]{2}{*}{ Discuss with Doctor } & 5.00 & 4.60 & $4.80 *$ \\
\hline & $(.09)$ & $(.09)$ & $(.06)$ \\
\hline \multirow[t]{2}{*}{ Discuss with Spouse } & 4.87 & 4.83 & $4.85^{*}$ \\
\hline & $(.05)$ & $(.05)$ & $(.03)$ \\
\hline \multirow[t]{2}{*}{ Discuss with Relative } & 3.09 & 3.38 & 3.24 \\
\hline & $(.27)$ & $(.27)$ & $(.19)$ \\
\hline \multirow[t]{2}{*}{ Discuss with Someone Else } & 2.46 & 2.80 & 2.63 \\
\hline & $(.24)$ & $(.24)$ & $(.17)$ \\
\hline \multirow[t]{2}{*}{ Ignore the Problem } & 1.76 & 1.38 & $1.57 *$ \\
\hline & $(.48)$ & $(.48)$ & $(.34)$ \\
\hline \multirow[t]{2}{*}{ Deal with Problem Alone } & 1.46 & 1.35 & $1.41 *$ \\
\hline & $(.16)$ & $(.16)$ & $(.11)$ \\
\hline \multirow[t]{2}{*}{ Total } & 3.11 & 3.06 & 3.08 \\
\hline & $(.10)$ & $(.10)$ & $(.07)$ \\
\hline
\end{tabular}

table continues 
Table 3 cont.

Total

\begin{tabular}{|c|c|c|c|}
\hline Strategy & Males & Females & Total \\
\hline \multirow[t]{2}{*}{ Discuss with Doctor } & 4.83 & 4.54 & 4.69 \\
\hline & $(.09)$ & $(.09)$ & $(.07)$ \\
\hline \multirow[t]{2}{*}{ Discuss with Spouse } & 4.85 & 4.73 & 4.79 \\
\hline & $(.06)$ & $(.06)$ & $(.05)$ \\
\hline \multirow[t]{2}{*}{ Discuss with Relative } & 3.00 & 3.34 & 3.17 \\
\hline & $(.25)$ & $(.25)$ & $(.18)$ \\
\hline \multirow[t]{2}{*}{ Discuss with Someone Else } & 2.14 & 2.85 & 2.49 \\
\hline & $(.21)$ & $(.21)$ & $(.15)$ \\
\hline \multirow[t]{2}{*}{ Ignore the Problem } & 1.50 & 1.61 & 1.55 \\
\hline & $(.26)$ & $(.26)$ & $(.18)$ \\
\hline \multirow[t]{2}{*}{ Deal with Problem Alone } & 1.93 & 1.61 & 1.77 \\
\hline & $(.17)$ & $(.17)$ & $(.12)$ \\
\hline \multirow[t]{2}{*}{ Grand Total } & 3.04 & 3.11 & 3.08 \\
\hline & $(.07)$ & $(.07)$ & $(.05)$ \\
\hline
\end{tabular}

Note. Matching letters within a row represent significant group differences, $p<.05$. Matching letters within a column represent significant group differences, $p<.05$. Asterisks $(*)$ represent a significant difference from the grand mean. 
Table 4

Problem-Solving Strategies for Married Adults on Arthritis Problems: Means and (Standard Errors)

Mild

\begin{tabular}{|c|c|c|c|}
\hline Strategy & Males & Females & Total \\
\hline \multirow[t]{2}{*}{ Discuss with Doctor } & 4.24 & 3.62 & $3.93_{\mathrm{a}}$ \\
\hline & $(.20)$ & $(.20)$ & $(.14)$ \\
\hline \multirow[t]{2}{*}{ Discuss with Spouse } & 4.42 & 4.23 & $4.32_{b}$ \\
\hline & $(.15)$ & $(.15)$ & $(.10)$ \\
\hline \multirow[t]{2}{*}{ Discuss with Relative } & 3.00 & 3.03 & 3.01 \\
\hline & $(.24)$ & $(.24)$ & $(.17)$ \\
\hline \multirow[t]{2}{*}{ Discuss with Someone Else } & 2.03 & 2.66 & 2.34 \\
\hline & $(.21)$ & $(.21)$ & $(.15)$ \\
\hline \multirow[t]{2}{*}{ Ignore the Problem } & 2.33 & 2.33 & 2.33 \\
\hline & $(.20)$ & $(.20)$ & $(.14)$ \\
\hline \multirow[t]{2}{*}{ Deal with Problem Alone } & 2.44 & 2.48 & 2.46 \\
\hline & $(.26)$ & $(.26)$ & $(.18)$ \\
\hline \multirow[t]{2}{*}{ Total } & 3.08 & 3.06 & 3.07 \\
\hline & $(.08)$ & $(.08)$ & $(.06)$ \\
\hline
\end{tabular}


Table 4 cont.

Severe

\begin{tabular}{|c|c|c|c|}
\hline Strategy & Males & Females & Total \\
\hline \multirow[t]{2}{*}{ Discuss with Doctor } & 4.78 & 4.36 & $4.57 \mathrm{a}$ \\
\hline & $(.13)$ & $(.13)$ & $(.09)$ \\
\hline \multirow[t]{2}{*}{ Discuss with Spouse } & 4.81 & 4.54 & $4.68_{b}$ \\
\hline & $(.11)$ & $(.11)$ & $(.08)$ \\
\hline \multirow[t]{2}{*}{ Discuss with Relative } & 2.91 & 3.32 & 3.11 \\
\hline & $(.25)$ & $(.25)$ & $(.18)$ \\
\hline \multirow[t]{2}{*}{ Discuss with Someone Else } & 2.19 & 3.28 & 2.73 \\
\hline & $(.19)$ & $(.19)$ & $(.13)$ \\
\hline \multirow[t]{2}{*}{ Ignore the Problem } & 2.50 & 1.74 & 1.12 \\
\hline & $(.25)$ & $(.25)$ & $(.18)$ \\
\hline \multirow[t]{2}{*}{ Deal with Problem Alone } & 1.91 & 2.20 & 2.05 \\
\hline & $(.25)$ & $(.25)$ & $(.18)$ \\
\hline \multirow[t]{2}{*}{ Total } & 3.18 & 3.24 & 3.21 \\
\hline & $(.07)$ & $(.07)$ & $(.05)$ \\
\hline
\end{tabular}

table continues 
Table 4 cont.

Total

\begin{tabular}{|c|c|c|c|}
\hline Strategy & Males & Females & Total \\
\hline \multirow[t]{2}{*}{ Discuss with Doctor } & $4.51^{\mathrm{c}}$ & $3.99^{\mathrm{c}}$ & 4.25 \\
\hline & $(.14)$ & $(.14)$ & $(.10)$ \\
\hline \multirow[t]{2}{*}{ Discuss with Spouse } & 4.62 & 4.39 & 4.50 \\
\hline & $(.12)$ & $(.12)$ & $(.08)$ \\
\hline \multirow[t]{2}{*}{ Discuss with Relative } & 2.95 & 3.18 & 3.06 \\
\hline & $(.21)$ & $(.21)$ & $(.15)$ \\
\hline \multirow[t]{2}{*}{ Discuss with Someone Else } & $2.11^{\mathrm{c}}$ & $2.96^{\mathrm{c}}$ & 2.54 \\
\hline & $(.15)$ & $(.15)$ & $(.11)$ \\
\hline \multirow[t]{2}{*}{ Ignore the Problem } & 2.41 & 2.04 & 2.22 \\
\hline & $(.15)$ & $(.15)$ & $(.11)$ \\
\hline \multirow[t]{2}{*}{ Deal with Problem Alone } & 2.17 & 2.34 & 2.26 \\
\hline & $(.22)$ & $(.22)$ & $(.15)$ \\
\hline \multirow[t]{2}{*}{ Grand Total } & 3.13 & 3.15 & 3.14 \\
\hline & $(.07)$ & $(.07)$ & $(.05)$ \\
\hline
\end{tabular}

Note. Matching letters within a row represent significant group differences, $p<.05$. Matching letters within a column represent significant group differences, $p<.05$ (note that table continues across 3 pages). 


\section{Table 5}

Number of Persons Reporting Personal Experience with Heart and Arthritis Conditions by Severity, Gender, and Marital Status

\begin{tabular}{lcccc} 
& \multicolumn{2}{c}{ Males } & \multicolumn{2}{c}{ Females } \\
\hline & Married & Unmarried & Married & Unmarried \\
\hline Heart Mild & 4 & 2 & 1 & 7 \\
PERSONAL & 6 & 17 & 10 & 10
\end{tabular}

Heart Severe

$\begin{array}{lllcl}\text { PERSONAL } & 2 & 1 & 5 & 10 \\ \text { VICARIOUS } & 4 & 10 & 8 & 12\end{array}$

Arthritis Mild

$\begin{array}{lllll}\text { PERSONAL } & 3 & 7 & 8 & 6 \\ \text { VICARIOUS } & 1 & 16 & 7 & 14\end{array}$

Arthritis Severe

\begin{tabular}{llccc} 
PERSONAL & 4 & 20 & 3 & 8 \\
VICARIOUS & 4 & 17 & 20 & 14 \\
\hline
\end{tabular}


Table 6

Intercorrelations Among Self-Rated Health, Perceived Control, Experience (continuous measure) and Ratings of Strategies for Mild Heart Problems

\begin{tabular}{|c|c|c|c|c|c|c|c|c|}
\hline & 1 & 2 & 3 & 4 & 5 & 6 & 7 & 8 \\
\hline 1. Perceived Control ${ }_{a}$ & 1.000 & .158 & .477 & -.033 & $-.287 * *$ & -.074 & .206 & .071 \\
\hline 2. Self-Rated Health & & 1.000 & -.186 & .018 & $.255^{* *}$ & -.019 & .064 & -.126 \\
\hline 3. Experience ${ }_{c}$ & & & 1.000 & -.173 & -.626 & -.676 & -.133 & .018 \\
\hline 4. Discuss with Doctor $r_{a}$ & & & & 1.000 & .127 & .021 & -.021 & -.182 \\
\hline 5. Discuss with Relative ${ }_{a}$ & & & & & 1.000 & $.322 * *$ & -.089 & $-.300 * *$ \\
\hline 6. Discuss with Someone Else & & & & & & 1.000 & -.033 & $-.234 * *$ \\
\hline 7. Ignore the Problem $a$ & & & & & & & 1.000 & .057 \\
\hline 8. Deal with Problem Alone ${ }_{a}$ & & & & & & & & 1.000 \\
\hline
\end{tabular}

Note. ** indicates a significant correlation, $p<.01$

a indicates $\mathrm{N}=113$.

$\mathrm{b}$ indicates $\mathrm{N}=112$.

c indicates $\mathrm{N}=11$. 
Table 7

Intercorrelations Among Self-Rated Health, Perceived Control, Experience (continuous measure) and Ratings of Strategies for Severe Heart Problems

\begin{tabular}{|c|c|c|c|c|c|c|c|c|}
\hline & 1 & 2 & 3 & 4 & 5 & 6 & 7 & 8 \\
\hline 1. Perceived Control $a$ & 1.000 & .158 & .194 & .107 & -.181 & -.009 & .072 & .059 \\
\hline 2. Self-Rated Health & & 1.000 & -.414 & .006 & -.015 & -.164 & -.058 & .013 \\
\hline 3. Experience ${ }_{c}$ & & & 1.000 & .005 & $.747 * *$ & $.848 * *$ & -.138 & .063 \\
\hline 4. Discuss with Doctor ${ }_{a}$ & & & & 1.000 & .147 & .046 & -.059 & -.109 \\
\hline 5. Discuss with Relative ${ }_{a}$ & & & & & 1.000 & $.484 * *$ & -.172 & $-.335^{* *}$ \\
\hline 6. Discuss with Someone Else & & & & & & 1.000 & -.124 & .169 \\
\hline 7. Ignore the Problem $a$ & & & & & & & 1.000 & -.002 \\
\hline 8. Deal with Problem Alone ${ }_{a}$ & & & & & & & & 1.000 \\
\hline
\end{tabular}

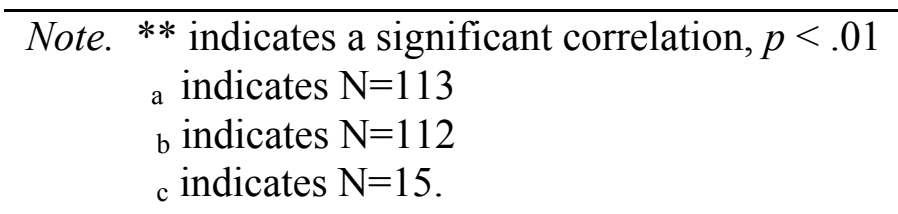


Table 8

Intercorrelations Among Self-Rated Health, Perceived Control, Experience (continuous measure) and Ratings of Strategies for Mild Arthritis Problems

\begin{tabular}{|c|c|c|c|c|c|c|c|c|}
\hline & 1 & 2 & 3 & 4 & 5 & 6 & 7 & 8 \\
\hline 1. Perceived Control $\mathrm{a}$ & 1.000 & .158 & .180 & -.185 & .027 & -.041 & -.235 & -.170 \\
\hline 2. Self-Rated Health & & 1.000 & $-.459 * *$ & -.023 & -.049 & -.074 & -.086 & -.184 \\
\hline 3. Experience ${ }_{c}$ & & & 1.000 & -.348 & .093 & -.216 & $.581 * *$ & .080 \\
\hline 4. Discuss with Doctor ${ }_{a}$ & & & & 1.000 & .159 & .096 & $-.247 * *$ & -.064 \\
\hline 5. Discuss with Relative ${ }_{a}$ & & & & & 1.000 & $.462 * *$ & -.060 & $-.524 * *$ \\
\hline 6. Discuss with Someone Else & & & & & & 1.000 & $-.238 * *$ & $-.345 * *$ \\
\hline 7. Ignore the Problem $a$ & & & & & & & 1.000 & .202 \\
\hline 8. Deal with Problem Alone ${ }_{a}$ & & & & & & & & 1.000 \\
\hline
\end{tabular}

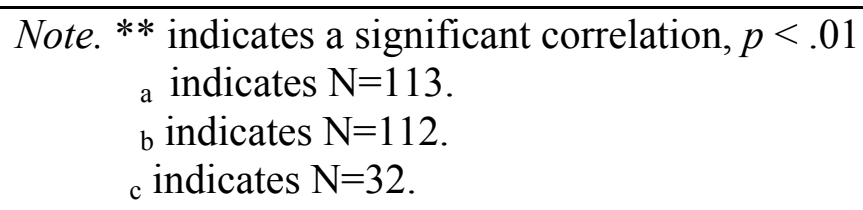


Table 9

Intercorrelations Among Self-Rated Health, Perceived Control, Experience (continuous measure) and Ratings of Strategies for Severe Arthritis Problems

\begin{tabular}{|c|c|c|c|c|c|c|c|c|}
\hline & 1 & 2 & 3 & 4 & 5 & 6 & 7 & 8 \\
\hline 1. Perceived Control ${ }_{\mathrm{a}}$ & 1.000 & .158 & .120 & .024 & $-.316 * *$ & -.118 & .129 & -.070 \\
\hline 2. Self-Rated Health & & 1.000 & -.333 & .100 & .219 & -.102 & -.148 & $-.393 * *$ \\
\hline 3. Experience ${ }_{c}$ & & & 1.000 & -.249 & -.238 & -.281 & .137 & .264 \\
\hline 4. Discuss with Doctor ${ }_{a}$ & & & & 1.000 & .064 & -.083 & -.044 & -.137 \\
\hline 5. Discuss with Relative ${ }_{a}$ & & & & & 1.000 & $.638 * *$ & $-.516^{* *}$ & $-.276^{* *}$ \\
\hline 6. Discuss with Someone Else & & & & & & 1.000 & $-.450 * *$ & -.114 \\
\hline 7. Ignore the Problem $a$ & & & & & & & 1.000 & $.391 * *$ \\
\hline 8. Deal with Problem Alone ${ }_{a}$ & & & & & & & & 1.000 \\
\hline
\end{tabular}

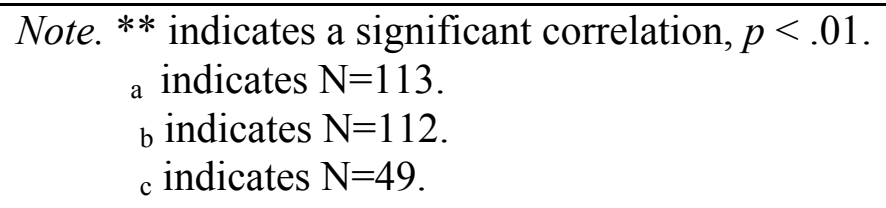


Table 10

Frequencies of Background Variables by Gender and Marital Status

Males $\quad$ Females

\begin{tabular}{|c|c|c|c|c|}
\hline & Married & Unmarried & Married & Unmarried \\
\hline Mean Age (SD) & $70.71(8.12)$ & $70.50(5.23)$ & $69.23(6.04)$ & $75.10(7.93)$ \\
\hline \multicolumn{5}{|l|}{ Education } \\
\hline High school & 22 & 18 & 20 & 15 \\
\hline Some college & 5 & 0 & 9 & 5 \\
\hline 4-year college degree & 3 & 0 & 2 & 5 \\
\hline Graduate degree & 1 & 13 & 1 & 6 \\
\hline \multicolumn{5}{|l|}{ Income } \\
\hline Less than $\$ 10,000$ & 1 & 4 & 2 & 5 \\
\hline$\$ 10,001-\$ 20,000$ & 10 & 8 & 5 & 6 \\
\hline$\$ 20,001-\$ 30,000$ & 6 & 8 & 7 & 11 \\
\hline$\$ 30,001-\$ 40,000$ & 9 & 12 & 11 & 16 \\
\hline$\$ 40,001-\$ 50,000$ & 4 & 0 & 1 & 2 \\
\hline$\$ 50,001-\$ 60,000$ & 1 & 0 & 1 & 0 \\
\hline More than $\$ 60,000$ & 0 & 0 & 1 & 0 \\
\hline
\end{tabular}


Table 11

Knowledge of Heart and Arthritis Problems by Gender and Marital Status: Means and (Standard Error)

\begin{tabular}{|c|c|c|c|c|c|c|c|c|c|}
\hline & \multicolumn{2}{|c|}{ Males } & \multicolumn{3}{|c|}{ Females } & \multicolumn{3}{|c|}{ Total } & \multirow[b]{2}{*}{ Total } \\
\hline & Married & Unmarried & Total & Married & Unmarried & Total & Married & Unmarried & \\
\hline \multirow[t]{2}{*}{ Heart } & 5.33 & 4.63 & $4.98^{\mathrm{a}}$ & 6.14 & 6.10 & $6.12^{\mathrm{a}}$ & 5.74 & 5.36 & 5.55 \\
\hline & $(.27)$ & $(.26)$ & $(.19)$ & $(.28)$ & $(.27)$ & $(.20)$ & $(.19)$ & $(.19)$ & $(.14)$ \\
\hline \multirow[t]{2}{*}{ Arthritis } & 5.97 & 6.50 & 6.23 & 6.31 & 6.33 & 6.32 & 6.14 & 6.42 & 6.28 \\
\hline & $(.26)$ & $(.25)$ & $(.18)$ & $(.27)$ & $(.26)$ & $(.19)$ & (.19) & $(.18)$ & $(.13)$ \\
\hline
\end{tabular}

Note: Matching letters within a row represent significant group difference, $F(1,118)=17.990, p<.01$, eta ${ }^{2}=.135$. 
Table 12

Number of Friends and Relatives with whom there is Contact by Gender and Marital Status: Means and (Standard Error)

$$
\text { Males Females Total }
$$

\begin{tabular}{lcccccccccc}
\hline & Married & Unmarried & Total & Married & Unmarried & Total & Married Unmarried & Total \\
\hline Friends & 7.25 & 6.10 & 6.66 & 8.72 & 4.29 & 6.51 & $7.98^{\mathrm{a}}$ & $5.18^{\mathrm{a}}$ & 6.58 \\
& $(1.14)$ & $(1.16)$ & $(.81)$ & $(1.14)$ & $(1.16)$ & $(.81)$ & $(.81)$ & $(.82)$ & $(.58)$ \\
& 5.52 & 2.97 & 4.24 & 5.34 & 4.22 & 4.78 & $5.43^{\mathrm{b}}$ & $3.59^{\mathrm{b}}$ & 4.51 \\
Relatives & $(.64)$ & $(.62)$ & $(.45)$ & $(.61)$ & $(.61)$ & $(.43)$ & $(.44)$ & $(.47)$ & $(.31)$
\end{tabular}

Note: Matching letters within a row represent significant group difference.

${ }^{\mathrm{a}}=F(1,125)=5.96, p<.05$, eta $^{2}=.047$.

$\mathrm{b}=F(1,123)=8.71, p<.01$, eta ${ }^{2}=.068$. 
Table 13

Self-Rated Health and Perceived Control by Gender and Marital Status: Means and (Standard Error)

Males Females Total

\begin{tabular}{|c|c|c|c|c|c|c|c|c|c|}
\hline & Married & Unmarried & Total & Married & Unmarried & Total & Married & Unmarried & Total \\
\hline \multirow[t]{2}{*}{ Self-Rated Health } & 6.02 & 5.87 & 5.94 & 5.96 & 5.86 & 5.91 & 5.99 & 5.86 & 5.93 \\
\hline & $(.30)$ & $(.31)$ & $(.22)$ & $(.30)$ & $(.31)$ & $(.22)$ & $(.21)$ & $(.22)$ & $(.15)$ \\
\hline \multirow[t]{2}{*}{ Perceived Control } & 54.58 & 49.67 & 52.12 & 53.26 & 53.65 & 53.46 & 53.92 & 51.66 & 52.79 \\
\hline & $(1.24)$ & $(1.24)$ & $(.88)$ & $(1.26)$ & $(1.28)$ & $(.90)$ & $(.88)$ & $(.89)$ & $(.63)$ \\
\hline
\end{tabular}


Table 14

Mean Number (standard deviation) of Physical Illnesses by Severity, Gender, and Marital Status Males $\quad$ Females

\begin{tabular}{lcccc}
\hline & Married & Unmarried & Married & Unmarried \\
\hline Physical & 1.53 & 1.38 & 1.55 & 1.29 \\
Illnesses & $(1.01)$ & $(.61)$ & $(.86)$ & $(.90)$ \\
\hline
\end{tabular}


Figure 1

Mean Strategy Ratings for Married and Unmarried Males on Mild Heart Problems

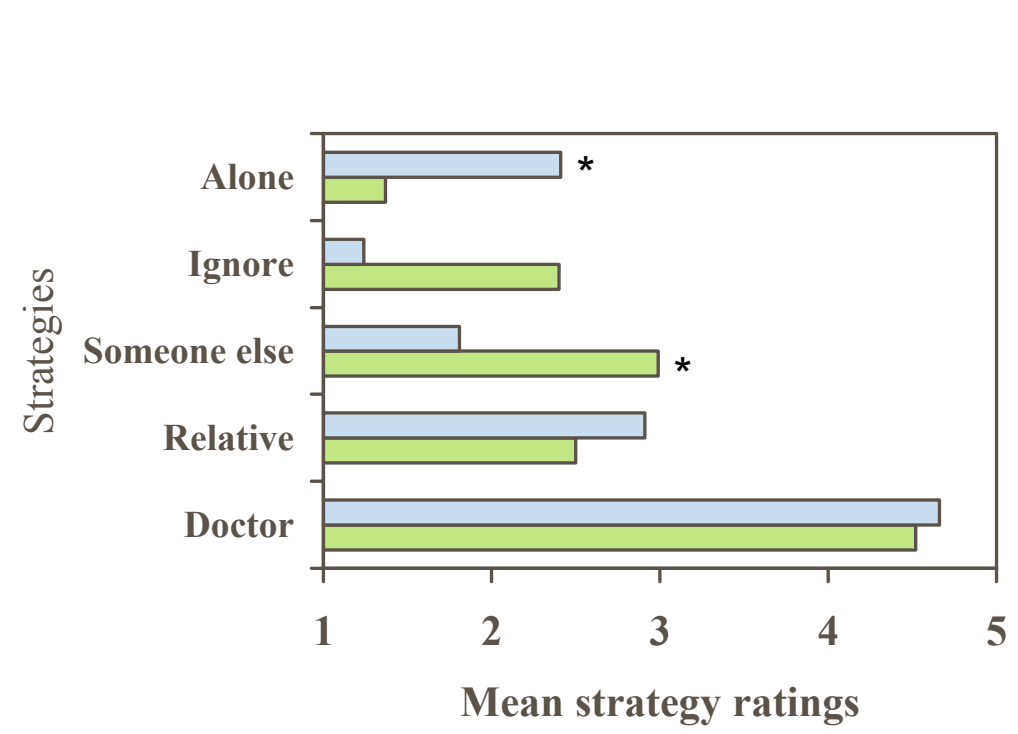

$\square$ Married Males

$\square$ Unmarried Males 
Figure 2

Mean Strategy ratings for Males and Females on Severe Heart Problems

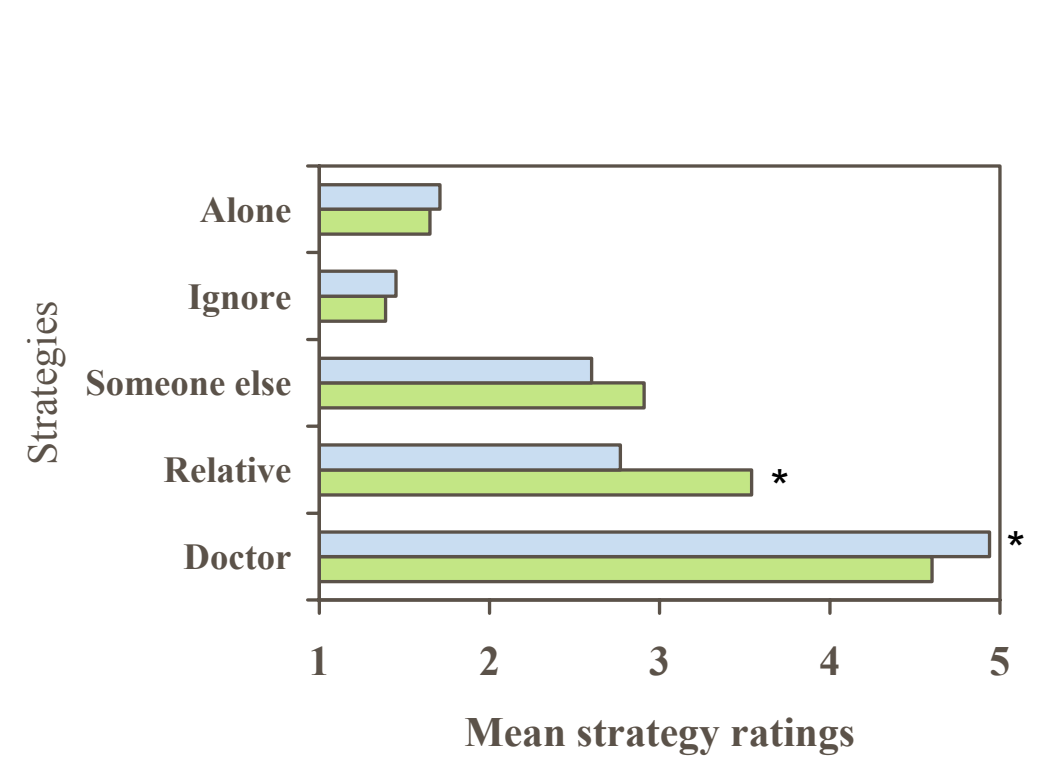

$\square$ Males

$\square$ Females 
Figure 3

Mean Strategy Ratings for Males and Females on Arthritis Problems

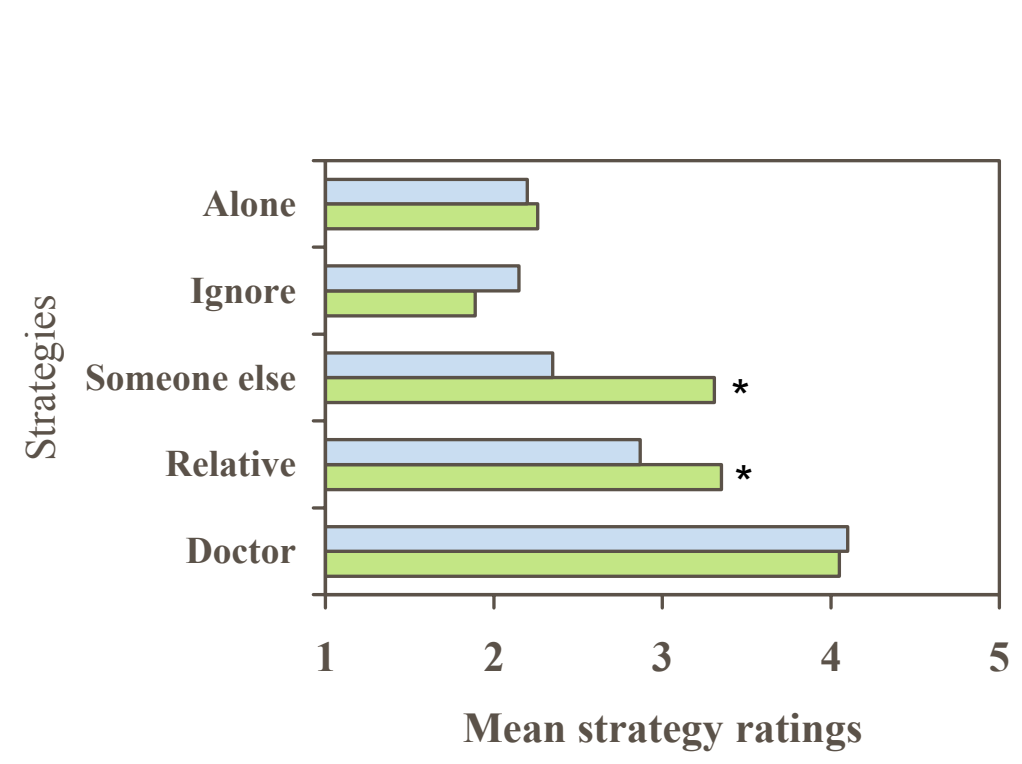

$\square$ Males

$\square$ Females 
Figure 4

Mean Strategy Ratings for Married and Unmarried Adults on Arthritis Problems

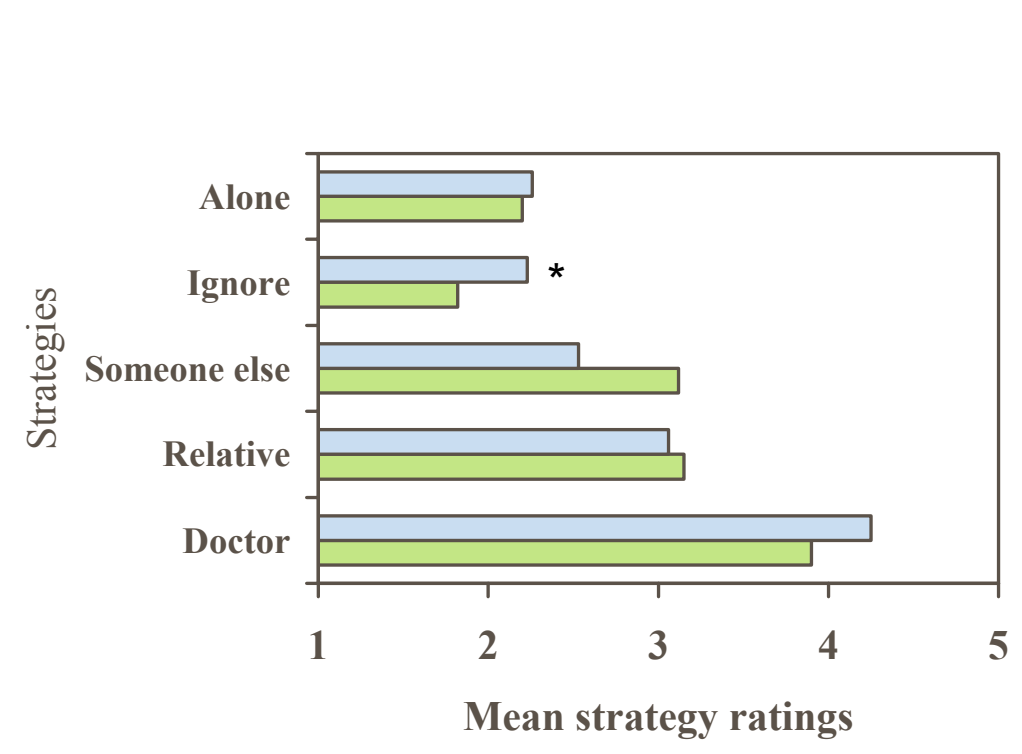

$\square$ Married

$\square$ Unmarried 
Figure 5

Mean Strategy Ratings for Mild and Severe Arthritis Problems

$\square$ Severe

$\square$ Mild

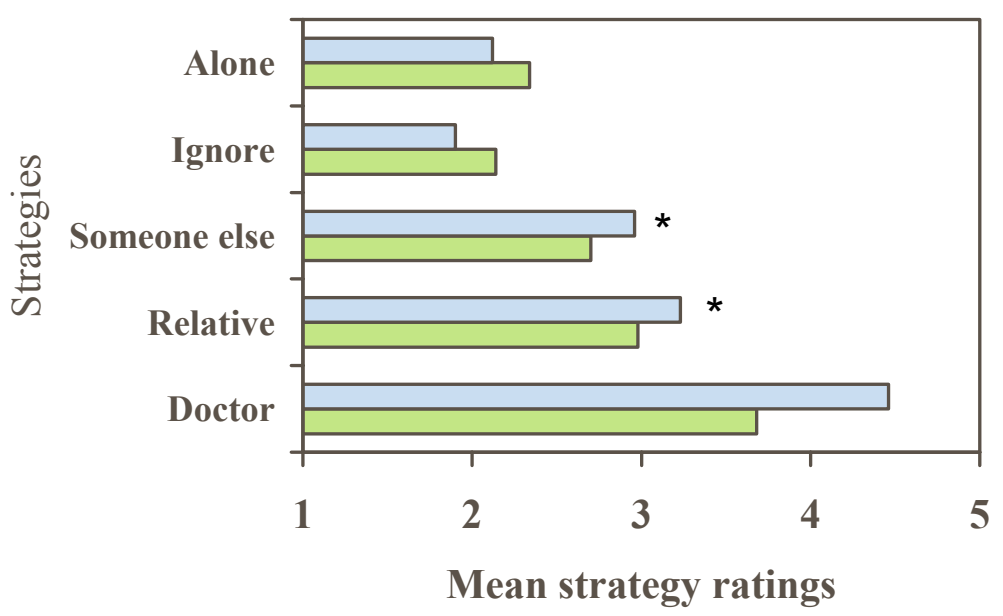


Figure 6

Mean Strategy Ratings for Females on Mild Heart Problems

$\square$ Females

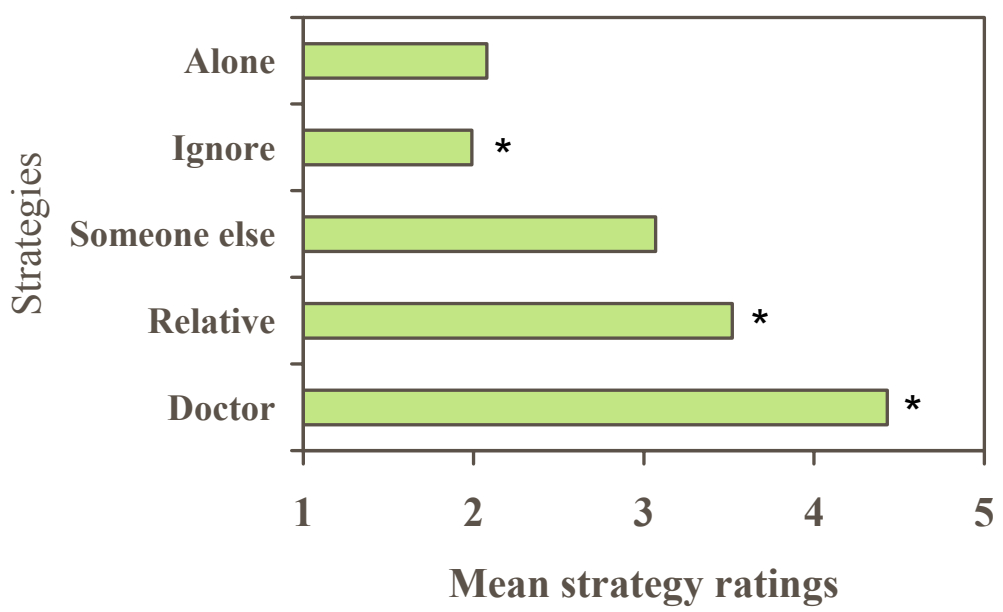


Figure 7

Mean Strategy Ratings for Mild Heart Problems by Marital Status and Gender

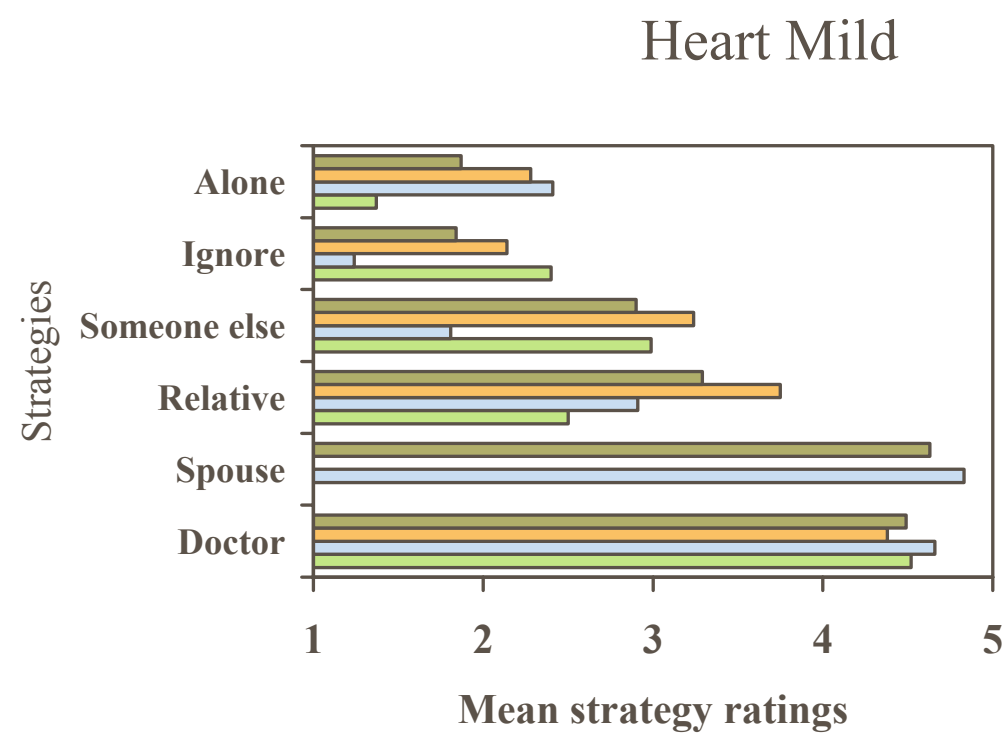

$\square$ Married Females $\square$ Unmarried Females $\square$ Married Males

$\square$ Unmarried Males 
Figure 8

Mean Strategy Ratings for Severe Heart Problems by Marital Status and Gender

\section{Heart Severe}

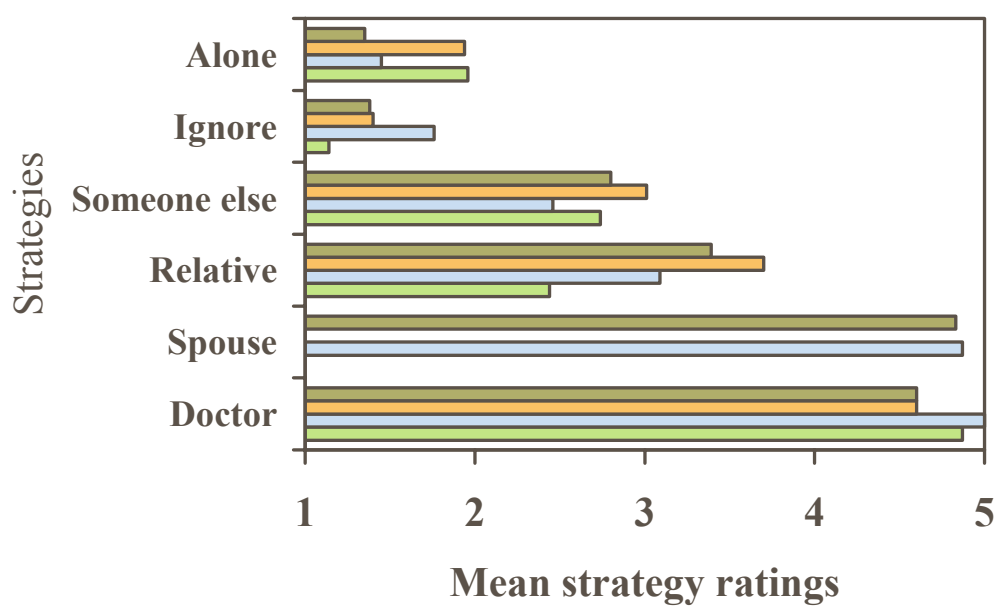

$\square$ Married Females $\square$ Unmarried Females $\square$ Married Males $\square$ Unmarried Males 
Figure 9

Mean Strategy Ratings for Mild Arthritis Problems by Marital Status and Gender

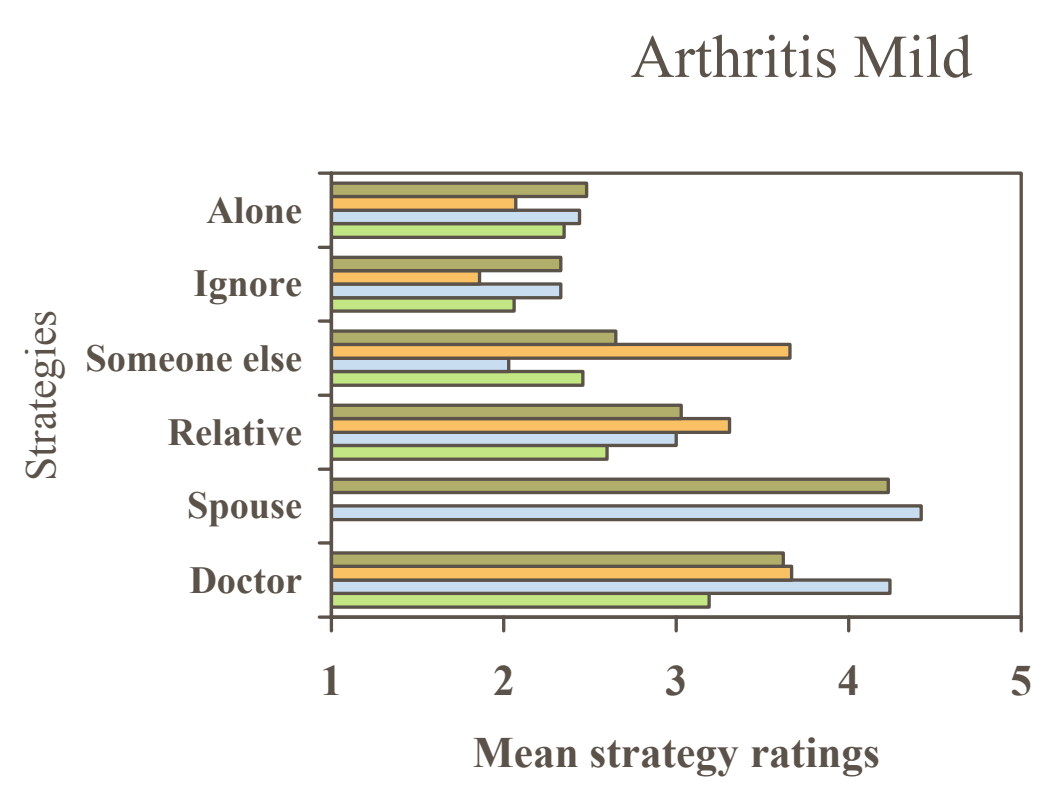

$\square$ Married Females $\square$ Unmarried Females $\square$ Married Males

$\square$ Unmarried Males 
Figure 10

Mean Strategy Ratings for Severe Arthritis Problems by Marital Status and Gender

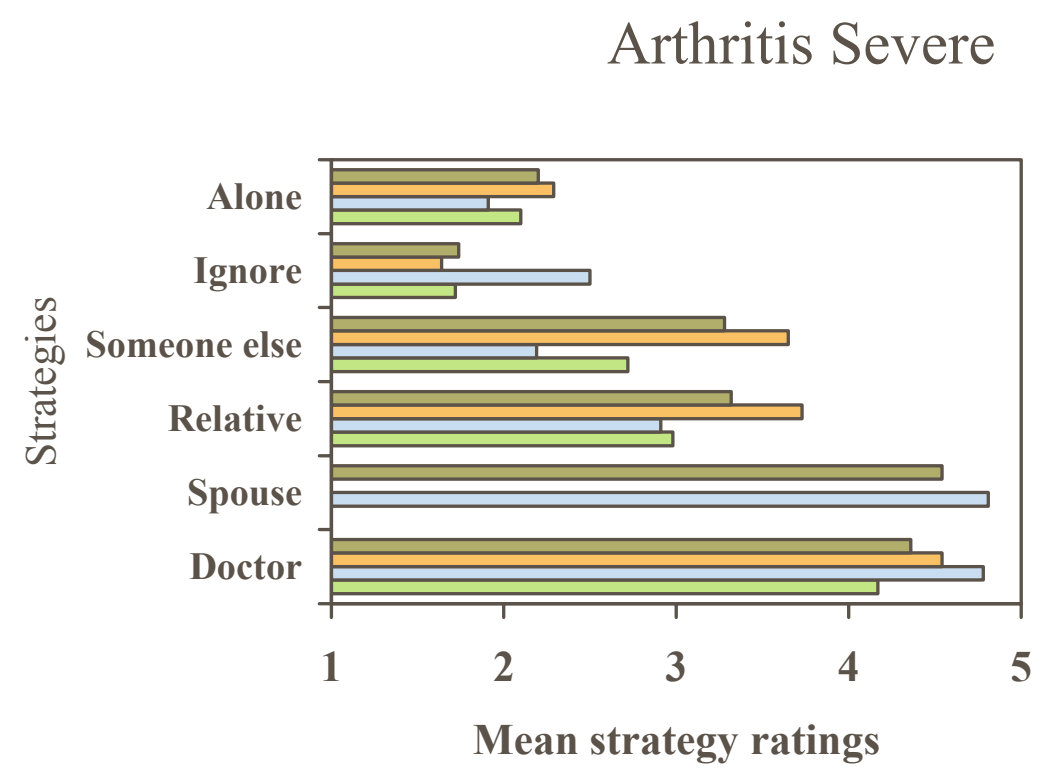

$\square$ Married Females $\square$ Unmarried Females $\square$ Married Males $\square$ Unmarried Males 
Appendix A

Think about the following situation. Please rate each option by circling the appropriate number.

Imagine that one evening as you are eating dinner, you notice a slight pain in your chest and it seems a little difficult to breathe. You break out into a cold sweat and start to feel nauseas. After 10 minutes the pain and nausea are still there. How likely would you be to:

\begin{tabular}{|c|c|c|c|}
\hline $\begin{array}{l}\text { Definitely } \\
\text { Would Not } \\
\text { Do }\end{array}$ & $\begin{array}{l}\text { Probably } \\
\text { Would Not } \\
\text { Do }\end{array}$ & Neutral & $\begin{array}{l}\text { Probably } \\
\text { Would Do }\end{array}$ \\
\hline
\end{tabular}

\begin{tabular}{llllll} 
a.) Do Nothing & 1 & 2 & 3 & 4 & 5 \\
\hline b.) Discuss with doctor & 1 & 2 & 3 & 4 & 5 \\
\hline
\end{tabular}

c.) Discuss with spouse (if married)

12

d.) Discuss with relative

1

2

3

4

5

e.) Discuss with someone else

1

2

3

4

5

f.) Ignore it

1

2

3

4
5

g.) Do something to take your mind off of it

h). Deal with it alone

i.) Take an aspirin or over-the-counter pain reliever j.) Pray

k.) Look up Information about what symptoms mean

1

2

2

3

4

4

4

5

$4 \quad 5$


1.) Answer this question only if you rated questions $D$ on page 2 as a 2 or above. What is the relationship of the person you talked to (e.g., child, friend)?

a. Has this person ever experienced a problem like the one described on page 2? (circle one) Yes No

b. If yes, how long ago did they experience the problem?

0

Within Past

Three Weeks
1

1 Month

or so ago
2

2 Months

or so ago
3

3 Months or so ago
4

4 Months or so ago
5

6

c. If yes, how often do they experience the problem?

$$
1
$$

$$
2
$$

3

4

5

6

5 Months or so ago
6 Months ago or more

$\begin{array}{ccccccc}\text { Every } & \text { At least } & \text { Every } & \text { At least } & \text { Weekly } & \text { Almost } & \text { Everyday } \\ \text { Few Years } & 1 \text { time } & \text { Few } & 1 \text { time } & & \text { Everyday } & \\ & \text { Per Year } & \text { Months } & \text { Per Month } & & & \\ & & & & & \end{array}$

2.) If you rated questions $E$ on page 2 as a 2 or above, what is the relationship of the person you talked to (e.g., child, friend)?

a. Has this person ever experienced a problem like the one described on page 2? (circle one) Yes No

b. If yes, how long ago did they experience the problem?

$\begin{array}{ccccccc}0 & 1 & 2 & 3 & 4 & 5 & 6 \\ \begin{array}{c}\text { Within Past } \\ \text { Three Weeks }\end{array} & \begin{array}{c}\text { 1 Month } \\ \text { or so ago }\end{array} & \begin{array}{c}2 \text { Months } \\ \text { or so ago }\end{array} & \begin{array}{l}3 \text { Months } \\ \text { or so ago }\end{array} & \begin{array}{c}\text { 4 Months } \\ \text { or so ago }\end{array} & \begin{array}{c}\text { 5 Months } \\ \text { or so ago }\end{array} & \begin{array}{c}6 \text { Months } \\ \text { ago or more }\end{array}\end{array}$

\begin{tabular}{|c|c|c|c|c|c|c|}
\hline 1 & 2 & 3 & 4 & 5 & 6 & 7 \\
\hline $\begin{array}{l}\text { Every } \\
\text { Few Years }\end{array}$ & $\begin{array}{l}\text { At least } \\
1 \text { time } \\
\text { Per Year }\end{array}$ & $\begin{array}{l}\text { Every } \\
\text { Few } \\
\text { Months }\end{array}$ & $\begin{array}{l}\text { At least } \\
1 \text { time } \\
\text { Per Month }\end{array}$ & Weekly & $\begin{array}{l}\text { Almost } \\
\text { Everyday }\end{array}$ & Everyday \\
\hline
\end{tabular}

c. If yes, how often do they experience the problem? 
Think about the situation in which one evening as you are eating dinner, you notice a slight pain in your chest and it seems a little difficult to breathe. You break out into a cold sweat and start to feel nauseas. After 10 minutes the pain and nausea are still there. Answer the following questions:

1.) Have you ever experienced a problem anything like the problem described above? (circle one) Yes No

a. If yes, how long ago did you experience the problem?

$\begin{array}{ccccccc}0 & 1 & 2 & 3 & 4 & 5 & 6 \\ \begin{aligned} \text { Within Past } \\ \text { Three Weeks }\end{aligned} & \begin{array}{c}\text { 1 Month } \\ \text { or so ago }\end{array} & \begin{array}{l}2 \text { Months } \\ \text { or so ago }\end{array} & \begin{array}{l}3 \text { Months } \\ \text { or so ago }\end{array} & \begin{array}{c}\text { 4 Months } \\ \text { or so ago }\end{array} & \begin{array}{c}5 \text { Months } \\ \text { or so ago }\end{array} & \begin{array}{c}6 \text { Months } \\ \text { ago or more }\end{array}\end{array}$

b. How often do you experience this problem? (circle one)

\begin{tabular}{|c|c|c|c|c|c|c|}
\hline 1 & 2 & 3 & 4 & 5 & 6 & 7 \\
\hline $\begin{array}{l}\text { Every } \\
\text { Few Years }\end{array}$ & $\begin{array}{l}\text { At least } \\
1 \text { time } \\
\text { Per Year }\end{array}$ & $\begin{array}{l}\text { Every } \\
\text { Few } \\
\text { Months }\end{array}$ & $\begin{array}{l}\text { At least } \\
1 \text { time } \\
\text { Per Month }\end{array}$ & Weekly & $\begin{array}{l}\text { Almost } \\
\text { Everyday }\end{array}$ & Everyday \\
\hline
\end{tabular}

2.) Do you know anyone who has experienced anything like the problem described above? (circle one) Yes No

a. If yes, how long ago did they experience the problem?

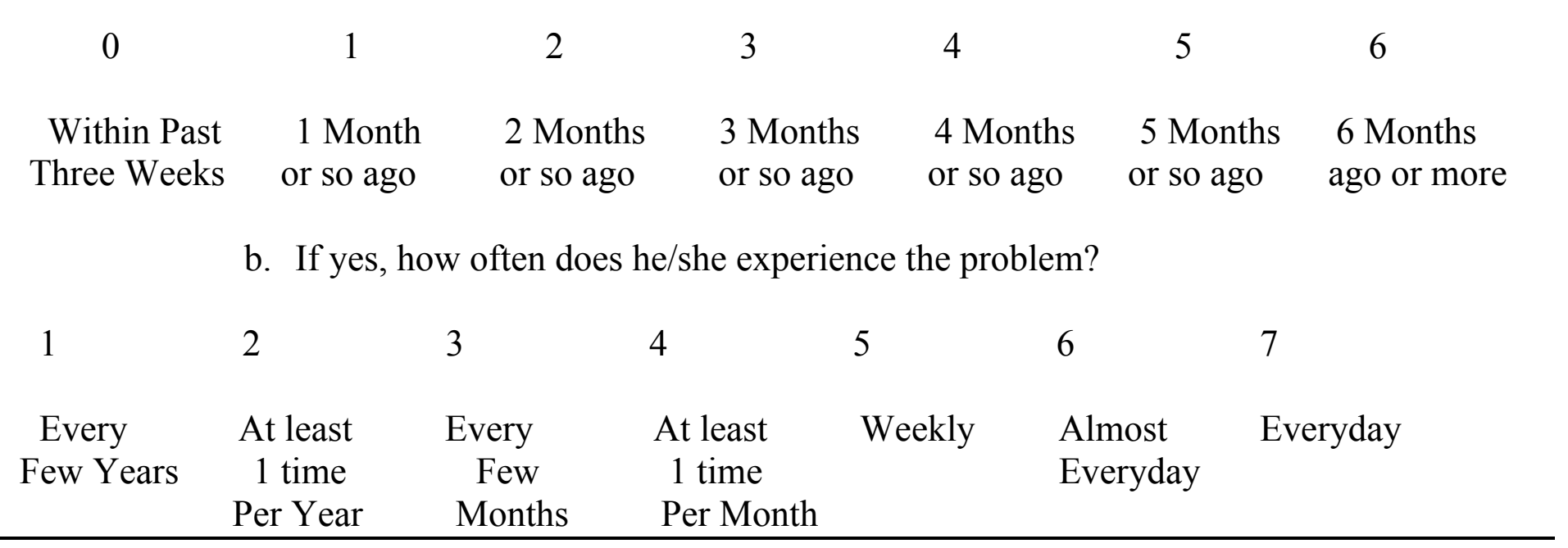


Think about the following situation. Please rate each option by circling the appropriate number.

Imagine that you awake suddenly in the middle of the night with throbbing pains in your chest and arm. You feel enormous pressure in the center of your chest and you are sweating. It is very difficult to breathe and $\mathbf{1 0}$ minutes later the pain is still there. How likely would you be to:

$\begin{array}{ccccc}\begin{array}{c}\text { Definitely } \\ \text { Would Not } \\ \text { Do }\end{array} & \begin{array}{c}\text { Probably } \\ \text { Would Not } \\ \text { Do }\end{array} & \text { Neutral } & \begin{array}{c}\text { Probably } \\ \text { Would Do }\end{array} & \begin{array}{c}\text { Definitely } \\ \text { Would Do }\end{array} \\ & & & \end{array}$

\begin{tabular}{llllll} 
a.) Do Nothing & 1 & 2 & 3 & 4 & 5 \\
b.) Discuss with doctor & 1 & 2 & 3 & 4 & 5 \\
\hline
\end{tabular}

c.) Discuss with spouse (if married)

2

d.) Discuss with relative

1

2

3

4

5

e.) Discuss with someone else

1

2

3

4

5

f.) Ignore it

$1 \quad 2$

3

4

5

h.) Do something to take your mind off of it

h). Deal with it alone

j.) Take an aspirin or over-the-counter pain reliever j.) Pray

1.) Look up Information about what symptoms mean

$\begin{array}{lllll}1 & 2 & 3 & 4 & 5\end{array}$

5

5


1.) Answer this question only if you rated questions $D$ on page 5 as a 2 or above. What is the relationship of the person you talked to (e.g., child, friend)?

a. Has this person ever experienced a problem like the one described on page 5? (circle one) Yes No

b. If yes, how long ago did they experience the problem?

0

Within Past

Three Weeks
1

1 Month

or so ago
2

2 Months

or so ago
3

3 Months or so ago
4

4 Months or so ago
5

6

c. If yes, how often do they experience the problem?

$$
1
$$

$$
2
$$

3

4

5

6

5 Months or so ago
6 Months ago or more

$\begin{array}{ccccccc}\text { Every } & \text { At least } & \text { Every } & \text { At least } & \text { Weekly } & \text { Almost } & \text { Everyday } \\ \text { Few Years } & 1 \text { time } & \text { Few } & 1 \text { time } & & \text { Everyday } & \\ & \text { Per Year } & \text { Months } & \text { Per Month } & & & \\ & & & & & \end{array}$

2.) If you rated questions $E$ on page 5 as a 2 or above, what is the relationship of the person you talked to (e.g., child, friend)?

a. Has this person ever experienced a problem like the one described on page 5? (circle one) Yes No

b. If yes, how long ago did they experience the problem?

$\begin{array}{ccccccc}0 & 1 & 2 & 3 & 4 & 5 & 6 \\ \begin{array}{c}\text { Within Past } \\ \text { Three Weeks }\end{array} & \begin{array}{c}\text { 1 Month } \\ \text { or so ago }\end{array} & \begin{array}{c}2 \text { Months } \\ \text { or so ago }\end{array} & \begin{array}{l}3 \text { Months } \\ \text { or so ago }\end{array} & \begin{array}{l}\text { 4 Months } \\ \text { or so ago }\end{array} & \begin{array}{c}5 \text { Months } \\ \text { or so ago }\end{array} & \begin{array}{c}6 \text { Months } \\ \text { ago or more }\end{array}\end{array}$

\begin{tabular}{|c|c|c|c|c|c|c|}
\hline 1 & 2 & 3 & 4 & 5 & 6 & 7 \\
\hline $\begin{array}{l}\text { Every } \\
\text { Few Years }\end{array}$ & $\begin{array}{l}\text { At least } \\
1 \text { time } \\
\text { Per Year }\end{array}$ & $\begin{array}{l}\text { Every } \\
\text { Few } \\
\text { Months }\end{array}$ & $\begin{array}{l}\text { At least } \\
1 \text { time } \\
\text { Per Month }\end{array}$ & Weekly & $\begin{array}{l}\text { Almost } \\
\text { Everyday }\end{array}$ & Everyday \\
\hline
\end{tabular}

c. If yes, how often do they experience the problem? 
Think about the situation in which you awake suddenly in the middle of the night with throbbing pains in your chest and arm. You feel enormous pressure in the center of your chest and you are sweating. It is very difficult to breather and $\mathbf{1 0}$ minutes later the pain is still there. Answer the following questions:

1.) Have you ever experienced a problem anything like the problem described above? (circle one) Yes No

a. If yes, how long ago did you experience the problem?

0

Within Past

Three Weeks
2

2 Months

or so ago
3

3 Months

or so ago
4

4 Months or so ago
5

6

or so ago

b. How often do you experience this problem? (circle one)

\begin{tabular}{|c|c|c|c|c|c|c|}
\hline 1 & 2 & 3 & 4 & 5 & 6 & 7 \\
\hline $\begin{array}{l}\text { Every } \\
\text { Few Years }\end{array}$ & $\begin{array}{l}\text { At least } \\
1 \text { time } \\
\text { Per Year }\end{array}$ & $\begin{array}{c}\text { Every } \\
\text { Few } \\
\text { Months }\end{array}$ & $\begin{array}{l}\text { At least } \\
1 \text { time } \\
\text { Per Month }\end{array}$ & Weekly & $\begin{array}{l}\text { Almost } \\
\text { Everyday }\end{array}$ & Everyday \\
\hline
\end{tabular}

2.) Do you know anyone who has experienced anything like the problem described above? (circle one) Yes No

a. If yes, how long ago did they experience the problem?

$\begin{array}{ccccccc}0 & 1 & 2 & 3 & 4 & 5 & 6 \\ \begin{aligned} \text { Within Past } \\ \text { Three Weeks }\end{aligned} & \begin{array}{c}\text { 1 Month } \\ \text { or so ago }\end{array} & \begin{array}{l}\text { 2 Months } \\ \text { or so ago }\end{array} & \begin{array}{l}\text { 3 Months } \\ \text { or so ago }\end{array} & \begin{array}{c}\text { 4 Months } \\ \text { or so ago }\end{array} & \begin{array}{c}\text { 5 Months } \\ \text { or so ago }\end{array} & \begin{array}{c}\text { a Months } \\ \text { ago or more }\end{array}\end{array}$

b. If yes, how often does he/she experience the problem?

$\begin{array}{cllllll}1 & 2 & 3 & 4 & 5 & 6 & 7 \\ \begin{array}{c}\text { Every } \\ \text { Few Years }\end{array} & \begin{array}{c}\text { At least } \\ 1 \text { time } \\ \text { Per Year }\end{array} & \begin{array}{c}\text { Every } \\ \text { Few } \\ \text { Months }\end{array} & \begin{array}{c}\text { At least } \\ 1 \text { time } \\ \text { Per Month }\end{array} & \text { Weekly } & \begin{array}{l}\text { Almost } \\ \text { Everyday }\end{array} & \text { Everyday } \\ & & & & & \end{array}$


Think about the following situation. Please rate each option by circling the appropriate number for each option.

Imagine that as you are getting dressed, your fingers begin to hurt and start to swell. Ten minutes later they are still hurting. How likely would you be to:

$\begin{array}{ccccc}\begin{array}{c}\text { Definitely } \\ \text { Would Not } \\ \text { Do }\end{array} & \begin{array}{c}\text { Probably } \\ \text { Would Not } \\ \text { Do }\end{array} & \text { Neutral } & \begin{array}{c}\text { Probably } \\ \text { Would Do }\end{array} & \begin{array}{c}\text { Definitely } \\ \text { Would Do }\end{array} \\ & & & \end{array}$

\begin{tabular}{llllll} 
a.) Do Nothing & 1 & 2 & 3 & 4 & 5 \\
b.) Discuss with doctor & 1 & 2 & 3 & 4 & 5 \\
\hline
\end{tabular}

c.) Discuss with spouse (if married)

2

d.) Discuss with relative

$1 \quad 2$

3

4

5

e.) Discuss with someone else

1

2

3

4

5

f.) Ignore it

$1 \quad 2$

3

4

5

i.) Do something to

12

23

3

4

5
take your mind off of it

h). Deal with it alone

k.) Take an aspirin or over-the-counter pain reliever

j.) Pray

m.) Look up Information about what symptoms mean
1.) Go to the hospital

m.) Do something else
1 1

2

2

1

1

1

1

2

2

2

3

3

3

4

4

5

5

5


1.) Answer this question only if you rated questions $D$ on page 8 as a 2 or above. What is the relationship of the person you talked to (e.g., child, friend)?

a. Has this person ever experienced a problem like the one described on page 8? (circle one) Yes No

b. If yes, how long ago did they experience the problem?

0

Within Past

Three Weeks

\begin{abstract}
1 Month
\end{abstract}
or so ago
2

2 Months or so ago
3

3 Months or so ago
4

4 Months or so ago
5

6

c. If yes, how often do they experience the problem?
1
2
3
4
5
6
7

Every At least Every At least Weekly Almost Everyday

Few Years 1 time $\quad$ Few 1 time $\quad$ Everyday

2.) If you rated questions $E$ on page 8 as a 2 or above, what is the relationship of the person you talked to (e.g., child, friend)?

a. Has this person ever experienced a problem like the one described on page 8? (circle one) Yes No

b. If yes, how long ago did they experience the problem?

$\begin{array}{ccccccc}0 & 1 & 2 & 3 & 4 & 5 & 6 \\ \begin{array}{c}\text { Within Past } \\ \text { Three Weeks }\end{array} & \begin{array}{c}1 \text { Month } \\ \text { or so ago }\end{array} & \begin{array}{c}2 \text { Months } \\ \text { or so ago }\end{array} & \begin{array}{l}3 \text { Months } \\ \text { or so ago }\end{array} & \begin{array}{l}\text { 4 Months } \\ \text { or so ago }\end{array} & \begin{array}{c}\text { 5 Months } \\ \text { or so ago }\end{array} & \begin{array}{c}\text { 6 Months } \\ \text { ago or more }\end{array}\end{array}$

c. If yes, how often do they experience the problem?

\begin{tabular}{|c|c|c|c|c|c|c|}
\hline 1 & 2 & 3 & 4 & 5 & 6 & 7 \\
\hline $\begin{array}{l}\text { Every } \\
\text { Few Years }\end{array}$ & $\begin{array}{l}\text { At least } \\
1 \text { time } \\
\text { Per Year }\end{array}$ & $\begin{array}{l}\text { Every } \\
\text { Few } \\
\text { Months }\end{array}$ & $\begin{array}{l}\text { At least } \\
1 \text { time } \\
\text { Per Month }\end{array}$ & Weekly & $\begin{array}{l}\text { Almost } \\
\text { Everyday }\end{array}$ & Everyday \\
\hline
\end{tabular}


Think about the situation in which you are getting dressed and your fingers begin to hurt and start to swell. Ten minutes later they are still hurting. Answer the following questions:

1.) Have you ever experienced a problem anything like the problem described above? (circle one) Yes No

a. If yes, how long ago did you experience the problem?

0

Within Past

Three Weeks

\begin{abstract}
1 Month
\end{abstract}
or so ago
2

2 Months

or so ago
3

3 Months

or so ago
4

4 Months or so ago
5

6

5 Months or so ago
6 Months ago or more

b. How often do you experience this problem? (circle one)
1
2
3
4
5
6
7

Every

At least

Every

At least

Weekly

Almost

Everyday

Few Years

1 time

Few

1 time

Per Year

Months

Per Month

Everyday

2.) Do you know anyone who has experienced anything like the problem described above? (circle one) Yes No

a. If yes, how long ago did they experience the problem?

$\begin{array}{ccccccc}0 & 1 & 2 & 3 & 4 & 5 & 6 \\ \begin{aligned} \text { Within Past } \\ \text { Three Weeks }\end{aligned} & \begin{array}{c}\text { 1 Month } \\ \text { or so ago }\end{array} & \begin{array}{l}\text { 2 Months } \\ \text { or so ago }\end{array} & \begin{array}{l}3 \text { Months } \\ \text { or so ago }\end{array} & \begin{array}{l}\text { 4 Months } \\ \text { or so ago }\end{array} & \begin{array}{c}\text { 5 Months } \\ \text { or so ago }\end{array} & \begin{array}{c}\text { 6 Months } \\ \text { ago or more }\end{array}\end{array}$

b. If yes, how often does he/she experience the problem?

\begin{tabular}{|c|c|c|c|c|c|c|}
\hline 1 & 2 & 3 & 4 & 5 & 6 & 7 \\
\hline $\begin{array}{l}\text { Every } \\
\text { Few Years }\end{array}$ & $\begin{array}{l}\text { At least } \\
1 \text { time } \\
\text { Per Year }\end{array}$ & $\begin{array}{l}\text { Every } \\
\text { Few } \\
\text { Months }\end{array}$ & $\begin{array}{l}\text { At least } \\
1 \text { time } \\
\text { Per Month }\end{array}$ & Weekly & $\begin{array}{l}\text { Almost } \\
\text { Everyday }\end{array}$ & Everyday \\
\hline
\end{tabular}


Think about the following situation. Please rate each option by circling the appropriate number.

Imagine that your hands and knees ache all the time. Simple things such as getting dressed, eating, and getting up out of chairs are always very difficult. How likely would you be to:

$\begin{array}{ccccc}\text { Definitely } & \text { Probably } & \text { Neutral } & \text { Probably } & \text { Definitely } \\ \text { Would Not } & \text { Would Not } \\ \text { Do } & \text { Do } & & \text { Would Do } & \text { Would Do } \\ & & & \end{array}$

\begin{tabular}{llllll} 
a.) Do Nothing & 1 & 2 & 3 & 4 & 5 \\
\hline b.) Discuss with doctor & 1 & 2 & 3 & 4 & 5 \\
\hline
\end{tabular}

\begin{tabular}{llllll} 
c.) Discuss with spouse (if married) & 1 & 2 & 3 & 4 & 5 \\
\hline
\end{tabular}

\begin{tabular}{llllll} 
d.) Discuss with relative & 1 & 2 & 3 & 4 & 5 \\
\hline
\end{tabular}

e.) Discuss with someone else $\quad 1 \quad 2 \quad 3 \quad$ r

$\begin{array}{llllll}\text { f.) Ignore it } & 1 & 2 & 3 & 4 & 5 \\ \begin{array}{l}\text { j.) Do something to } \\ \text { take your mind } \\ \text { off of it }\end{array} & 1 & 2 & 3 & 4 & 5 \\ \end{array}$

h). Deal with it alone
1.) Take an aspirin or over-the-counter pain reliever
j.) Pray

$1 \quad 2$
n.) Look up Information about what symptoms mean

12
3
4

5

2
4
5

1.) Go to the hospital

1

2

3

4

5

m.) Do something else

1

2

3

4 
1.) Answer this question only if you rated questions $D$ on page 11 as a 2 or above. What is the relationship of the person you talked to (e.g., child, friend)?

a. Has this person ever experienced a problem like the one described on page 11? (circle one) Yes No

b. If yes, how long ago did they experience the problem?

0

Within Past

Three Weeks

1 Month
or so ago

2 Months or so ago
3

3 Months or so ago
4

4 Months or so ago
5

6

c. If yes, how often do they experience the problem?

$$
2
$$

At least

1 time

Per Year
3

4

5

6

5 Months or so ago
6 Months ago or more

\begin{tabular}{ccccccc} 
Every & At least & Every & At least & Weekly & Almost & Everyday \\
Few Years & 1 time & Few & 1 time & & Everyday & \\
& Per Year & Months & Per Month & & & \\
\hline
\end{tabular}

2.) If you rated questions $E$ on page 11 as a 2 or above, what is the relationship of the person you talked to (e.g., child, friend)?

a. Has this person ever experienced a problem like the one described on page 11? (circle one) Yes No

b. If yes, how long ago did they experience the problem?

$\begin{array}{ccccccc}0 & 1 & 2 & 3 & 4 & 5 & 6 \\ \begin{array}{c}\text { Within Past } \\ \text { Three Weeks }\end{array} & \begin{array}{c}1 \text { Month } \\ \text { or so ago }\end{array} & \begin{array}{c}2 \text { Months } \\ \text { or so ago }\end{array} & \begin{array}{l}3 \text { Months } \\ \text { or so ago }\end{array} & \begin{array}{l}\text { 4 Months } \\ \text { or so ago }\end{array} & \begin{array}{c}\text { 5 Months } \\ \text { or so ago }\end{array} & \begin{array}{c}\text { 6 Months } \\ \text { ago or more }\end{array}\end{array}$

\begin{tabular}{|c|c|c|c|c|c|c|}
\hline 1 & 2 & 3 & 4 & 5 & 6 & 7 \\
\hline $\begin{array}{l}\text { Every } \\
\text { Few Years }\end{array}$ & $\begin{array}{l}\text { At least } \\
1 \text { time } \\
\text { Per Year }\end{array}$ & $\begin{array}{c}\text { Every } \\
\text { Few } \\
\text { Months }\end{array}$ & $\begin{array}{l}\text { At least } \\
1 \text { time } \\
\text { Per Month }\end{array}$ & Weekly & $\begin{array}{l}\text { Almost } \\
\text { Everyday }\end{array}$ & Everyday \\
\hline
\end{tabular}

c. If yes, how often do they experience the problem? 
Think about the situation in which your hands and knees ache all the time. Simple things such as getting dressed, eating, and getting up out of chairs are always very difficult. Answer the following questions:

1.) Have you ever experienced a problem anything like the problem described above? (circle one) Yes No

a. If yes, how long ago did you experience the problem?

$\begin{array}{ccccccc}0 & 1 & 2 & 3 & 4 & 5 & 6 \\ \text { Within Past } & \begin{array}{c}\text { 1 Month } \\ \text { or so ago }\end{array} & \begin{array}{c}2 \text { Months } \\ \text { or so ago }\end{array} & \begin{array}{l}3 \text { Months } \\ \text { or so ago }\end{array} & \begin{array}{c}\text { 4 Months } \\ \text { or so ago }\end{array} & \begin{array}{c}5 \text { Months } \\ \text { or so ago }\end{array} & \begin{array}{c}\text { 6 Months } \\ \text { ago or more }\end{array}\end{array}$

b. How often do you experience this problem? (circle one)
1
2
3
4
5
6
7

$\begin{array}{ccccccc}\text { Every } & \text { At least } & \text { Every } & \text { At least } & \text { Weekly } & \text { Almost } & \text { Everyday } \\ \text { Few Years } & 1 \text { time } & \text { Few } & 1 \text { time } & & \text { Everyday } & \\ & \text { Per Year } & \text { Months } & \text { Per Month } & & & \end{array}$

2.) Do you know anyone who has experienced anything like the problem described above? (circle one) Yes No

0

a. If yes, how long ago did they experience the problem?

$\begin{array}{ccccccc}0 & 1 & 2 & 3 & 4 & 5 & 6 \\ \text { Within Past } & \begin{array}{c}\text { 1 Month } \\ \text { or so ago }\end{array} & \begin{array}{l}2 \text { Months } \\ \text { or so ago }\end{array} & \begin{array}{l}3 \text { Months } \\ \text { or so ago }\end{array} & \begin{array}{c}\text { 4 Months } \\ \text { or so ago }\end{array} & \begin{array}{c}5 \text { Months } \\ \text { or so ago }\end{array} & \begin{array}{c}\text { 6 Months } \\ \text { ago or more }\end{array}\end{array}$

b. If yes, how often does he/she experience the problem?

$\begin{array}{lllllll}1 & 2 & 3 & 4 & 5 & 6 & 7\end{array}$

Every At least Every At least Weekly Almost Everyday

Few Years 1 time Few 1 time Everyday

Per Year Months Per Month




\section{Please circle the one that BEST describes you:}

1.) How would you rate your overall health at the present time?
1) Excellent
2) Good
3) Fair
4) Poor

2.) Is your health now better, about the same, or not as good as it was 3 years ago?
1) Better
2) Same
3) Not as good

3.) Do your health problems stand in the way of your doing the things you want to do?

1) Not at all

2) A little

3) A great deal

4.) Compared with most other people your age, would you say your health is:

1) Better

2) The same

3) Not as good

For the following, please indicate your answer by circling the appropriate phrase.

1.) When solving problems pertaining to your health, do you prefer to work alone?

1

2

3

4

5

Do Not

Somewhat

Neutral

Prefer

Very Much

Prefer

Prefer

Prefer

2.) When solving problems pertaining to your health, do you prefer to work with another person?

1

Do Not

Prefer
2

Somewhat

Prefer
3

Neutral

Prefer

4

5

Very Much Prefer 
3.) When solving problems pertaining to your health, do you prefer to work with a doctor?

1

Do Not

Prefer
2

Somewhat

Prefer
3

Neutral

Prefer
5

Very Much Prefer

4.) When solving problems pertaining to your health, do you prefer to work with your spouse (if married)?
1
2
3
4
5
Do Not
Somewhat
Neutral
Prefer
Very Much
Prefer
Prefer
Prefer

5.) When solving problems pertaining to your health, do you prefer to work with a relative?
1
2
3
4
5
Do Not
Somewhat
Neutral
Prefer
Very Much
Prefer
Prefer
Prefer

6.) When solving problems pertaining to your health, how often do you work alone?

1

Never
2

Not Very

Often

3

Sometimes Often

Often

4

5

7.) When solving problems pertaining to your health, how often do you work with another person?

$$
1
$$

Never
2

Not Very
3

Sometimes
4 5

8.) When solving problems pertaining to your health, how often do you work with a doctor?

$$
1
$$

Never
2

Not Very

Often
3

Sometimes
4

5

Often

Often
Very Often

Very Often 
9.) When solving problems pertaining to your health, how often do you work with your spouse (if married)?

1

Never
2

Not Very

Often
3

4

5

Sometimes Often

Very Often

10.)When solving problems pertaining to your health, how often do you work with a relative?

1

Never
2

Not Very
3

Sometimes
4

Often
5

Very Often

11.)When solving problems pertaining to your health, do you like to work alone?

1

Do Not

Like
2

Somewhat

Like
3

Neutral

Like

4

5

Like Very

Much

12.)When solving problems pertaining to your health, do you like to work with another person?

1

Do Not

Like
2

Somewhat

Like
3

Neutral

Like
5

Like Very Much

13.)When solving problems pertaining to your health, do you like to work with a doctor?

1

Do Not

Like
2

Somewhat

Like
3

Neutral
4

Like
5

Like Very Much

14.)When solving problems pertaining to your health, do you like to work with your spouse (if married)?

1

Do Not

Like
2

Somewhat

Like
3

Neutral

4 5

Like

Like Very

Much 
15.) When solving problems pertaining to your health, do you like to work with a relative?
1
2
3
4
5

Do Not

Somewhat

Neutral

Like

Like

Like Very

Like

Much

\section{Please circle how much you agree or disagree with each statement.}

\begin{tabular}{|c|c|c|c|c|c|c|c|}
\hline & & $\begin{array}{l}\text { Strongly } \\
\text { Agree }\end{array}$ & Agree & $\begin{array}{l}\text { Mildly } \\
\text { Agree }\end{array}$ & $\begin{array}{c}\text { Mildly } \\
\text { Disagree }\end{array}$ & Disagree & $\begin{array}{l}\text { Strongly } \\
\text { Disagree }\end{array}$ \\
\hline 1 & $\begin{array}{l}\text { If I become sick, I have the } \\
\text { power to make myself well } \\
\text { again. }\end{array}$ & $\begin{array}{l}\text { Strongly } \\
\text { Agree }\end{array}$ & Agree & $\begin{array}{l}\text { Mildly } \\
\text { Agree }\end{array}$ & $\begin{array}{l}\text { Mildly } \\
\text { Disagree }\end{array}$ & Disagree & $\begin{array}{l}\text { Strongly } \\
\text { Disagree }\end{array}$ \\
\hline 2 & $\begin{array}{l}\text { Often I feel that no matter what I } \\
\text { do, if I am going to get sick, I } \\
\text { will get sick. }\end{array}$ & $\begin{array}{l}\text { Strongly } \\
\text { Agree }\end{array}$ & Agree & $\begin{array}{l}\text { Mildly } \\
\text { Agree }\end{array}$ & $\begin{array}{l}\text { Mildly } \\
\text { Disagree }\end{array}$ & Disagree & $\begin{array}{l}\text { Strongly } \\
\text { Disagree }\end{array}$ \\
\hline 3 & $\begin{array}{l}\text { If I see an excellent doctor } \\
\text { regularly, I am less likely to have } \\
\text { health problems. }\end{array}$ & $\begin{array}{l}\text { Strongly } \\
\text { Agree }\end{array}$ & Agree & $\begin{array}{l}\text { Mildly } \\
\text { Agree }\end{array}$ & $\begin{array}{l}\text { Mildly } \\
\text { Disagree }\end{array}$ & Disagree & $\begin{array}{l}\text { Strongly } \\
\text { Disagree }\end{array}$ \\
\hline 4 & $\begin{array}{l}\text { It seems that my health is greatly } \\
\text { influenced by accidental } \\
\text { happenings }\end{array}$ & $\begin{array}{l}\text { Strongly } \\
\text { Agree }\end{array}$ & Agree & $\begin{array}{l}\text { Mildly } \\
\text { Agree }\end{array}$ & $\begin{array}{l}\text { Mildly } \\
\text { Disagree }\end{array}$ & Disagree & $\begin{array}{l}\text { Strongly } \\
\text { Disagree }\end{array}$ \\
\hline 5 & $\begin{array}{l}\text { I can only maintain my health by } \\
\text { consulting health professionals. }\end{array}$ & $\begin{array}{l}\text { Strongly } \\
\text { Agree }\end{array}$ & Agree & $\begin{array}{l}\text { Mildly } \\
\text { Agree }\end{array}$ & $\begin{array}{l}\text { Mildly } \\
\text { Disagree }\end{array}$ & Disagree & $\begin{array}{l}\text { Strongly } \\
\text { Disagree }\end{array}$ \\
\hline 6 & $\begin{array}{l}\text { I am directly responsible for my } \\
\text { health. }\end{array}$ & $\begin{array}{l}\text { Strongly } \\
\text { Agree }\end{array}$ & Agree & $\begin{array}{l}\text { Mildly } \\
\text { Agree }\end{array}$ & $\begin{array}{l}\text { Mildly } \\
\text { Disagree }\end{array}$ & Disagree & $\begin{array}{l}\text { Strongly } \\
\text { Disagree }\end{array}$ \\
\hline 7 & $\begin{array}{l}\text { Other people play a big part in } \\
\text { whether I stay healthy or become } \\
\text { sick. }\end{array}$ & $\begin{array}{l}\text { Strongly } \\
\text { Agree }\end{array}$ & Agree & $\begin{array}{l}\text { Mildly } \\
\text { Agree }\end{array}$ & $\begin{array}{l}\text { Mildly } \\
\text { Disagree }\end{array}$ & Disagree & $\begin{array}{l}\text { Strongly } \\
\text { Disagree }\end{array}$ \\
\hline 8 & $\begin{array}{l}\text { Whatever goes wrong with my } \\
\text { health is my own fault. }\end{array}$ & $\begin{array}{l}\text { Strongly } \\
\text { Agree }\end{array}$ & Agree & $\begin{array}{l}\text { Mildly } \\
\text { Agree }\end{array}$ & $\begin{array}{l}\text { Mildly } \\
\text { Disagree }\end{array}$ & Disagree & $\begin{array}{l}\text { Strongly } \\
\text { Disagree }\end{array}$ \\
\hline 9 & $\begin{array}{l}\text { When I am sick, I just have to let } \\
\text { nature run its course. }\end{array}$ & $\begin{array}{l}\text { Strongly } \\
\text { Agree }\end{array}$ & Agree & $\begin{array}{l}\text { Mildly } \\
\text { Agree }\end{array}$ & $\begin{array}{c}\text { Mildly } \\
\text { Disagree }\end{array}$ & Disagree & $\begin{array}{l}\text { Strongly } \\
\text { Disagree }\end{array}$ \\
\hline
\end{tabular}




\begin{tabular}{|c|c|c|c|c|c|c|c|}
\hline 10 & $\begin{array}{l}\text { Health professionals keep me } \\
\text { healthy. }\end{array}$ & $\begin{array}{l}\text { Strongly } \\
\text { Agree }\end{array}$ & Agree & $\begin{array}{l}\text { Mildly } \\
\text { Agree }\end{array}$ & $\begin{array}{l}\text { Mildly } \\
\text { Disagree }\end{array}$ & Disagree & $\begin{array}{l}\text { Strongly } \\
\text { Disagree }\end{array}$ \\
\hline 11 & $\begin{array}{l}\text { When I stay healthy, I'm just } \\
\text { plain lucky. }\end{array}$ & $\begin{array}{l}\text { Strongly } \\
\text { Agree }\end{array}$ & Agree & $\begin{array}{l}\text { Mildly } \\
\text { Agree }\end{array}$ & $\begin{array}{l}\text { Mildly } \\
\text { Disagree }\end{array}$ & Disagree & $\begin{array}{l}\text { Strongly } \\
\text { Disagree }\end{array}$ \\
\hline 12 & $\begin{array}{l}\text { My physical well-being depends } \\
\text { on how well I take care of } \\
\text { myself. }\end{array}$ & $\begin{array}{l}\text { Strongly } \\
\text { Agree }\end{array}$ & Agree & $\begin{array}{l}\text { Mildly } \\
\text { Agree }\end{array}$ & $\begin{array}{l}\text { Mildly } \\
\text { Disagree }\end{array}$ & Disagree & $\begin{array}{l}\text { Strongly } \\
\text { Disagree }\end{array}$ \\
\hline 13 & $\begin{array}{l}\text { When I feel ill, I know it is } \\
\text { because I have not been taking } \\
\text { care of myself properly. }\end{array}$ & $\begin{array}{l}\text { Strongly } \\
\text { Agree }\end{array}$ & Agree & $\begin{array}{l}\text { Mildly } \\
\text { Agree }\end{array}$ & $\begin{array}{l}\text { Mildly } \\
\text { Disagree }\end{array}$ & Disagree & $\begin{array}{l}\text { Strongly } \\
\text { Disagree }\end{array}$ \\
\hline 14 & $\begin{array}{l}\text { The type of care I receive from } \\
\text { other people is what is } \\
\text { responsible for how well } \\
\text { I recover from an illness. }\end{array}$ & $\begin{array}{l}\text { Strongly } \\
\text { Agree }\end{array}$ & Agree & $\begin{array}{l}\text { Mildly } \\
\text { Agree }\end{array}$ & $\begin{array}{l}\text { Mildly } \\
\text { Disagree }\end{array}$ & Disagree & $\begin{array}{l}\text { Strongly } \\
\text { Disagree }\end{array}$ \\
\hline 15 & $\begin{array}{l}\text { Even when I take care of myself, } \\
\text { it's easy to get sick. }\end{array}$ & $\begin{array}{l}\text { Strongly } \\
\text { Agree }\end{array}$ & Agree & $\begin{array}{l}\text { Mildly } \\
\text { Agree }\end{array}$ & $\begin{array}{l}\text { Mildly } \\
\text { Disagree }\end{array}$ & Disagree & $\begin{array}{l}\text { Strongly } \\
\text { Disagree }\end{array}$ \\
\hline 16 & $\begin{array}{l}\text { When I become ill, it's a matter } \\
\text { of fate. }\end{array}$ & $\begin{array}{l}\text { Strongly } \\
\text { Agree }\end{array}$ & Agree & $\begin{array}{l}\text { Mildly } \\
\text { Agree }\end{array}$ & $\begin{array}{l}\text { Mildly } \\
\text { Disagree }\end{array}$ & Disagree & $\begin{array}{l}\text { Strongly } \\
\text { Disagree }\end{array}$ \\
\hline 17 & $\begin{array}{l}\text { I can pretty much stay healthy by } \\
\text { taking good care of myself. }\end{array}$ & $\begin{array}{l}\text { Strongly } \\
\text { Agree }\end{array}$ & Agree & $\begin{array}{l}\text { Mildly } \\
\text { Agree }\end{array}$ & $\begin{array}{l}\text { Mildly } \\
\text { Disagree }\end{array}$ & Disagree & $\begin{array}{l}\text { Strongly } \\
\text { Disagree }\end{array}$ \\
\hline 18 & $\begin{array}{l}\text { Following doctor's orders to the } \\
\text { letter is the best way for me to } \\
\text { stay healthy. }\end{array}$ & $\begin{array}{l}\text { Strongly } \\
\text { Agree }\end{array}$ & Agree & $\begin{array}{l}\text { Mildly } \\
\text { Agree }\end{array}$ & $\begin{array}{l}\text { Mildly } \\
\text { Disagree }\end{array}$ & Disagree & $\begin{array}{l}\text { Strongly } \\
\text { Disagree }\end{array}$ \\
\hline
\end{tabular}

19.) Compared to other people your age and sex, is your risk of having a heart attack (circle one):
1.) higher
2.) lower
3.) about the same

20.) Compared to other people your age and sex, is your risk of getting arthritis (circle one):
1.) higher
2.)lower
3.)about the same

21.) Is there at least 1 person you can turn to for assistance in solving problems? (circle one) Yes No 
22.) How many relatives are you in regular contact with (speak or write at least once a month or more)? Number of relatives

23.) How many friends are you in regular contact with (speak or write at least once a month)? Number of friends 


\section{Information about you}

1. Sex (circle one)

Male

Female

2. Age years Date of Birth:

3. Race

African American

Asian

Caucasian

Hispanic

Other Specify

4. Highest Education

High school

Some college

4-year college degree

Graduate degree

5. What city/town and state are you a permanent resident of?

City/town

State

6. Your current yearly income

Less than $\$ 10,000$

$\$ 10,001-\$ 20,000$

$\$ 20,001-\$ 30,000$

$\$ 30,001-\$ 40,000$

$\$ 40,001-\$ 50,000$

$\$ 50,001-\$ 60,000$

More than $\$ 60,000$

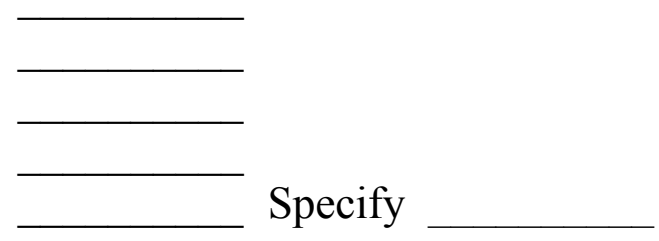


11. Religious affiliation

$\begin{array}{ll}\text { Jewish } & \\ \text { Protestant } & \text { (specify denomination } \\ \text { Roman Catholic } & \text { (specify } \\ \text { Other } & \end{array}$

12. What is your marital status, are you:

1.) Married (indicate number of years married

2.) Not married, but living together as married (indicate number of years

3.) Widowed (indicate number of years married widowed and number of years

4.) Divorced (indicate number of years married and number of years divorced

5.) Never married

6.) Other

13. Do you currently live:

1.) alone

2.) with a spouse

3.) with a friend/not related

4.) with relatives (specify relationship

5.) with others (specific relationship

14. What kind of work have you done most of your life?

For what kind of business, company or agency is that?

15. What is your current work status? Are you:

1.) Employed full time

2.) Employed part time

3.) Retired

4.) Unemployed

5.) Homemaker

6.) Other (specify

16. How long have you been a patient of your family physician?

Years

Months

17. What is the gender of your physician? (circle one) Male Female 
18. How comfortable are you speaking to your physician about your health? (circle one)

$\begin{array}{ccccc}1 & 2 & 3 & 4 & 5 \\ \text { Not at all } & \text { Somewhat } & \text { Neutral } & \text { Comfortable } & \text { Very } \\ \text { Comfortable } & \text { Uncomfortable } & & & \text { Comfortable }\end{array}$

19. Think about the past year, how many times did you go to your doctor? Number of times

20. Do you have health insurance? (circle one) Yes No

If yes, is your health care provided by private insurance? Yes No

Is your health insurance related to a current or former employer? Yes No

Do you receive benefits from Medicaid? Yes No

Do you receive benefits from Medicare? Yes No

Do you have prescription Drug Benefits? $\quad$ Yes $\quad$ No

Are you a member of an HMO? Yes No

How much choice do you have in choosing a physician?

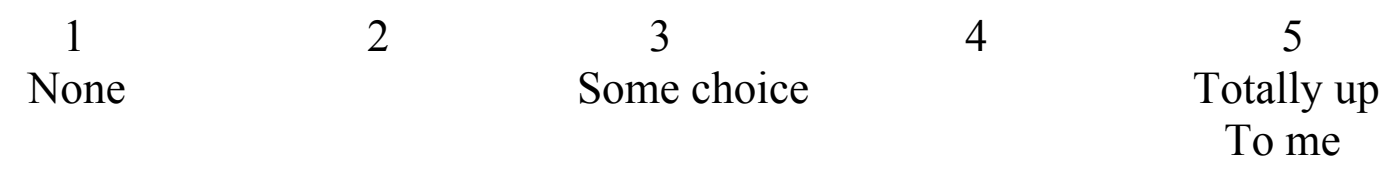

21. How easy is it for you to get to your doctor? (circle one)

$\begin{array}{lcccccc}1 & 2 & 3 & 4 & 5 & 6 & 7 \\ \text { Very } & \text { Difficult } & \text { Somewhat } & \text { Neutral } & \text { Fairly Easy } & \text { Easy } & \text { Extremely } \\ \text { Difficult } & & \text { Difficult } & & & & \text { Easy }\end{array}$

22. In the past, has a physician diagnosed:

a. Arthritis? ......................................................... No

Osteoarthritis?............................................. Nes No

- If Yes, when was this diagnosed? _ _ (Month/Year)

Rheumatoid Arthritis?.......................................

- If Yes, when was this diagnosed? __ (Month/Year) 
b. Chronic Bronchitis?

No

If Yes, when was this diagnosed? ___ (Month/Year)

c. Emphysema? ..Yes

If Yes, when was this diagnosed? ___ (Month/Year)

d. Any heart trouble?. ..Yes

If Yes, when was this diagnosed?

(Month/Year)

e. Hardening of the arteries? ...Yes

If Yes, when was this diagnosed?

(Month/Year)

f. Stomach Ulcer?

..Yes No

If Yes, when was this diagnosed?

(Month/Year)

g. Cataracts?

....Yes No

If Yes, when was this diagnosed?

(Month/Year)

h. Glaucoma?. ...Yes

If Yes, when was this diagnosed?

(Month/Year)

i. Cancer?

If Yes, when was this diagnosed?

j. Nervous condition?. (Month/Year)

If Yes, when was this diagnosed? (Month/Year)

$\mathrm{k}$. Trouble getting to or staying asleep?

If Yes, when was this diagnosed?

1. Headaches?

(Month/Year)

If Yes, when was this diagnosed?

(Month/Year)

m. Parkinson's disease?.

If Yes, when was this diagnosed?

n. Diabetes?

If Yes, when was this diagnosed?

o. Hypertension or high blood pressure?

If Yes, when was this diagnosed?

p. Stroke?

If Yes, when was this diagnosed?

(Month/Year)

q. Other effects of stroke?

If Yes, when was this diagnosed?

...............................Yes
Yes

No

No

No

No

No

No

No

No

No

No

No

No

No

r. Paralysis from any condition other than stroke?

If Yes, when was this diagnosed?

(Month/Year)

(Month/Year)

s. Circulation trouble in arms or legs?

(Month/Year)

If Yes, when was this diagnosed?
.

(Month/Year)

(Month/Year)

t. Asthma?

If Yes, when was this diagnosed?

(Month/Year)

u. Broken hip?

If Yes, when was this diagnosed?

v. Other broken bones?

If Yes, when was this diagnosed?

(Month/Year)

No

No

No 
w. Bladder problems?

No

If Yes, when was this diagnosed?

(Month/Year)

$\mathrm{x}$. Liver problems?

Yes

If Yes, when was this diagnosed? Yes

No

y. Gall bladder?

(Month/Year)

If Yes, when was this diagnosed? Yes

No

z. Kidney trouble?

If Yes, when was this diagnosed?

(Month/Year)

aa. Anemia?

If Yes, when was this diagnosed?

(Month/Year)

bb. Back Problems?

If Yes, when was this diagnosed?

(Month/Year)

cc. Epileptic Seizures?...

...................Yes

If Yes, when was this diagnosed?

(Month/Year)

dd. High Cholesterol?

If Yes, when was this diagnosed?

(Month/Year)

ee. Depression?.

If Yes, when was this diagnosed?

(Month/Year)

ff. Bipolar disorder (manic/depressive illness)?

If Yes, when was this diagnosed?

(Month/Year)

dd. Did a physician diagnose any other condition? Yes

No

If yes, what condition(s)?

When diagnosed (Month/Year)

No

No

No

No

No

No

No



23. For the following, please check any of the conditions that you now experience and the extent that each condition causes you problems (circle one):

\section{a. arthritis (circle one) osteoarthritis rheumatoid NONE MILD MODERATE SEVERE}

\section{b. heart trouble}

NONE MILD MODERATE SEVERE

\section{c. back problems}

NONE MILD MODERATE SEVERE h. diabetes

NONE MILD MODERATE

SEVERE

\section{i. high blood pressure}

NONE MILD MODERATE

SEVERE

j. stroke

NONE MILD MODERATE

SEVERE 


\section{d. breathing problems}

NONE MILD MODERATE SEVERE

$\square$ e. headaches

NONE MILD MODERATE

SEVERE

$\square$ f. anemia

NONE MILD MODERATE

SEVERE

g. hardening of arteries

NONE MILD MODERATE

SEVERE k. nervous condition

NONE MILD MODERATE

SEVERE

1. cancer

NONE MILD MODERATE

SEVERE

$\square$ m. high cholesterol

NONE MILD MODERATE

SEVERE

n. other

NONE MILD MODERATE

SEVERE

24. About how many days have you spent in the hospital in the past 12 months?

Number of days

25. About how many days during the past twelve months have you been sick in bed all or most of the day? Number of days

26. Are you currently taking any prescription drugs? Yes No

If yes, please list what prescriptions and why you are taking them.

27. Are you currently taking any over the counter drugs? Yes No

If yes, please list what and why you are taking them.

28. Do you smoke cigarettes or cigars? (circle one) Yes No

29. Do you have a heart condition? (circle one) Yes No

If yes, answer questions $30-33$ : 
30. Please rate the degree that heart problems stop you from doing things you used to do. (circle one).

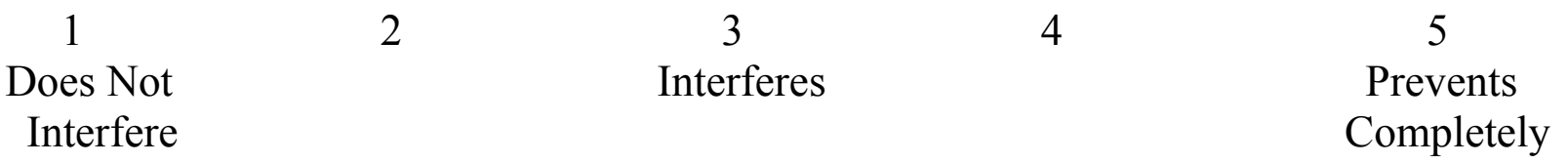

31. Please rate the degree that heart problems stop you from doing things you want to do. (circle one).

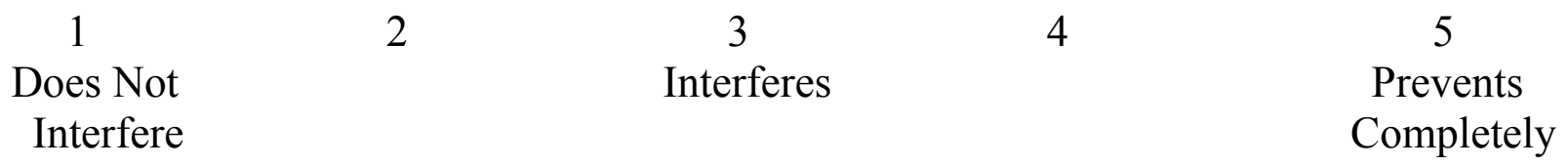

32. How long ago was your most recent experience with a problem related to your heart? (circle one)

$\begin{array}{ccccccc}0 & 1 & 2 & 3 & 4 & 5 & 6 \\ \begin{array}{r}\text { Within Past } \\ \text { Three Weeks }\end{array} & \begin{array}{c}\text { 1 Month } \\ \text { or so ago }\end{array} & \begin{array}{l}\text { 2 Months } \\ \text { or so ago }\end{array} & \begin{array}{l}3 \text { Months } \\ \text { or so ago }\end{array} & \begin{array}{l}4 \text { Months } \\ \text { or so ago }\end{array} & \begin{array}{c}\text { 5 Months } \\ \text { or so ago }\end{array} & \begin{array}{c}\text { ago orths } \\ \text { ago ore }\end{array}\end{array}$

33. How often do you experience problems related to your heart?
1

$$
2
$$
3
4
5
6
7

$\begin{array}{ccccccc}\text { Every } & \text { At least } & \text { Every } & \text { At least } & \text { Weekly } & \text { Almost } & \text { Everyday } \\ \text { Few Years } & 1 \text { time } & \text { Few } & 1 \text { time } & & \text { Everyday } & \\ & \text { Per Year } & \text { Months } & \text { Per Month } & & & \end{array}$

34. Do you have arthritis? (circle one) Yes No

If yes, answer questions 35-38:

35. Please rate the degree that arthritis problems stop you from doing things you used to do. (circle one).

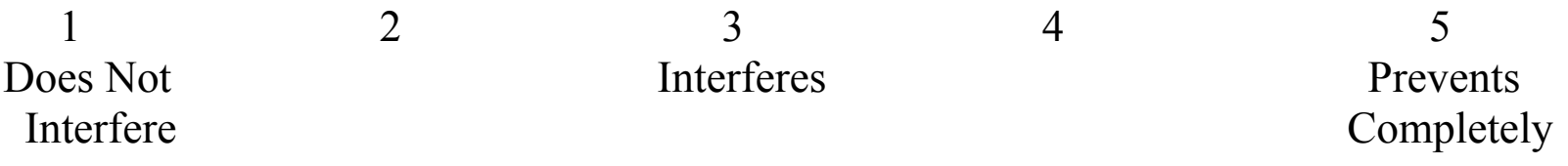


36. Please rate the degree that arthritis problems stop you from doing things you want to do? (circle one).

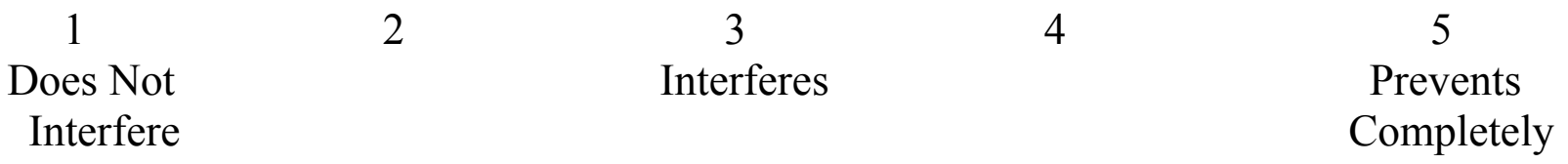

37. How long ago was your most recent experience with a problem related to arthritis? (circle one)

0

Within Past

Three Weeks
1

$$
1 \text { Month }
$$$$
\text { or so ago }
$$

2

2 Months

or so ago
3

3 Months or so ago
4

4 Months or so ago
5

6

38. How often do you experience problems related to arthritis?

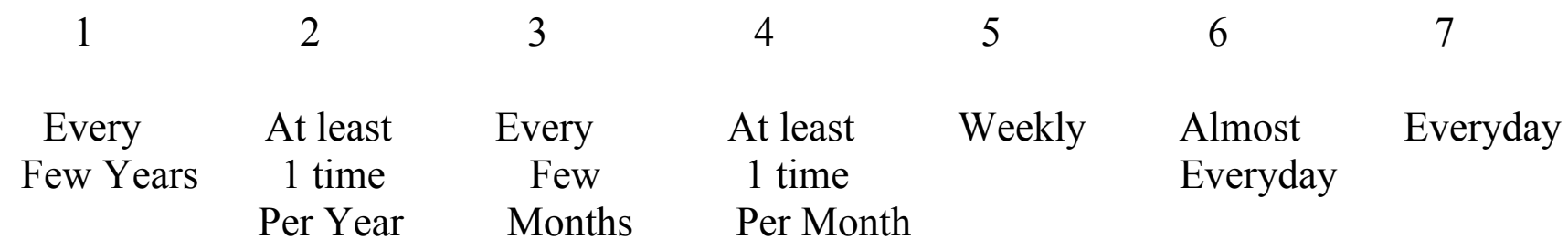

\section{Please answer the following questions true $(T)$ or false $(F)$ : (circle one)}

1. Discomfort in the center of the chest is a symptom of a heart attack. $\quad$ T $\quad F$

2. Shortness of breath and a cold sweat are symptoms of a heart attack. $\quad$ T $\quad F$

3. Coronary heart disease is America's \#3 killer. $\quad \mathrm{T} \quad \mathrm{F}$

4. Sudden numbness on one side of the face and weakness in the limbs $\quad$ T $\quad F$ are warning signs of a heart attack.

5. Sudden trouble seeing in one or both eyes is a warning sign of of a heart attack.

6. Being overweight or obese increases your risk of heart attack.

7. Eating a diet that is low in cholesterol decreases your risk of a heart attack.

8. Exercise decreases your risk of a heart attack. 
9. You may not realize that you have had a heart attack.

T $\quad \mathrm{F}$

10. Smoking and drinking alcohol increases your risk of heart attack. $\quad$ T $\quad F$

\section{Please answer the following questions true $(T)$ or false $(F)$ : (circle one)}

1. If you have had an injury to your knee severe enough to put you in bed; to force you to use a cane, crutch or brace; or to require surgery then you are at risk for arthritis.

2. If you are more than 10 pounds overweight then you are at risk for $\quad T \quad F$ arthritis.

3. If you currently (or in the past) participate in greater than 3 hours $\quad$ T $\quad F$ per day of heavy physical activities, such as bending, lifting, or carrying items on a regular basis you are at risk for arthritis.

4. Pain in your knee or hip when climbing stairs or walking 2-3 blocks $\quad \mathrm{T} \quad \mathrm{F}$ $(1 / 4$ mile) on flat ground is a warning sign of arthritis.

5. Obesity may increase your risk of arthritis.

T F

6. Laughing may decrease the symptoms of arthritis.

T F

7. Calcium intake may increase your risk of arthritis.

T $\quad \mathrm{F}$

8. Arthritis is the \#2 cause of disability in the United States. $\quad T \quad F$

9. Shoes that are snug on your toes may help relieve arthritic $\quad$ T $\quad F$ symptoms.

10. Swimming may help relieve arthritic symptoms. 


\section{Appendix B}

Summary Table for Gender x Marital Status x Domain x Severity x Strategy Repeated Measures MANOVA

\begin{tabular}{|c|c|c|c|c|}
\hline Adult Problem Solving Strategies & $F$ & $p$ & $E t a^{2}$ & $d f$ \\
\hline domain $\mathrm{x}$ severity $\mathrm{x}$ strategy $\mathrm{x}$ gender $\mathrm{x}$ marital status & 2.88 & $<.05$ & .09 & 4,121 \\
\hline domain $\mathrm{x}$ severity $\mathrm{x}$ strategy $\mathrm{x}$ gender & .31 & $>.05$ & .01 & 4,121 \\
\hline domain $\mathrm{x}$ severity $\mathrm{x}$ strategy $\mathrm{x}$ marital status & 1.05 & $>.05$ & .03 & 4,121 \\
\hline domain $\mathrm{x}$ severity $\mathrm{x}$ strategy & 1.24 & $>.05$ & .04 & 4,121 \\
\hline severity $\mathrm{x}$ strategy $\mathrm{x}$ marital status $\mathrm{x}$ gender & 1.21 & $>.05$ & .04 & 4,121 \\
\hline severity $\mathrm{x}$ strategy $\mathrm{x}$ gender & .56 & $>.05$ & .02 & 4,121 \\
\hline severity x strategy x marital status & 5.94 & $<.01$ & .16 & 4,121 \\
\hline severity x strategy & 13.59 & $<.01$ & .31 & 4,121 \\
\hline domain $\mathrm{x}$ strategy $\mathrm{x}$ marital status $\mathrm{x}$ gender & 7.00 & $<.01$ & .19 & 4,121 \\
\hline domain $\mathrm{x}$ strategy $\mathrm{x}$ gender & 5.02 & $<.01$ & .14 & 4,121 \\
\hline domain $\mathrm{x}$ strategy $\mathrm{x}$ marital status & 1.46 & $>.05$ & .05 & 4,121 \\
\hline domain $\mathrm{x}$ strategy & 25.35 & $<.01$ & .46 & 4,121 \\
\hline domain $\mathrm{x}$ severity $\mathrm{x}$ marital status $\mathrm{x}$ gender & .45 & $>.05$ & .00 & 1,124 \\
\hline domain $\mathrm{x}$ severity $\mathrm{x}$ gender & 1.95 & $>.05$ & .02 & 1,124 \\
\hline domain $\mathrm{x}$ severity $\mathrm{x}$ marital status & 2.01 & $>.05$ & .02 & 1,124 \\
\hline domain $\mathrm{x}$ severity & 6.26 & $<.05$ & .05 & 1,124 \\
\hline strategy x marital status $\mathrm{x}$ gender & 2.03 & $>.05$ & .06 & 4,121 \\
\hline strategy $\mathrm{x}$ gender & 5.84 & $<.01$ & .16 & 4,121 \\
\hline strategy x marital status & 5.63 & $<.01$ & .16 & 4,121 \\
\hline strategy & 190.26 & $<.01$ & .86 & 4,121 \\
\hline severity $\mathrm{x}$ marital status $\mathrm{x}$ gender & .20 & $>.05$ & .00 & 1,124 \\
\hline severity $\mathrm{x}$ gender & .55 & $>.05$ & .00 & 1,124 \\
\hline severity & .68 & $>.05$ & .01 & 1,124 \\
\hline domain $\mathrm{x}$ marital status $\mathrm{x}$ gender & .26 & $>.05$ & .00 & 1,124 \\
\hline domain $\mathrm{x}$ gender & .01 & $>.05$ & .00 & 1,124 \\
\hline domain $\mathrm{x}$ marital status & 2.31 & $>.05$ & .02 & 1,124 \\
\hline domain & .95 & $>.05$ & .01 & 1,124 \\
\hline
\end{tabular}

